\title{
Effects of nicotine on content of corticotropin releasing factor (CRF) in rat amygdala, hypothalamus and brain stem
}

Sibonisiwe Ntini Masilela

West Virginia University

Follow this and additional works at: https://researchrepository.wvu.edu/etd

\section{Recommended Citation}

Masilela, Sibonisiwe Ntini, "Effects of nicotine on content of corticotropin releasing factor (CRF) in rat amygdala, hypothalamus and brain stem" (1999). Graduate Theses, Dissertations, and Problem Reports. 952.

https://researchrepository.wvu.edu/etd/952

This Thesis is protected by copyright and/or related rights. It has been brought to you by the The Research Repository @ WVU with permission from the rights-holder(s). You are free to use this Thesis in any way that is permitted by the copyright and related rights legislation that applies to your use. For other uses you must obtain permission from the rights-holder(s) directly, unless additional rights are indicated by a Creative Commons license in the record and/ or on the work itself. This Thesis has been accepted for inclusion in WVU Graduate Theses, Dissertations, and Problem Reports collection by an authorized administrator of The Research Repository @ WVU. For more information, please contact researchrepository@mail.wvu.edu. 
Effects of Nicotine on Content of Corticotropin Releasing Factor

$(\mathrm{CRF})$ in Rat Amygdala, Hypothalamus and Brain Stem

Sibonisiwe Ntini Masilela
Thesis submitted to the School of Medicine
at West Virginia University
in partial fulfillment of the requirements
for the degree

\author{
Master of Science \\ in
}

Pharmacology and Toxicology
Dale L. Birkle, Ph. D., Chair
Charles R. Craig, Ph. D.
David J. Smith, Ph. D.
Morgantown, West Virginia
1999

Key words: Locus coeruleus, CeA, nicotinic receptors, neurotransmitters, pharmacokinetics, anxiolytic, frozen sections.

Copyright (C) 1999 Sibonisiwe Ntini Masilela 


\begin{abstract}
Effects of Nicotine on Content of Corticotropin Releasing Factor (CRF) in Rat Amygdala, Hypothalamus and Brain Stem
\end{abstract}

Sibonisiwe Ntini Masilela

Effects of $1.0 \mathrm{mg} / \mathrm{kg}$ and $0.4 \mathrm{mg} / \mathrm{kg}$ intraperitoneal nicotine on hypothalamic and extra hypothalamic levels of corticotropin releasing factor (CRF) were examined in 104 rats. CRF, a 41-amino acid peptide involved in responses to stress, fear and anxiety, influences the same neurotransmitter systems as nicotine, a psychoactive component of tobacco. Radioimmunoassays revealed that in macro-dissected hypothalami, 15 minutes treatment with $1.0 \mathrm{mg} / \mathrm{kg}$ nicotine significantly increased CRF content compared to no treatment. The $1.0 \mathrm{mg} / \mathrm{kg}$ dose did not elicit effects in macro-dissected amygdala and brain stem. With $0.4 \mathrm{mg} / \mathrm{kg}$ nicotine, no significant effects were observed in microdissected hypothalamic paraventricular nucleus, amygdaloid and brain stem nuclei. As expected, plasma corticosterone levels were significantly increased with both doses of nicotine. Overall, no clear cut effects of nicotine on CRF were observed. Microdissection studies on specific nuclei using varying doses and time points would help elucidate interactions of nicotine with CRF systems. 


\section{ACKNOWLEDGMENTS}

Much appreciation is extended to Dr. D. L. Birkle, my advisor, for directing the study and for her guidance. Special gratitude goes to my committee members, Dr. C. R. Craig and Dr. D. J. Smith, for the constructive criticism and moral support. Thanks to the staff in Dr. Birkle's laboratory for their assistance. Many thanks, Drs. Strobl, Wonderlin and Graber for your time. Gratitude goes to Chris Van Dyke for providing the much needed technical support when needed. Special thanks to Chifundo Lemani for lending his computer skills. Fernando Suarez, thanks for being there. Many thanks to Randy, Elizabeth, Deanna and Andrew for everything.

I am thankful for the financial support provided by the Department of Pharmacology and Toxicology and West Virginia School of Medicine. Financial support was also provided by the BOT Minority Fellowship and the Association for Women in Science (AWIS)-WV Chapter, and for this I am grateful.

The largest share of credit goes to my family, to my husband Calvin, the shoulder to lean on, for we come a long way together, and to our children Lizwe and Ayanda, for being great. To the Ntini and Masilela families in Bulawayo, your love crosses the seas and keeps us going. 


\section{TABLE OF CONTENTS}

Chapter

Page

List of Tables................................................................. vii

List of Tables.................................................................. viii

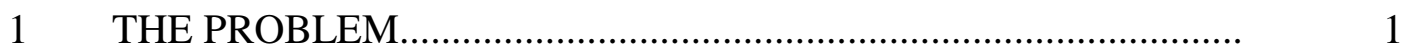

Corticotropin releasing factor, amygdala and nicotine........... 1

Statement of problem...................................................... 4

Significance of the problem............................................. 5

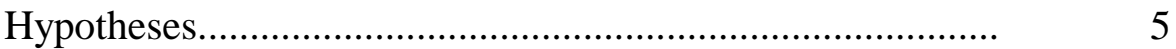

Assumptions............................................................. 6

Limitations of the study...............................................

II $\quad$ REVIEW OF THE LITERATURE............................................. 8

The amygdala.............................................................. 8

Functions of the amygdala...................................... 9

Neuronal transmission in the amygdala..................... 12

Amygdaloid CRF and other neurotransmitters........... 14

Manifestations of Amygdaloid CRF........................ 16

Amygdala and hypothalamo-pituitary-adrenal (HPA) axis.......................................... 17

CRF release, CRF receptors and CRF binding protein........... 19

CRF Release...................................................... 19

CRF receptors …............................................... 20

CRF binding protein........................................... 22

Brain stem nuclei............................................................... 22

Effects of acute and chronic stress on CRF levels................. 24

CRF in affective and neurological disorders......................... 25

Glucocorticoid receptors.................................................. 26

Circulating corticosterone............................................... 27

Manifestations of nicotine................................................ 28

Nicotine..........................................................

Nicotine Pharmacokinetics.................................... 28

Neuronal Nicotinic receptors................................ $\quad 30$

Nicotine and HPA axis.................................................... 33

Nicotine and the amygdala............................................ 34

Nicotine and neurotransmitters........................................ $\quad 35$

Acetylcholine secretion....................................... 35 
II Norepinephrine secretion........................................... 36

Dopamine release...................................................... $\quad 39$

5-hydroxytryptamine (serotonin) secretion......................... 42

Nicotine and the NMDA receptor...................................... 44

Positive reinforcing properties of nicotine........................... 45

Nicotine and neurological diseases................................. $\quad 46$

Is nicotine anxiolytic?..................................................... 47

Is nicotine anxiogenic?................................................... 49

Nicotine and corticosterone............................................ $\quad 50$

Nicotine versus CRF..................................................... 53

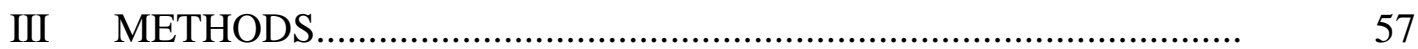

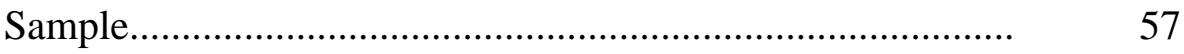

Drug Solutions..................................................................... $\quad 57$

Animal treatment procedure ............................................ $\quad 58$

Cryostat frozen sections of the brain................................... 61

Micro-punch dissections of brain nuclei.............................. 62

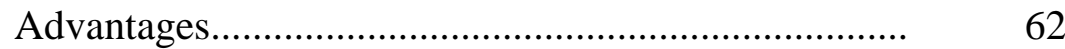

Disadvantages.................................................... 63

Macro-dissections of brain regions..................................... 63

Advantages.......................................................... 64

Disadvantages................................................... 64

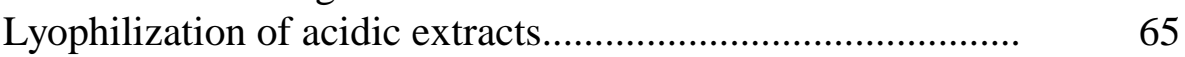

Radioimmunoassays..................................................... $\quad 67$

Corticotropin Releasing Factor (CRF) radioimmunoassays.... $\quad 67$

Procedure ..................................................... 68

Corticosterone radioimmunoassays.................................... $\quad 70$

Procedure.................................................... 71

Protein determination on acidic extracts.............................. 71

Procedure ...........................................................

IV DATA AND ANALYSIS ................................................... 73

Treatment of data.........................................................

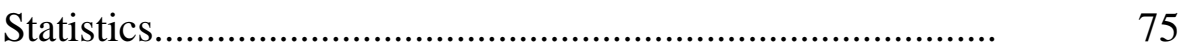

V RESULTS ..................................................................

Sources of error......................................................... $\quad 76$

Animal observations......................................................... $\quad 76$ 
Expected results. 77

Plasma corticosterone................................................... $\quad 78$

Summary of protein levels for all experimental animals......... $\quad 81$

CRF content in the rat brain after nicotine treatment............... $\quad 81$

CRF content in untreated rats.................................. 81

CRF content in hypothalamus and paraventricular nucleus...................................................... 83

CRF content in amygdala and amygdaloid nuclei......... $\quad 85$

CRF content in brain stem and locus coeruleus/ parabrachial nucleus..................................... $\quad 88$

VI DISCUSSION AND FUTURE DIRECTIONS............................... 93

Discussion...................................................................... 93

Plasma Corticosterone after $0.4 \mathrm{mg} / \mathrm{kg}$ treatment.................... 94

Plasma Corticosterone after $1.0 \mathrm{mg} / \mathrm{kg}$ treatment.................... $\quad 94$

CRF content in brain regions............................................. 95

Hypothalamus....................................................... 96

Paraventricular nucleus........................................... 97

Amygdala............................................................. 98

Amygdaloid nuclei................................................. 99

Brain stem ............................................................ 100

Brain stem nuclei (Locus coeruleus and parabrachial nucleus)................................ 100

General conclusion.................................................................. 101

Future directions........................................................................ 102

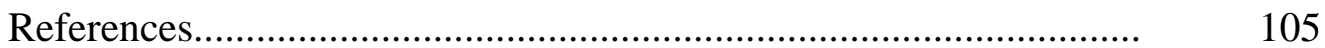

Curriculum Vitae........................................................................ 135 


\section{LIST OF TABLES}

Table Page

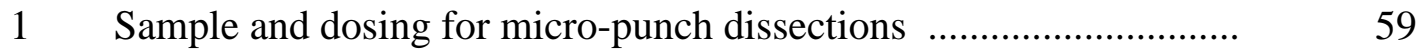

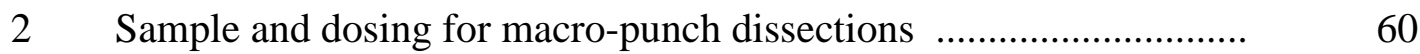

$3 \quad$ Assayed brain regions and nuclei..................................................... 66 


\section{LIST OF FIGURES}

Figure

Page

$1 \quad$ Plasma corticosterone levels after 15 and 30 minutes treatment with nicotine $0.4 \mathrm{ml} / \mathrm{kg}, 0.9 \%$ saline (vehicle, $1.0 \mathrm{ml} / \mathrm{kg}$ ) or no treatment

2 Plasma corticosterone levels after 15, 30 and 60 minutes treatment with nicotine $1.0 \mathrm{mg} / \mathrm{kg}, 0.9 \%$ saline (vehicle, $1.0 \mathrm{ml} / \mathrm{kg}$ ) or no treatment.

$3 \quad$ CRF content in untreated rats

4 CRF content in macro-dissections of hypothalamus after 15,30 and 60 minutes treatment with nicotine $1.0 \mathrm{mg} / \mathrm{kg}$, $0.9 \%$ saline (vehicle, $1.0 \mathrm{ml} / \mathrm{kg}$ ) or no treatment

$5 \quad$ CRF content in micro-punches of paraventricular nucleus after 15 and $30 \mathrm{~min}$ treatment with nicotine $0.4 \mathrm{mg} / \mathrm{kg}$, $0.9 \%$ saline (vehicle, $1.0 \mathrm{ml} / \mathrm{kg}$ ) or no treatment.

6 CRF content in macro-dissections of amygdala after 15, 30 and 60 minutes treatment with nicotine $1.0 \mathrm{mg} / \mathrm{kg}$, $0.9 \%$ saline (vehicle, $1.0 \mathrm{ml} / \mathrm{kg}$ ) or no treatment

$7 \quad \mathrm{CRF}$ content (pg CRF/mg protein) micro-punches of amygdaloid nuclei after 15 and $30 \mathrm{~min}$ treatment with nicotine $0.4 \mathrm{mg} / \mathrm{kg}$, $0.9 \%$ saline (vehicle, $1.0 \mathrm{ml} / \mathrm{kg}$ ) or no treatment.

$8 \quad \mathrm{CRF}$ content ( $\mathrm{pg} \mathrm{CRF} / \mathrm{mg}$ protein) in macro-dissections of brain stem after 15, 30 and $60 \mathrm{~min}$ treatment with nicotine $1.0 \mathrm{mg} / \mathrm{kg}$, $0.9 \%$ saline (vehicle, $1.0 \mathrm{ml} / \mathrm{kg}$ ) or no treatment

9 CRF content (pg CRF/mg protein) in micro-punches of locus coeruleus/parabrachial nucleus after 15 and 30 min treatment with nicotine $0.4 \mathrm{mg} / \mathrm{kg}, 0.9 \%$ saline (vehicle, $1.0 \mathrm{ml} / \mathrm{kg}$ ) or no treatment. 


\section{CHAPTER I}

\section{THE PROBLEM}

\section{Corticotropin releasing factor, amygdala and nicotine}

Corticotropin releasing factor (CRF) is a 41-amino acid peptide secreted mainly by the paraventricular nucleus (PVN) of the hypothalamus (Owens and Nemeroff, 1991; Vale, et al., 1981). CRF is the chemical messenger by which the central nervous system (CNS) controls the activity of the hypothalamic-pituitary-adrenal (HPA) axis and therefore, is responsible for mediating the neuroendocrine response to stress. CRF is also released from other brain regions, particularly the amygdala, an almond shaped structure located in the temporal lobe of the brain (Gray and Bingaman, 1996; Haines, 1991; Owens and Nemeroff, 1991). The median eminence which is served by the paraventricular nucleus (PVN) of the hypothalamus has the highest levels of CRF. The PVN and central nucleus of the amygdala (CeA) also have considerably high levels (Chappell, et al., 1986; Palkovits, et al., 1985; Skofitsch and Jacobowitz, 1985). This suggests that the neuropeptide is also an important mediator for the emotional responses to stress and anxiety, which are mediated through the amygdala (Gray and Bingaman, 1996; Owens and Nemeroff, 1991).

The amygdala is rich in CRF expressing cell bodies and terminals, receptors and CRF binding protein immunoreactivity (Gray, 1993; Gray and Bingaman, 1996; Owens and Nemeroff, 1991). Dense CRF cell bodies and terminals are located in the amygdaloid central nucleus (CeA) while the basolateral nuclei have a high number of receptors (Gray and Bingaman, 1996; Owens and Nemeroff, 1991; Sanakana, et al., 1986). The amygdala 
has afferent and efferent neurons to and from structures including the hypothalamus, brain stem nuclei, bed nucleus of stria terminalis and substantia nigra (Gray and Bingaman, 1996; Swanson, et al., 1983; Uryu, et al., 1992). These reciprocal projections enable the amygdala to influence or be influenced by these brain regions through the action of their neurotransmitters including norepinephrine, epinephrine, dopamine and serotonin (Gray and Magnuson, 1987; Sanakana, et al., 1986; Van Bockstaele, et al., 1996). The amygdala also contains steroid receptors showing that it could be influenced by glucocorticoids or other steroids (Swanson, et al., 1983). Therefore, there are afferent and efferent amygdaloid CRFergic neurons that are strategically localized to mediate both autonomic and emotional responses to stress (Gray, 1992; Gray and Bingaman, 1996).

Animal studies have shown CRF to be a neuromodulator in functions associated with the amygdala. Behavioral models of anxiety including social interaction, elevated plus maze and fear potentiated startle, indicate that CRF is anxiogenic at increased levels (Dunn and Berridge, 1990; Koob, et al., 1992; Liang, et al., 1992a; Liang, et al., 1992b). Reactions seen in electrical stimulation or lesions of the amygdala parallel those seen in the injection or inhibition of CRF release, respectively. Imbalances in levels of CRF in the brain have been associated with psychiatric and affective disorders (DeSouza, 1995; Nemeroff, et al., 1991; Owens and Nemeroff, 1991; Owens, et al., 1991). Anti-anxiety drugs such as benzodiazepines have been reported to induce modifications in CRF in the hypothalamus, bed nucleus of stria terminalis (BNST), and septum. In addition, alprazolam and adinozolam decreased CRF immunoreactivity in the amygdala, piriform cortex and cingulate cortex (Owens and Nemeroff, 1991; Owens, et al., 1989). The 
question is whether or not other CNS drugs including nicotine exert their effects through modulation of CRF levels in the brain.

Nicotine is a poisonous, volatile alkaloid derived from tobacco and is responsible for many of the tobacco effects (McDonough, 1994). Nicotine can be either a psychostimulant or a depressant at high and low dose respectively (Balfour and Fagerström, 1996; McDonough, 1994). Neuronal nicotinic receptors (nAChRs) are the primary receptors for the excitatory neurotransmitter acetylcholine and are located in sympathetic and parasympathetic ganglia, and the adrenal cortex (Mycek, et al., 1992). The receptors exist in various brain regions particularly the hippocampus, cortex and also in the amygdala and brain stem (Clarke and Pert, 1985; Fu, et al., 1998; Maren, 1996). The nAChRs consist of a family of heterogeneous receptor subtypes composed of $\alpha$ - and $\beta$ - subunits encoded by 12 different genes (Wada, et al., 1989; Luetje and Patrick, 1991; Lukas, 1995). The $\alpha_{4} \beta_{2}$ receptor which is sensitive to nicotine and analogues is located in both the somatodendritic membrane and nerve terminal (Bylund and Yamamura, 1990; Flores, et al., 1997; Watson, et al., 1987). The receptor is a ligand gated ion channel permeable to $\mathrm{Na}^{+}, \mathrm{K}^{+}$, and $\mathrm{Ca}^{2+}$, and mediates neurotransmission (McGehee and Role, 1995; McGehee and Role, 1996; Schwartz and Kandel, 1991).

Nicotine and its analogues seem to influence brain neural systems that are implicated in psychiatric and neural disorders; addictive mechanisms of nicotine have yet to be determined (Balfour, 1982; Balfour and Fagerström, 1996). In addition to the welldemonstrated stimulation of acetylcholine release in the brain and peripheral nerves (Armitage, et al., 1969; Balfour and Fagerström, 1996), animal studies have shown 
nicotine to act on various brain regions to modulate the secretion of neurotransmitters, including dopamine, epinephrine, norepinephrine and serotonin (Benwell, et al., 1988; Benwell, et al., 1990; Fu, et al., 1997; Fu, et al., 1998; Mifsud, et al., 1989; Nisell, et al., 1994; Sugita, et al., 1992). The rewarding properties of nicotine are believed to be elicited through the interaction of neuronal nicotinic receptors with these neurotransmitter systems (Benwell and Balfour, 1979; Dawe, et al., 1995; Rapier, et al., 1988; Rapier, et al., 1990; ). Nicotine is believed to exert differing responses in normal individuals compared to depressed, and in stressed and unstressed animals (Balfour, et al., 1975; Donnerer and Lembeck, 1990; Hall and Morrison, 1973). One of the most prominent effects of nicotine is the elevation of circulating ACTH and corticosterone, the stress response hormones. (Andersson, et al., 1983; Benwell and Balfour, 1982; Cam and Bassett, 1983; Freund, et al., 1988).

\section{$\underline{\text { Statement of problem }}$}

Studies have been done on the effects of nicotine on neurotransmitters in the hypothalamus and some extrahypothalamic regions including the locus coeruleus, hippocampus, cortex and striatum, effects of nicotine on the corticotropin releasing factor (CRF) have scarcely been documented. Whether or not nicotine exerts its effects in the CNS by modulating CRF content is not known. A recent immunocytochemical study by Matta, et al., 1997, reported a dose dependent increased $c$-fos expression in CRF-positive neurons in limbic structures after low dose nicotine treatment. The proto-oncogene $c$-fos is an early detector for neuronal activity. This suggests that nicotine stimulated neuronal 
activity in CRF neurons of extrahypothalamic regions, including central nucleus of the amygdala, basal nucleus of stria terminalis, dorsal raphe, Barrington's nucleus and also in paraventricular nucleus of the hypothalamus. The present study was undertaken to examine the effects of nicotine on the content of CRF rich regions regions.

The objective of the study was achieved by examining effects of nicotine on CRF content in rat amygdala, hypothalamus and brain stem, using two doses of nicotine at different treatment time points.

\section{$\underline{\text { Significance of the problem }}$}

The ultimate goal is to find effects of chronic nicotine on CRF content in hypothalamus and extrahypothalamic regions; this study will demonstrate whether or not acute nicotine has effects on CRF which would open a way for investigating the chronic effects. This study is a step towards the studies that will compare responses to nicotine in stressed and unstressed animals. An elucidation of effects of nicotine on CRF systems would also call for a study on the effects of nicotine withdrawal. This work is a lead to studies that will examine effects of prenatal exposure to nicotine, on CRF levels.

\section{Hypotheses}

1 There are significant increases in amygdaloid CRF levels for nicotine treated rats compared to untreated and saline treated rats, at a given dose and time point.

2 There are significant increases in hypothalamic CRF levels for nicotine treated rats compared to untreated and saline treated rats, at a given dose and time point. 
3 There are significant decreases in brain stem CRF levels for nicotine treated rats compared to untreated and saline treated rats, at a given dose and time point.

4 There are significant differences in CRF levels per brain region at same dose of nicotine and different time points.

\section{$\underline{\text { Assumptions }}$}

- The hypothesis of this study was based o the assumption that acute nicotine would evoke changes in CRF content due to one or more of the following: (I) increased release and utilization leading to decreased content, (II) increased synthesis, processing or reuptake leading to increased levels, (III) decreased utilization and degradation, leading to increased levels and (IV) inhibition of release leading to increase levels. The present study did not directly address these mechanisms but only measured CRF content.

- $\quad$ For untreated rats, CRF levels in a specific brain region would be similar at all time points, but would vary depending on method of dissection.

- $\quad$ For saline treated rats, CRF levels per brain region, would be similar at all time points, but would vary depending on method of dissection.

- $\quad$ Corticosterone levels for untreated rats would be similar at all time points. 


\section{Limitations of the study}

(1) Two different doses were used with two different methods of dissection. The cryostat-micro-punch method targeted selected brain nuclei, while the macrodissection obtained the whole structure of the specific region. Results from these dissections can not necessarily be compared.

(2) The specificity of nicotine was not confirmed by pretreatment with nicotinic receptor antagonist such as mecamylamine or dihydro- $\beta$-erythroidine.

(3) Neither control nor test rats were handled prior to the test; handling all the rats would minimize non-specific stress. 


\section{CHAPTER II}

\section{REVIEW OF THE LITERATURE}

\section{The amygdala}

The amygdala is located in the temporal lobe of the brain and is part of the limbic system, enveloped by the cortex, hippocampus, striatum, hypothalamus and lateral ventricles (Amaral, et al., 1992; Kupfermann, 1991). The amygdala is composed of heterogeneous nuclei which are functionally distinct, making two subsystems which mediate responses of anxiety and fear conditioning, that is, emotional memory storage and regulation of memory storage in the hippocampus (Cahill and McGaugh, 1996; Cahill, et al., 1996; McGaugh, et al., 1996). The nuclei consist of the lateral, basolateral and basomedial nuclei (collectively, the basolateral nuclei) and the central nucleus (CeA) (Amaral, et al., 1992; Kupfermann, 1991; Maren, 1996). The basolateral nuclei have a higher number of $\mathrm{CRF}$ receptors compared to $\mathrm{CeA}$ and function as the primary sensory system of the amygdala, with the CeA being the major output of the amygdala (with more CRF cell bodies and terminals) mediating the anxiety and fear responses (De Souza, et al., 1985;

De Souza, 1995; Sanakana, et al., 1986; Swanson, et al., 1983). Therefore, lesions of either or both nuclei result in deficits in acquisition and expression of conditioned fear. Within the amygdala, therefore, the flow of information is from the basolateral nucleus to the CeA (Maren, 1996). Output from the CeA of amygdala is through two fiber bundles, the stria terminalis (which projects to the basal nucleus of the stria terminalis) and the ventral amygdalofugal pathway (Amaral, et al., 1992; Haines, 1991; Kupfermann, 1991). The amygdala has afferent and efferent neurons to and from the hypothalamus, 
dorsal vagal complex, nucleus tractus solitarius (NTS), parabrachial nucleus, mesencephalic nucleus, locus coeruleus and bed nucleus of stria terminalis (BNST) (Gray and Bingaman, 1996; Haines, 1991; Swanson, et al., 1983; Uryu, et al., 1992). These reciprocal projections enable the amygdala to influence or be influenced by these brain regions through their neurotransmitters, including norepinephrine, epinephrine, dopamine and serotonin (Gray and Bingaman, 1996; Gray and Magnuson, 1987; Sanakana, et al., 1986; Sugita, et al., 1992). Even though the presence of efferents from the amygdala have been established in the midbrain central gray, substantia nigra and ventromedial medulla, afferents from these regions to the amygdala still need to be identified (Gray and Bingaman, 1996).

\section{Functions of the amygdala}

The amygdala, CRF, steroids and monoaminergic systems together play a role the expression of behavioral, autonomic and neuroendocrine changes that occur in response to stressful stimuli (De Souza, et al., 1985; Gray and Bingaman, 1996; Owens and Nemeroff, 1991). The amygdala mediates the perception of emotions and is associated with behaviors connected with emotional and arousal components related to stress, fear and anxiety; that is, defensive/aggressive responses, and also reproductive and feeding behaviors (Goldstein, et al., 1996; Gray and Bingaman, 1996; Owens and Nemeroff, 1991; Maren, 1996). The amygdala, therefore is believed to be influential in a variety of psychopathological disorders such as depression, Tourette's syndrome, schizophrenia and panic and anxiety disorders (De Souza, 1995; Gray and Bingaman, 1996; Jadresic, 1992; 
Owens and Nemeroff, 1991). The amygdala is also linked to the development of cardiovascular disease and gastric pathology (Gray and Bingaman, 1996; Junien and Gue, 1993; Tache, et al., 1993).

Direct outputs from the CeA to the hypothalamus and brain stem are believed to mediate (through CRF) the symptoms of fear and anxiety which include, the arrest reaction (cessation of behavior in anticipation of fight or flight), increased arousal/vigilance and parasympathetic and sympathetic activation (increased heart rate, sweating, decreased gastric motility (Davis, 1992; Gray and Bingaman, 1996; Owens and Nemeroff, 1991). Similarly, electrical stimulation of the amygdala in animals results in reactions of fear, aggression, and activation of the autonomic nervous system (Davis, 1992; Gray and Bingaman, 1996; Owens and Nemeroff, 1991). Bilateral lesions of the amygdala produce disturbances of emotional behavior and block acquisition of fear memory (as measured by fear potentiated acoustic startle responses); animals become placid and display no reaction of fear, rage or aggression (Goldstein, et al., 1996; Kupfermann, 1991; Roozendaal, et al., 1993). Lesions of the amygdala block CRFpotentiated acoustic startle (Liang, et al., 1992a). Lesions of the CeA or bilateral injection of benzodiazepines, gamma-aminobutyric acid (GABA; the major inhibitory neurotransmitter in the brain) receptor agonists, to amygdala diminish the conditioned fear and defensive freezing (Helmstetter and Bellgowan, 1993; Maren and Fanselow, 1996; Maren, et al., 1996; Owens and Nemeroff, 1991).

A number of studies have reported cellular mechanisms of fear conditioning. Amygdaloid synaptic processes that mediate acquisition and expression of learned fear are 
believed to be mediated by glutamatergic, GABAergic, noradrenergic and glucocorticoid processes (Galvez, et al., 1996; Maren, 1996; Roozendaal, et al., 1996). It is believed that long term potentiation (LTP) plays a pivotal role in cellular mechanisms of fear conditioning (Cahill, et al., 1996; Maren, 1996). LTP is a "long term increase in synaptic transmission induced by high frequency stimulation of excitatory afferents" (Kandel, 1991; Maren, 1996; Morris, et al., 1986). Roozendaal, et al., (1996), studied adrenalectomized rats with bilateral lesions into the basolateral, medial and central nucleus of the amygdala. The researchers concluded that learning and memory storage was modulated through glucocorticoid receptors in the basolateral nucleus. After studying changes in muscarinic acetylcholine receptor immunoreactivity neurons in the amygdala, Roozendaal, et al., (1997), concluded that fear conditioning was mediated through the dynamic plasticity of muscarinic acetylcholine receptors in the amygdala. Furthermore, Van der Zee, et al., (1997), in an immunocytochemical study, concluded that GABAergic and cholinoceptive neural interactions in the CeA played an important role in fear induced responses.

Intra-amygdaloid infusions of norepinephrine or $\beta$-agonists, after training animals for conditioned fear, indicated the amygdala plays a critical role in mediating the memorymodulating effects of endogenously released stress hormones and the effects of drugs that affect neuromodulator systems (Cahill and McGaugh, 1996; McGaugh, et al., 1996). Stressful stimuli cause an activation of noradrenergic neurons and increased NE release into the amygdala (Galvez, et al., 1996; Ida, et al., 1984; Tanaka, et al., 1991). Sugita, et al., (1992), also reported that serotonin (a neurotransmitter that modulates mood states and is implicated in affective disorders), functions as a neurotransmitter in the amygdala. 
Neuronal transmission in the amygdala

Electrophysiological studies have demonstrated that afferent stimulation of the basolateral nuclei results in both excitatory and inhibitory synaptic transmission (Gean and Chang, 1991; Rainnie, et al., 1991a; Rainnie, et al., 1991b; Washburn and Moises, 1992). These findings have been confirmed by in vivo iontophoretic pharmacological studies on the basolateral nuclei complex which showed that excitatory responses were mediated by glutamate receptors, with GABA receptors mediating inhibitory responses ( $\mathrm{Li}$, et al., 1995; Maren, 1996; Maren and Fanselow, 1995; Mello, et al., 1992).

The amygdala has various glutamate receptor subtypes: $\alpha$-amino-3-hydroxy-5methyl-4-isoxazolepropionate (AMPA), kainate and N-methyl-D-aspartate (NMDA), and also has glutamatergic cell bodies and neurons. Glutamate (major excitatory amino acid in the brain) is concentrated in the CeA (Farb and LeDoux, 1997; Farb, et al., 1992; McDonald, 1996). Glutamatergic terminals originate in the cerebral cortex and subcortical structures that transmit sensory information to the basolateral nuclei of the amygdala, the primary sensory region for anxiety and stress stimuli (Davis, 1992; Farb, et al., 1992).

In the 1996 review, Maren concluded from the studies that "glutamatergic projections synapse on both principal neurons, (class I) and inhibitory interneurons (Class II), and that inhibitory neurons, in turn, send feed forward information to GABAergic projections to principal neurons." Studies using an agonist of metabotropic glutamate receptors revealed a role for these glutamate receptors in inhibitory processes (Maren, et al., 1996; Rainnie, et al., 1994). The ionotropic receptors for AMPA and NMDA mediate 
excitatory responses. This indicates that in the amygdala glutamate receptors generate both excitatory and inhibitory responses (Campeau, et al., 1992; Maren, et al., 1996). The degree of ionotropic and metabotropic activation determines the excitability of cells in the amygdala. Researchers have reported that treatment of animals with glutamate receptor antagonists diminish the acquisition and expression of fear conditioning (Fanselow and Kim, 1994; Liang, et al., 1994). As NMDA receptors and CRF receptors colocalize (McDonald, 1996; Niehoff and Kuhar, 1983; Thomas, et al., 1985), it is likely that the two neurotransmitters, CRF and glutamate, influence each other in amygdaloid processes.

In addition to glutamate and GABA, the main sources of amygdaloid neurotransmission, other neurotransmitters in the amygdala have been reported to contribute to inhibition or excitation of neuronal activity. These include CRF, acetylcholine, endogenous opioids, norepinephrine and serotonin ( Gray and Bingaman, 1996; Owens and Nemeroff, 1991; Sugita, et al., 1992). Researchers have observed membrane hyperpolarization and inhibition of presynaptic transmission in the basolateral complex after application of $\mu$-opioid agonists, the cytokine, interleukin $1 \beta$ and anticholinesterase agent tetrahydro-9-aminoacridine (THA) (Sugita and North, 1993; Wang, et al., 1995; Yu and Shinnick-Gallagher, 1994). Membrane depolarization and excitability have been observed in the rat basolateral amygdala after treatment with muscarinic and nicotinic acetylcholine receptor agonist carbachol and THA (Wang, et al., 1995; Womble and Moises, 1993). Inhibitory effects have been observed after application of CRF in both basolateral complex and CeA and this supports an autoregulatory role for CRF in amygdaloid nuclei (Rainnie, et al., 1992). Noradrenergic receptor agonists like 
isoproterenol have been shown to modulate cell excitability in the amygdala and also enhance presynaptic calcium influx, thus facilitating neurotransmitter release (Gean and Chang, 1992; Huang, et al., 1996).

\section{$\underline{\text { Amygdaloid CRF and other neurotransmitters }}$}

Monoaminergic terminals are colocalized with CRF dendrites and cell bodies in the amygdala (Gray and Bingaman, 1996; Fallon and Ciofi, 1992; Van Bockstaele, et al., 1996). The amygdala has efferents and afferents to and from BNST, thalamus, lateral hypothalamus, substantia nigra, central gray, nucleus raphe, parabrachial nucleus, locus coeruleus, ventrolateral medulla and nucleus tractus solitarius (Fallon and Ciofi, 1992; Moga and Gray, 1985; Van Bockstaele, et al., 1996). Norepinephrine originates from the locus coeruleus and nucleus tractus solitarius and epinephrine from the ventrolateral medulla (Fallon and Ciofi, 1992; Fu, et al., 1998). Dopamine originates from substantia nigra and ventral tegmental area (Fallon and Ciofi, 1992; Haines, 1991). Serotonin originates from the central gray and nucleus raphe and acetylcholine is from septum and basal forebrain (Fallon and Ciofi, 1992; Haines, 1991; Sugita, et al., 1992). The colocalization of CRF systems with these neurotransmitters systems suggests that different neurotransmitters potentially play modulatory role in CRF expressing neurons in the amygdala (Gray and Bingaman, 1996; Haines, 1991).

GABA containing cells which express enkephalin immunoreactivity are located in close proximity with CRF containing cells in the CeA (McDonald, 1996; Niehoff and Kuhar, 1983; Thomas, et al., 1985). The following peptidergic terminals are also 
colocalized with CRF neurons; enkephalin, substance P, cholecystokinin, neurotensin, vasoactive intestinal peptide, neuropeptide $\mathrm{Y}$ and thyrotropin releasing factor (Gray and Magnuson, 1992; Heilig, et al., 1994; Larsen, et al., 1993; Shimada, et al., 1989b). Substance P and CGRP are colocalized and likely to be contained within the same terminals that synapse with CRF cells in the central nucleus (Larsen, et al., 1993; Shimada, et al., 1985).

To mediate the physiological and behavioral responses to stress, CRF also interacts with serotonergic and noradrenergic neurons (Liang and Lee, 1988; Sugita, et al., 1992;). Enhanced in vivo activity of tryptophan hydroxylase, (the rate limiting enzyme for 5hydroxytryptamine (5-HT) synthesis) in the dorsal raphe is seen after intra-amygdaloid injections of CRF, actions that are blocked by $\mathrm{CRF}$ antagonist $\mathrm{CRF}_{9-41}$ (Beaulieu, et al., 1986; Swiergiel, et al., 1993). Stress increases norepinephrine (NE) levels in NE producing brain regions and also in the amygdala (Tanaka, et al., 1991; Valentino, et al., 1991). These increases may be centrally mediated by CRF because CRF injections intracerebroventricularly produced stress-like alterations in central noradrenergic activation in locus coeruleus and parabrachial nucleus, an effect that is abolished by $\mathrm{CRF}_{9-}$ ${ }_{41}$ administration and bilateral lesions of CeA (Tanaka, et al., 1991).

An increase in noradrenergic cell firing in locus coeruleus, (LC) caused by CRF administration, has been reported to result in anxiogenic effects as seen in open field testing, and local release of CRF also triggered increased activation of NE release from LC (Valentino, et al., 1991; Valentino, et al., 1983). These and other studies point to increased CRF as being anxiogenic and suggest that CRF possibly acts both directly and 
indirectly through other neurotransmitters to produce net anxiogenic effects (Liang, et al., 1992a; Liang, et al., 1992b; Stenzel-Poore, et al., 1994).

\section{Manifestations of Amygdaloid CRF}

The role of the amygdala and amygdaloid CRF in stress and anxiety has been studied in behavioral models of anxiety (Gray and Bingaman, 1996; Owens and Nemeroff, 1991). The amygdala is associated with behaviors involving emotional and arousal components, such as defensive/aggressive, reproductive and feeding (Gray and Bingaman, 1996; Goldstein, et al., 1996; Maren, 1996; Owens and Nemeroff, 1991). CRF injected intracerebroventricularly (ICV CRF) or into the amygdala mimics the behavioral and autonomic effects exerted by electrical stimulation of the amygdala (Davis, 1992; Dunn and Berridge, 1987). When injected into the amygdala, CRF has been shown to interfere with exploratory behavior while enhancing inhibitory avoidance/avoidance learning (Liang and Lee, 1988). The acoustic startle (conditioned fear) responses are potentiated when CRF is injected into the ventricles, but lesions of the amygdala block CRF potentiated acoustic startle (Liang, et al., 1992a; Liang, et al., 1992b; Liang and Lee, 1988). In

elevated plus maze, ICV CRF decreased exploratory behavior (Koob and Bloom, 1985). In novel environment, ICV CRF increased defensive freezing and grooming, decreased locomotion and rearing, while potentiating acoustic startle responses (Dunn and Berridge, 1987; Dunn and Berridge, 1990). In addition, Owens, et al., (1989), showed that anxiolytics like adinozolam and alprazolam resulted in decreased CRF immunoreactivity in the amygdala, piriform cortex and cingulate cortex. These researchers also showed that 
these benzodiazepine induced modifications in levels of CRF in the hypothalamus, bed nucleus of stria terminalis and septum. These studies indicate an activation of endogenous release of CRF in the amygdala during stress or anxiety like behaviors. These findings suggest that CRF is anxiogenic.

The anxiogenic effects of high levels of CRF levels are manifested by increased sensitivity to stressful stimuli, and are blocked by the CRF antagonist $\alpha$-helical $\mathrm{CRF}_{9-41}$ (Cratty, et al., 1995; Swiergiel, et al., 1992; Swiergiel, et al., 1993; Wiersma, et al., 1995). Injection of a small dose of $\alpha$-helical $\mathrm{CRF}_{9-41}$ into the amygdala reverses the stress induced suppression of behavior in plus maze test of anxiety (Heilig, et al., 1994). Tests on the elevated plus maze show that $\mathrm{CRF}$ antagonists injected into the $\mathrm{CeA}$ reversed the anxiogenic effects of alcohol withdrawal, reduced stress induced freezing and increased exploratory behavior (Rassnick, et al., 1993; Swiergiel, et al., 1992).

Amygdala and hypothalamo-pituitary-adrenal (HPA) axis

Hypothalamic mechanisms are reported to be modulated by limbic structures including the amygdala and activation of NE neuronal projections to the amygdala is believed to contribute to the stimulation of hypothalamus, in a process that involves $\alpha$ adrenoceptors (Feldman and Weidenfeld, 1996a; Feldman and Weidenfeld, 1996b). The amygdala projects neurons directly to the PVN and innervates areas that contain neurons which regulate the release of adrenocorticotrophic hormone (ACTH) in the anterior pituitary (Feldman and Weidenfeld, 1996b; Gray, et al., 1989; Gray and Bingaman, 1996; Owens and Nemeroff, 1991). The PVN projects to the median eminence, which in turn 
releases CRF into the portal vessels to transport CRF to the anterior pituitary (Rivier and Plotsky, 1986; Sawchenko and Swanson, 1990; Swanson, et al., 1983). Hypothalamic $\mathrm{CRF}$ triggers the release of $\mathrm{ACTH}$ from the anterior pituitary, causes increased sympathetic outflow and also stimulates $\beta$-endorphin for analgesic effects (Brown, et al., 1982; Rivier, et al., 1982). ACTH in turn triggers the release of glucocorticoids from the adrenal cortex, which in turn can exert feedback inhibition on CRF (Feldman and Weidenfeld, 1996b; Makino, et al., 1995; Owens and Nemeroff, 1991; Sapolsky, et al., 1990).

The amygdala is also indirectly connected to the PVN through projections to the bed nucleus of the stria terminalis, which in turn sends a dense plexus of axon terminals to the PVN (Gray and Bingaman, 1996; Owens and Nemeroff, 1991). Other amygdaloid connections via the brain stem nuclei also influence the PVN. After electrical stimulation of the amygdala, immunoreactivity of the $c$-fos proto-oncogene is observed in the parvocellular part of the PVN indicating activation of neurons (Gray, et al., 1989; Petrov, et al., 1994). Lesions of the amygdala have been shown to attenuate ACTH release and plasma corticosterone after the animal has been subjected to immobilization and psychological stress, while electrical stimulation results in increased corticosterone levels (Beaulieu, et al., 1986; Van de Kar, et al., 1991). Allen and Allen, (1974), reported that hypersecretion of ACTH which normally occurs after adrenalectomy is attenuated if the amygdala is destroyed. This indicates that the amygdala has a tonic excitatory effect on the HPA axis in the absence of glucocorticoids. 


\section{$\underline{\mathrm{CRF} \text { release, receptors and CRF binding protein }}$}

\section{$\underline{\text { CRF Release }}$}

CRF synthesis occurs in the parvocellular cell of the paraventricular nucleus (PVN) (Vale, et al., 1981). The cells project to the median eminence (ME) where CRF is released into the portal circulation of the hypophysis to be transported to the anterior pituitary to trigger ACTH release (Lightman and Harbuz, 1993). Regulation of CRF release in the hypothalamus has been studied and both protein kinase A (PKA) and protein kinase $\mathrm{C}$ (PKC) play a role in mediating CRF release (Hu, et al., 1992). It has been reported by Furutani, et al., (1983) and Castro, et al., (1991) that CRF is synthesized as pre-proCRF, and after post-translational processing the active CRF is stored in vesicles at terminals. Gabr, et al., (1995), reported a depolarization-induced, calcium dependent release of CRF into the median eminence of stressed rats. In their study of the possible involvement of interleukin-2 and nitric oxide in CRF release, Raber, et al., (1995) also reported that both acetylcholine and norepinephrine induced the release of CRF from the hypothalamus and amygdala. The acetylcholine effect was antagonized by both atropine and mecamylamine indicating the involvement of both muscarinic and nicotinic receptors. The norepinephrine effect was also antagonized by phentolamine and propranolol suggesting that both $\alpha$ and $\beta$ adrenergic receptors are involved in stimulation of CRF release in amygdala and hypothalamus. Plotsky, (1988) and Joanny, et al., (1989) however, found that norepinephrine has either stimulatory or inhibitory effects depending on predominant receptor subtype ( $\alpha$ or $\beta$ ) localized on CRF neurons. GABA, ACTH and

corticosterone have an inhibitory effect on CRF release (Calogero, et al., 1988; Lightman 
and Harbuz, 1993).

For amygdaloid CRF, Cratty, et al., (1995), studied release of CRF from amygdala minces of prenatally stressed rats and found that these rats had increased levels of the peptide and released more CRF compared to rats from unstressed mothers. Furthermore, in a study on primary neuronal cultures, Cratty and Birkle, (1994), reported a depolarization induced release of corticotropin-releasing factor in the amygdala. Raber, et al., (1995) used rat amygdala slices and reported that interleukin-2, acetylcholine and norepinephrine play an important role in the induction of CRF release and also concluded that this is possibly mediated through nitric oxide signaling. In addition, immunocytochemical techniques by Kasckow, et al., (1997) demonstrated that interleukin6 possibly acts to stimulate CRF release in the hypothalamus and amygdala.

\section{$\underline{\text { CRF receptors }}$}

In situ hybridization has enabled the identification of the two subtypes of receptors $\mathrm{CRF}_{1}$ and $\mathrm{CRF}_{2}$ (De Souza, 1995; Dieterich, et al., 1997; Gray and Bingaman, 1996). $\mathrm{CRF}_{1}$ is densely located in the basolateral nucleus and moderate in the cortical, medial, and lateral amygdaloid nuclei. $\mathrm{CRF}_{2 \alpha}$ is exclusive to the brain; the densest $\mathrm{CRF}_{2 \alpha}$ mRNA hybridization has been observed in the cortical and medial nucleus and moderate labeling in the basolateral nucleus (Chalmers, et al., 1996; Lovenberg, et al., 1995). $\mathrm{CRF}_{2 \beta}$ is mainly found in the peripheral muscles including heart, skeletal muscle, adrenal medulla, spleen, liver, kidney, prostrate and testes (Chalmers, et al., 1995; Lovenberg, et al., 1995). Studies have shown that the CRF receptor is a seven member transmembrane 
protein linked to $\mathrm{G}_{\mathrm{s}}$ proteins, with the generation of cyclic AMP (Battaglia, et al., 1987;

De Souza, 1995; Olianas and Onali, 1995). Cyclic AMP generation results in ACTH release in pituitary and is a substrate for potentiation by protein kinase $\mathrm{C}$ activators $\left(\mathrm{Ca}^{2+}\right.$, diacylglycerol and phosphatidyl serine) (Battaglia, et al., 1987; De Souza, 1995; Hu, et al., 1992; Olianas and Onali, 1995). Owens and Nemeroff, (1991) reported that the presence of CRF resulted in increased phosphoinositide turnover. CRF may also activate the calcium-calmodulin system (Murakami, et al., 1985). This infers a possible cross-talk between second messenger systems or synergistic effects between mechanism of ACTH release and other neurotransmitters (Koch and Lutz-Bucher, 1991).

Autoradiographic methods and in situ hybridization have been used to study CRF binding sites and showed that the anterior pituitary has the highest density of CRF binding receptors (De Souza, 1987; DeSouza, 1995; Owens and Nemeroff, 1991). This is to be expected since the pituitary is the site for ACTH release. A significant number of binding sites is also found in the olfactory bulb, cerebellum, cerebral cortex and striatum (De Souza, et al., 1985; De Souza, 1987). Autoradiographic methods have shown the highest number CRF receptor binding in the basolateral nuclei of the amygdala compared to the central nucleus which has the highest number of cell bodies and terminals instead (Cummings, et al., 1983; De Souza, et al., 1985; De Souza, 1995; Meister, 1993; Swanson, et al., 1983). A high number of CRF receptors is also found in regions of the brain that are targeted by the CeA, including BNST, PBN, LC, PVN and solitary nucleus (De Souza, 1987). While CRF has an excitatory action at receptors in CeA targets, the neuropeptide has both excitatory and inhibitory effects, and functions in autoregulation of CRF release 
in the CeA and PVN (De Souza, et al., 1985; Rainnie, et al., 1992).

\section{$\underline{\text { CRF binding protein }}$}

Deactivation of CRF occurs by degradation to smaller fragments by endopeptidases or through binding by CRF binding protein (Behan, et al., 1993a). A 37-kDa protein that binds CRF to block the HPA axis was identified in human plasma and has been termed CRF-binding protein (CRBP) (Behan, et al., 1993a). CRF-binding protein and its mRNA have been observed in rat brain, with large concentrations being found colocalized with CRF in the amygdala (Behan, et al., 1993). Increased levels of the CRBP mRNA have been found in the medial amygdala and CeA (Behan, et al., 1993a; Potter, et al., 1992). In addition, Potter, et al., (1992) used dual labeling experiments to demonstrate that in the central nucleus, both CRF immunoreactivity and CRBP are mainly expressed in the same neurons, but not colocalized in the same neurons in other amygdaloid nuclei. Although studies on the specific functions of the protein in the amygdala are still needed, studies done on hypothalamic $\mathrm{CRBP}$ indicate that the protein functions to limit CRF transport and release, thus regulating activity of CRF neurons (Behan, et al., 1993b; Gray and Bingaman, 1996; Potter, et al., 1992).

\section{$\underline{\text { Brain stem nuclei }}$}

The CRF-containing brain stem nuclei include the locus coeruleus (LC), parabrachial nucleus (PBN), nucleus tractus solitarius, Barrington's nucleus and the raphe nuclei (Gray, 1993; Valentino, et al., 1991; Valentino, et al., 1994). The amygdalofugal 
pathway is the major CeA output bundle to the brain stem nuclei. The putative role of brain stem nuclei is in the modulation of sympathetic and parasympathetic activation, the associated behavioral changes and also in nociceptive functions (Fu, et al., 1997; Gray and Bingaman, 1996; Owens and Nemeroff, 1991). CRF is found in regions that are involved in pain processing, that is, periaquiductal gray (PAG), raphe nucleus and spinal cord (Swanson, et al., 1983). The LC is located in the upper pons and is the center for norepinephrine containing neurons and projections. Injections of CRF antagonists into LC by Valentino, et al., (1991) demonstrated that this nucleus has a role in integrating CRF and noradrenergic mediation of the stress response. Koegler-Muly et al., (1993) showed that electrolytic lesions of the CeA caused a threefold decrease in CRF levels in the LC, thus implying a CRF pathway from CeA to locus coeruleus. In 1986, Chappell reported that stress caused an increase in content of CRF in the LC. CRF from the amygdala is believed to activate the locus coeruleus to trigger the production of catecholamines (Gray and Bingaman, 1996; Owens and Nemeroff, 1991).

CRF neurons are densely innervated by calcitonin gene related peptide (CGRP)containing terminals that originate from the parabrachial nucleus and thalamus (Harrigan, et al., 1994; Shimada, et al., 1989a; Shimada, et al., 1992). These studies indicate that the interrelationships between amygdala and brain stem nuclei manifest a concerted role involving CRF and brain stem neurotransmitters in the expression of behavioral and autonomic components of anxiety, fear and defense responses. 


\section{$\underline{\text { Effects of acute and chronic stress on CRF levels }}$}

The fluctuations in CRF levels in hypothalamus and amygdala that are observed in acute and chronic stress and related pathologies may signify alterations in the synthesis, active releasable pool, release or degradation of the neuropeptide (Chappell, et al., 1986; Lightman, et al., 1993). Chappell, et al., (1986) demonstrated that in the rat, acute stress caused a two fold increase in CRF levels in the LC and a decrease in the median eminence/arcuate nucleus and median preoptic nucleus. Chronic stress maintained similar changes in the locus coeruleus and median eminence/arcuate nucleus with decreased levels in the dorsal vagal complex and increases in anterior hypothalamus and PVN (Chappell, et al., 1986). In situ hybridization techniques demonstrated that hypothalamic CRF mRNA was reduced by corticosterone, confirming inhibition of CRF synthesis (Makino, et al., 1995). A study by Herman, et al., (1992), demonstrated that a 15 minute reduction in the corticosterone negative feedback of hypothalamic CRF increases $c$-fos in the hypothalamus resulting in detectable changes of CRF mRNA pools which were observable in 60 minutes. Chronic stress also down regulates CRF receptors in the hypothalamus (Anderson, et al., 1993), which may be an adaptation to high levels of amygdaloid CRFergic input, in addition to corticosterone's feed back inhibition. Ratka, et al., (1989) studied the neuroendocrine regulation by Type I and Type II glucocorticoid receptors by using antimineralocorticoid RU28318 and antiglucocorticoid RU38486 respectively, and both antagonists prolonged the adrenocortical secretion following stress, indicating a blockade of receptors to the feedback inhibition of corticosteroids.

Immobilization stress affects both the amygdala and CRF systems, eliciting 
adaptive changes in CeA (Henke, 1983; Honkaniemi, et al., 1992a; Honkaniemi, et al., 1992b). Immobilization stress caused changes in the firing rate of amygdaloid neurons (Henke, 1983) and also increased $c$-fos and corticosteroid receptor expression (Honkaniemi, et al., 1992a; Honkaniemi, et al., 1992b). This change in $c$-fos was in conjunction with increased CRF mRNA in the CeA and hypothalamus (Mamalaki, et al., 1992). Kalin, et al., (1994) reported an increase in CRF mRNA content in PVN and amygdala after restraint stress, suggesting that chronic stress elicits chronic elevations of corticosterone, which manifests opposing effects to the putative inhibitory effects of corticosterone on the PVN. A down regulation of CRF receptors in amygdala can also occur after chronic CRF administration and in mild stress (De Souza, 1995; Hauger, et al., 1988; Hauger, et al., 1993).

\section{$\underline{\mathrm{CRF} \text { in affective and neurological disorders }}$}

CRF plays a role in affective disorders and this is due to the persistent activation of HPA axis, as has been observed in depressed patients (De Souza, et al., 1985; De Souza, 1995; Owens, et al., 1991). There is evidence that CRF is hypersecreted in depressed patients, thus causing increased ACTH and adrenal glucocorticoid activation (De Souza, 1995; Owens, et al., 1991; Owens and Nemeroff, 1993). These researchers further reported that CRF is increased in cerebrospinal fluid of depressed patients. This hypersecretion of CRF would ultimately lead to down regulation of CRF receptors, as reported by Nemeroff, et al., (1988), after studying the frontal cerebral cortex of suicide victims. CRF imbalances have been implicated in other neurological diseases including 
Alzheimer's, Parkinson's and Huntington's diseases (De Souza, 1995; De Souza, et al., 1986). Alzheimer's disease is manifested by a decrease in CRF content in the frontal, occipital, temporal lobes of the cerebral cortex, amygdala, caudate and cerebrospinal fluid while an up-regulation of CRF receptors is observed in some of these regions (De Souza, 1995; De Souza, et al., 1986). In Parkinson's disease CRF concentrations are decreased in the frontal, temporal, and occipital cortices and a significant decrease in caudate/putamen CRF is seen in Huntington's disease (De Souza, 1995). CRF is also implicated to play a role in satiation and weight control (Appel, et al., 1991; Le Feuvre, et al., 1991).

\section{$\underline{\text { Glucocorticoid receptors }}$}

In vitro binding assays conducted by Reul and De Kloet, (1985) on microdissected brain regions were the initial studies to demonstrate the presence of glucocorticoid receptors in central nucleus, amygdala-hippocampal region and anterior amygdaloid area. Other studies using immunocytochemistry, autoradiography and in situ hybridization have also reported the presence of glucocorticoid receptors in the amygdala (Honkaniemi, et al., 1992a; Ahima and Harlan, 1990). The inference from these studies is that glucocorticoids can modulate CRF expressing neurons in the amygdala.

A majority of CRF neurons that contain glucocorticoid receptor immunoreactivity descend to the brain stem autonomic regions and thus influence catecholaminergic sectretion (Honkaniemi, et al., 1992a; Honkaniemi, et al., 1992b). Circulating glucocorticoids are believed to directly modulate production of CRF in the amygdala. Administration of increasing doses of corticosterone to adrenalectomized animals have 
been shown to correspond to as much as five fold increase in CRF mRNA expression in the CeA of the amygdala, while CRF mRNA in the hypothalamus decreased (Makino, et al., 1994; Swanson and Simmons, 1989). In animals and humans, increased anxiety or fear have been reported to increase circulating levels of CRF and glucocorticoids (Nemeroff, et al., 1991; Owens, et al., 1991). Glucocorticoids therefore have direct effects on the amygdaloid CRF expressing neurons, altering their activity during stress.

\section{Circulating corticosterone}

Corticosterone is the main glucocorticoid (equivalent of human cortisol) secreted by the adrenal cortex of rats in response to stress and is a useful indicator of the neuroendocrine response to stress in the laboratory animal (Shimizu, et al., 1983). ACTH is released in the pituitary in response to CRF release from hypothalamus and ACTH triggers adrenal secretion (Rattner, et al., 1980). Exposure to stressful stimuli including drug injection, barometric shock, excessive handling, disease and abrupt changes in temperature or environment, augment circulating corticosterone levels (Rattner, et al., 1980; Shimizu, et al., 1983). Concentrations of the hormone vary according to handling techniques, sample collection method and time of day. Generally, the baseline range for rat corticosterone is between 50 and 400 nanograms/milliliter (ng/ml) (Shimizu, et al., 1983). In this study, corticosterone was measured as a marker for the presence of nicotine in the system. It was expected that nicotine would elevate corticosterone levels as reported by other researchers (Benwell and Balfour, 1979; Cam and Bassett, 1983; Winders and Grunberg, 1990). Notably, corticosterone has been reported to increase CRH mRNA in 
the amygdala while not inducing it in the hypothalamus (Makino, et al., 1994; Makino, et al., 1995). The effects of nicotine induced corticosterone at chronic levels have not been documented.

\section{Manifestations of nicotine}

\section{Nicotine}

Nicotine (1-methyl-2-(3-pyridyl) pyrolidine) is a poisonous, volatile alkaloid derived from tobacco and is responsible for many of the tobacco effects (McDonough, 1994). Nicotine has a pKa of 7.9 and at blood $\mathrm{pH}(7.4)$ is approximately $69 \%$ ionized and $31 \%$ unionized, making it more lipid soluble (Beckett, et al., 1972; Jones, 1987). Nicotine therefore crosses the blood brain barrier, and is a psychostimulant acting on neuronal nicotinic receptors located in various brain regions. In small doses, nicotine stimulates the CNS (Armitage, et al., 1969; Gray, et al., 1996; Nordberg, et al., 1989; Rowell, 1995), while large doses depress the nervous system at autonomic ganglia and myoneuronal junctions (Benwell and Balfour, 1982; Benwell and Balfour, 1985; Sharp, et al., 1993).

\section{Nicotine Pharmacokinetics}

Nicotine has been reported to accumulate rapidly in the brain after intravenous injections, within five minutes, and high levels last up to 50 minutes (Sastry, et al., 1995; Schmiterlöw, et al., 1967). In the 1967 review, Schmiterlow, et al., reported the fate of ${ }^{14} \mathrm{C}$ and ${ }^{3} \mathrm{H}$ labeled nicotine in rat, mouse and cat, on studies that used autoradiographic methods. Nicotine was reported to accumulate rapidly in the brain, within five minutes 
peaking at about 15 minutes and decreasing by 30 minutes. (Sastry, et al., 1995) studied the distribution and retention of nicotine and its metabolite, cotinine, in rat plasma and brain homogenates after intravenous administration of a $1.0 \mathrm{mg} / \mathrm{kg}$ dose. Using high performance liquid chromatography (HPLC) for nicotine measurements, the researchers reported that nicotine peaked in plasma after 5-10 minutes to $2.2 \mathrm{nmol} / \mathrm{ml}$. They observed a $50 \%$ decrease (in plasma levels) by 20 minutes which remained constant up to 60 minutes. Within 20 minutes, plasma cotinine levels had peaked to $1.2 \mathrm{nmol} / \mathrm{ml}$, with levels remaining similar to nicotine levels for up to 60 minutes. In the brain, nicotine peaked within five minutes of treatment, remaining constant for 20 minutes with a decline by 60 minutes. The peak levels of nicotine in the brain were about half of plasma levels. The brain retained more nicotine compared to other organs including the heart, liver, kidney and plasma, this possibly due to the fact that the brain has a higher density of nicotinic receptors which would bind nicotine with high affinity (Sastry, et al., 1995). Isaac and Rand, (1972), collected blood samples in humans from 0.5-60 minutes after a single cigarette. The researchers measured plasma levels of nicotine using gasliquid chromatography and reported that plasma levels increased within two minutes of smoking and peaked to $50 \mathrm{ng} / \mathrm{ml}$ by five minutes, and then decreased to half of the peak by 20 minutes. Nicotine is metabolized by liver and kidney and its biological half life is about 0.5, 0.6 and 0.96 hour in humans, dogs and rats respectively (Adir, et al., 1976; Castro, 1979; Isaac and Rand, 1972; Monji and Benowitz, et al., 1988). The resultant metabolite cotinine has a half life of 19-24 hours and remains constant in all the organs, meaning that it has a longer retention time (Sastry, et al., 1995). 
$\underline{\text { Neuronal Nicotinic receptors }}$

The neuronal acetylcholine nicotinic receptor (nAChR) is a ligand-gated ion channel permeable to sodium $\left(\mathrm{Na}^{+}\right)$, potassium $\left(\mathrm{K}^{+}\right)$, and calcium $\left(\mathrm{Ca}^{2+}\right)$, and therefore participates in neurotransmission (McGehee and Role, 1995; McGehee and Role, 1996; Schwartz and Kandel, 1991). The neuronal nAChR, is the primary receptor for acetylcholine in neurons and is found in sympathetic and parasympathetic ganglia, and the adrenal cortex (Mycek, et al., 1992). Molecular biology, immunocytochemistry and in situ hybridization techniques have demonstrated that nAChRs consist of a family of heterogeneous receptor subtypes composed of $\alpha$ - and $\beta$ - subunits encoded by 12 different genes (Luetje and Patrick, 1991; Lukas, 1995; Wada, et al., 1989). The formation of nicotinic receptors with heterogeneous subunit stoichemistry gives rise to multiple channel properties and therefore, receptor types (Balfour and Fagerström, 1996; Cooper, et al., 1991; Luetje and Patrick, 1991; Wada, et al., 1989; ).

Eight alpha $(\alpha 2-\alpha 9)$ and four beta $(\beta 2-\beta 5)$ subunits have been identified in rat (Benwell and Balfour, 1982; McGehee and Role, 1995; Steinbach and Ifune, 1989; Vidal, 1996). The neuronal type nicotinic receptors include $\alpha 2-5$ and $\beta 2-4$ (Fu, et al., 1997; Fu, et al., 1998). While the $\beta 2-\beta 4$ subunits are widely distributed in the brain, the $\alpha 2, \alpha 3$, and $\alpha 4$ subunits are expressed only in distinct brain areas (Shioda, et al., 1997; Wada, et al., 1989). Molecular biology studies using Xenopus oocytes to express genes coding for the nicotinic receptors have shown that when the oocytes were injected with mRNA or cDNA of $\alpha 2, \alpha 3$, or $\alpha 4$ combined with $\beta 2$ or $\beta 4$, the receptors became functional and responded to acetylcholine or nicotine stimulation, by exhibiting depolarizations (Bertrand, et al., 
1990). The alpha subunit is the agonist binding site and the beta subunit influences the affinity and response of the receptor to the agonists (Luetje and Patrick, 1991; Lukas, 1995; Wada, et al., 1989).

In situ hybridization techniques have shown that different combinations of $\alpha$-and $\beta$ - subunits exist in various brain regions (Papke, et al., 1989; Wada, et al., 1989). The $\alpha 4 \beta 2$ receptor is widely distributed in the brain, while other subunit combinations are restricted to specific areas (Clarke, et al., 1984; Flores, et al., 1991; Flores, et al., 1997). For example, the $\alpha 2 \beta 2$ is found in the interpeduncular nucleus, $\alpha 3 \beta 4$ in the medial habenula (Wada, et al., 1989). The $\alpha 7$ subunit which is mainly expressed in muscular AChRs, is expressed only in the hippocampus and hypothalamus (Bylund and Yamamura, 1990; Clarke, et al., 1985; Seguela, et al., 1993). The $\alpha 4 \beta 2$ receptor is sensitive to nicotine, acetylcholine, and other agonists including lobeline, epibatidine, cytisine and ABT418, but not sensitive to $\alpha$-bungarotoxin, the snake venom (Bylund and Yamamura, 1990; Flores, et al., 1997; Watson, et al., 1987). Alpha bungarotoxin selectively binds to the $\alpha 7$ subunit (Bylund and Yamamura, 1990; Watson, et al., 1987).

Nicotinic receptors are believed to exist in two inter convertible states; ground and refractory (Bhat, et al., 1994; Colquhoun, et al., 1987; McGehee and Role, 1996). The ground state of the receptor is activated by binding of agonists whereas the refractory is the desensitized state and is non functional (McGehee and Role, 1996; Bhat, et al., 1994). High or chronic doses of nicotine desensitize the receptors and an up-regulation of receptors ensues, to compensate for the non functional receptors (Flores, et al., 1997; Rowell and Li, 1997; Schwartz and Kellar, 1985; Ulrich, et al., 1997). Benwell, et al., 
(1988) reported an increase in density of nicotinic receptor binding sites in post mortem brains of smokers, suggesting that over-exposure to nicotine may have induced this increase. It also has been reported that the up-regulated receptors, like the desensitized, are not active and therefore can not be associated with behavioral effects of nicotine (Caggiula, et al., 1993; Collins, et al., 1990; Pauly, et al., 1992; Rowell and Li, 1997). In addition to exciting neurons in the brain, effects of nicotine are also enhanced by its metabolites mainly cotinine, which also remain active on the nAChRs (Crooks and Dwoskin, 1997; Sharp, et al., 1993).

Autoradiographic techniques and immunocytochemistry have demonstrated the existence of neuronal nicotinic receptors (nAChRs) in various brain regions, particularly in the cerebral cortex and hippocampus (Clarke, et al., 1984; Rubboli, et al., 1994). The presence of nicotinic receptors and choline acetyl transferase, the acetylcholine (ACh) synthetic enzyme, has been reported in the amygdala (Hellendall, et al., 1986; Van der Zee, et al., 1997; Yajeya, et al., 1997). Electrophysiological data suggest that nAChRs are located in both the somatodendritic membrane and in the nerve terminal (Clarke and Pert, 1985; Vidal, 1996). This makes the receptor mediate neural activity in two ways. At the nerve terminal, the nicotinic receptor influences neurotransmitter secretion on target neurons; at dendrites, the receptor mediates changes in rate and pattern of firing. Both mechanisms are believed to be present in the brain (Balfour and Fagerström, 1996; Vidal, 1996). In presynaptic terminals for example, low doses of nicotine activate nAChRs on synaptic terminals to evoke an influx of $\mathrm{Ca}^{2+}$ which in turn enhances exocytosis of a neurotransmitter, for example, glutamate (McGehee and Role, 1996). 
Biochemical studies on synaptosome have demonstrated that nicotine administration triggers the release of neurotransmitters including ACh, GABA, norepinephrine, epinephrine, dopamine, serotonin, aspartate and glutamate, therefore confirming the presence of presynaptic nAChRs, (Armitage, et al., 1969; Balfour and Fagerström, 1996; Rapier, et al., 1988; Rowell and Hillebrand, 1994; Toth, et al., 1992; Valentine, et al., 1996). As discussed earlier, CRF neuronal systems are colocalized with those of other neurotransmitters, which are influenced by nicotine (Fallon and Ciofi, 1992; Okuda, et al., 1993; Shinohara, et al., 1988; Van Bockstaele, et al., 1996). Since nicotine influences neuronal systems that colocalize with CRF systems (Okuda, et al., 1993), this suggests that nicotine could also have an influence on the CRF.

\section{$\underline{\text { Nicotine and HPA axis }}$}

Nicotine administration into rats increases plasma ACTH and corticosterone levels (Benwell and Balfour, 1979; Cam and Bassett, 1983; Freund, et al., 1988).

Catecholamines are reported to play a role in triggering CRF release in the PVN of hypothalamus for the ultimate release of ACTH in the anterior pituitary (Andersson, et al., 1983; Matta, et al., 1993b). Nicotine stimulates $c$-fos immunoreactivity in the CeA, PVN and brain stem catecholaminergic regions (Matta, et al., 1993a; Matta, et al., 1997; Salminen, et al., 1996). This suggests that nicotine is a potent activator of neuronal activity in catecholaminergic and CRF regions. It has been reported that CRF receptors are possibly colocalized with nAChRs in the median eminence (Okuda, et al., 1993) suggesting that nicotine may modulate CRF release at median eminence. Majewska, et al., 
(1985) reported that glucocorticoids also induced muscimol binding in the GABA receptors which are possibly colocalized with nicotinic and CRF receptors. Together this and other studies further confirm the inhibitory effects contributed by glucocorticoids on CRF receptors and possibly on nicotinic receptors (Johnson, et al., 1995; Sapolsky, et al., 1990).

\section{$\underline{\text { Nicotine and the amygdala }}$}

The amygdala has considerable levels of CRF, cholinergic projections from basal forebrain (Heckers and Mesulam, 1994) and also expresses nicotinic receptor immunoreactivity, and choline acetyl transferase, the acetylcholine synthetic enzyme (Hellendall, et al., 1986). Cholinergic fibers from basal forebrain reach the amygdala through the stria terminalis and the amygdalofugal pathway (Heckers and Mesulam, 1994). Roozendaal, et al., (1997), reported that in amygdala, 90\% of the cholinergic afferents expressed nicotinic receptor immunoreactivity, and as seen in the neocortex, muscarinic and nicotinic receptors are colocalized in amygdala (Van der Zee, et al., 1992; Van der Zee, et al., 1997). Electrophysiological techniques by Yajeya, et al., (1997), showed that most of the amygdaloid neurons responded to carbachol which is an agonist at both nicotinic and muscarinic receptors. A more specific nicotinic agonist would be necessary to help determine nicotinic receptor responses in the amygdala. Microdialysis techniques showed that administration of nicotine into the amygdala induced NE release in brain stem catecholaminergic regions (Fu, et al., 1997; Fu, et al., 1998). Raber, et al., (1995), studied primary cultures and reported that CRF release in the amygdala was 
influenced by interleukin, ACh and norepinephrine. A 1997 study by Matta, et al., reported increased $c$-fos expression in CRF immunoreactive neurons after nicotine administration.

\section{Nicotine and neurotransmitters}

$\underline{\text { Acetylcholine secretion }}$

Acetylcholine (ACh) is an excitatory neurotransmitter, its secretion in the brain is strongly associated with locomotor activity and cognitive stimulation (Armitage, et al., 1969; Balfour and Fagerström, 1996; Warburton and Rusted, 1993). Nicotine has been shown to modulate locomotor activity in animals and this is mediated through activation of ACh secretion resulting in muscarinic activation (Armitage, et al., 1969; Levin, 1992). There are variations in responses elicited by different dosing times, regimens and routes of administration of nicotine. However, Armitage, et al., 1968 showed that high doses of nicotine suppressed ACh release, and could be demonstrated by decreased locomotion, due to desensitization of the nicotinic receptor (Armitage, et al., 1968; Armitage, et al., 1969; Hakan and Ksir, 1991). This is to be expected because nicotine is a stimulant at low doses and depressant at high doses (Benwell and Balfour, 1982; Gray, et al., 1996; Sharp, et al., 1993).

Role in nicotine rewarding properties. It is believed that smokers use tobacco for nicotine to modulate level of arousal, attention or sustained concentration and cognitive performance (Acri, et al., 1994; Balfour and Fagerström, 1996; Warburton, 1992). The need to satisfy this CNS effect is believed to modulate the desire to smoke. It has been 
reported that one of the ways nicotine elicits these CNS effects is through stimulation of the ACh secretion in the brain, particularly the hippocampus (Levin, 1992; Armitage, et al., 1968; Armitage, et al., 1969).

Pharmacological disruption of cholinergic neurotransmission or neurodegeneration cause impairments in cognitive skills (Balfour and Fagerström, 1996; Levin, 1992; Levin, et al., 1992). For example, Alzheimer's and Parkinson's diseases are characterized by a loss of cortical nAChRs and patients show an improvement in memory and attention after nicotine treatment (Balfour and Fagerström, 1996; Kellar, et al., 1987; Levin, 1992; Vidal, 1996). Two reviews by Warburton, (1992) and Warburton and Rusted, (1993) surmised that tobacco smoking or administration of nicotine elicited cognitive-enhancing effects, more related to information processing, as observed in Alzheimer's patients treated with nicotine. In monkeys, ABT418, an agonist at nAChRs, improved accuracy in learning and memory (Prendergast, et al., 1997).

\section{$\underline{\text { Norepinephrine secretion }}$}

Nicotine has been reported to excite noradrenergic neurons in the brain stem (Fu, et al., 1997; Fu, et al., 1998; Sharp and Matta, 1993). Noradrenergic innervation arises from the locus coeruleus, nucleus tractus solitarius and neurons of the reticular formation (Gray, 1993; Haines, 1991). The noradrenergic system innervates mainly the cortical, subcortical and spino medullary regions and PVN (Haines, 1991). Norepinephrine plays a vital role in memory and learning, sleep-wake cycle and affective disorders (Bremner, et al., 1996). Svensson and Engberg, (1980) used single cell recording techniques and 
demonstrated that noradrenergic neurons express nicotinic receptors on both somatodendritic membranes in the LC and the nerve terminal membranes. Egan and North, (1986), used LC slices to demonstrate that nicotine and ACh depolarize LC neurons, indicating the presence of nAChRs. This and other studies suggest that nicotine plays a part in exciting the NE neurons in brain stem (Benwell and Balfour, 1997; Fu, et al., 1997; Fu, et al., 1998; Sharp and Matta, 1993).

In vivo microdialysis studies performed by Andersson, et al., (1981), and Mitchell, (1993), showed that nicotine administration increased NE turnover in the rodent brain. This was further confirmed in immunocytochemical studies (Valentine, et al., 1996) which showed that an increase in $c$-fos immunonoreactivity in PVN correlated with $c$-fos in nucleus tractus solitarius. Studies on hypothalamic synaptosomes revealed that low concentrations of nicotine $\left(5 \times 10^{-6} \mathrm{M}\right)$ caused an increase in NE release (Balfour, 1973; Yoshida, et al., 1980). Acute administration of $100 \mu \mathrm{M}$ nicotine increased NE in fetal LC cell cultures (Gallardo and Leslie, 1998). Nicotine also induces NE release from nucleus tractus solitarius and $\mathrm{LC}$ which project to the PVN and contribute to NE release for ultimate stimulation of CRF release in PVN (Gray and Bingaman, 1996). A recent study by $\mathrm{Fu}$, et al., (1998) using microdialysis techniques showed nicotine to induce NE release in amygdala and hippocampus. All these effects were inhibited by mecamylamine, a centrally acting noncompetitive antagonist of nicotine (Morgan and Pfeil, 1979). A decrease in NE in the amygdala has been associated with an increase in hypothalamic activity (Goldstein, et al., 1996), suggesting a role of amygdala in activation of the hypothalamus. 
In addition to its brain stem effects, nicotine also modulates NE levels in other brain regions. However, brain regions including the hippocampus, cerebral cortex, and cerebellum, require high concentrations of nicotine to cause an increase in NE turnover (Smith, et al., 1991). Sershen, et al., (1997) studied hippocampal slices and reported that $\alpha_{3} \beta_{2}$ receptor controlled NE release in the slices. Three studies have reported that chronic nicotine injections seem to exert selective sensitization of hippocampal NE release and turnover probably due to increased synthesis of tyrosine hydroxylase, the rate limiting enzyme in the synthesis of NE (Joseph, et al., 1990; Mitchell, 1993; Smith, et al., 1991). However, subcutaneous minipump infusion of nicotine elicited contrasting results. Kirch, et al., (1987), reported that minipump infusions of nicotine lowered NE levels in the frontal cortex, possibly abolishing NE overflow in the hippocampus (Balfour and Fagerström, 1996). These findings suggest that NE secreting neurons located in the hippocampus originating from the LC get desensitized by chronic exposure to nicotine levels that are comparable to the 10-25 $\mathrm{ng} / \mathrm{ml}$ found in habitual smokers (Armitage, et al., 1968; Balfour and Fagerström, 1996; Isaac and Rand, 1972). Therefore, nicotine influences both cholinergic and catecholaminergic systems that play a role in the interrelationships between hypothalamus, amygdala and brain stem (Fu, et al., 1997; Fu, et al., 1998; Levin, et al., 1992; Matta, et al., 1993b; Valentine, et al., 1996).

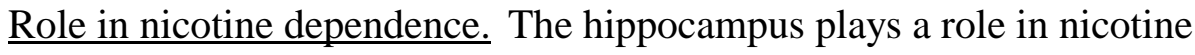
dependence (Markou, et al., 1998; Mitchell, 1993; Smith, et al., 1991). Chronic infusions of nicotine using minipumps desensitize nicotinic receptors and decrease NE release in neurons which innervate the hippocampus, originating from the LC (Balfour and 
Fagerström, 1996; Smith, et al., 1991). This desensitization of receptors and reduction in NE is believed to play a critical role in mediating the "calming" effects of tobacco (Gilbert, et al., 1997; Pomerleau and Pomerleau, 1987). This therefore, suggests that smokers seek to smoke in order to maintain desensitized nicotinic receptors and that an individual would adjust the smoking behavior in order to achieve this effect (Benowitz and Jacob, III, 1997).

\section{Dopamine release}

Nicotine stimulates and sensitizes dopamine neurons to increase dopamine (DA) secretion, and nicotine also inhibits DA reuptake by neurons (Benwell and Balfour, 1992; Izenwasser, et al., 1991; Shoaib, et al., 1994). DA is abundant in the brain, mainly found in the basal ganglia particularly the caudate nucleus (Carlsson and Waldeck, 1958). DA secreting neurons originating from the ventral tegmental area (VTA) to the nucleus accumbens (NAcc) and from substantia nigra $(\mathrm{SN})$ to caudate/putamen $(\mathrm{CP})$ have nicotinic receptors on both the somatodendritic membranes and nerve terminal membranes (Clarke and Pert, 1985; Corrigall, et al., 1992; Marshall, et al., 1997). Nicotine has been reported to increase (DA) overflow in NAcc and CP, and dopamine release increased in striatal synaptosomes (Grady, et al., 1994; Rapier, et al., 1988; Rapier, et al., 1990; Rowell and Hillebrand, 1994). These researchers demonstrated that when synaptosomes derived from caudate putamen (CP) area or nucleus accumbens were stimulated with nicotine an increase in DA secretion was observed. The response was calcium dependent and antagonized by mecamylamine, the nicotine noncompetitive antagonist. These 
findings confirmed that responses to nicotine are elicited through presynaptic nicotinic receptors. Microdialysis probes into the NAcc also demonstrated increased DA overflow after nicotine treatment (Mifsud, et al., 1989; Nisell, et al., 1994). Microdialysis techniques have shown that DA overflow in the NAcc increases due to systemic nicotine injections and this overflow mediated mainly by nicotinic receptors located in the somatodendritic membranes in the VTA (Bassareo, et al., 1996; Benwell and Balfour, 1992; Marshall, et al., 1997).

Studies by Imperato, et al., (1986) and Mereu, et al., (1987), suggested that, compared to nigrostriatal system, mesolimbic neurons are more sensitive to nicotine. Garris and Wightman, (1994), used microdialysis and voltametric probes and which indicated that DA flow in the both $\mathrm{CP}$ and NAcc synaptic clefts is tightly controlled by a transport system which is more efficient in the $\mathrm{CP}$, which would partly explain the differences in the sensitivity to nicotine. Unlike the desensitization effects observed in the ACh, NE and 5-HT systems, repeated injections of nicotine enhance DA overflow in the NAcc (Benwell and Balfour, 1992; Pietilä, et al., 1996), but this was contrasted by a study that demonstrated a decrease in dopamine release in synaptosomes after repeated nicotine doses (Grady, et al., 1994). Sensitization of the mesolimbic DA system is modulated through the nicotinic receptor since it is attenuated by prior administration of mecamylamine. It has also been reported that sensitization of these DA receptors depends on the co-stimulation of the NMDA receptor since this sensitization is diminished by prior treatment with NMDA receptor antagonists (Shoaib, et al., 1994; Shoaib, et al., 1997). This sensitization of DA neurons, reinforces the belief that DA systems mediate 
behavioral responses to nicotine, particularly, locomotor stimulation and rewarding properties of the drug (Clarke and Pert, 1985; Corrigall and Coen, 1989; Corrigall, et al., 1992).

$\underline{\text { Role in nicotine dependence. }}$ Existing studies on experimental models of depression (stress) indicate that behavioral activation is dependent on the enhanced secretion of dopamine (DA) in mesoaccumbens system, and the system is a critical component of the reward system that influences reinforcement (Benwell and Balfour, 1992; Gray and Bingaman, 1996). Piccioto, et al., (1998) reported stimulation of dopamine release by nicotine in ventral striatum of wild type mice compared to $\beta 2$ subunit mutant mice. These researchers concluded that striatal nAchRs containing the $\beta 2$ subunit are involved in the reinforcing properties of nicotine. This as discussed earlier, suggests the involvement of the nicotine sensitive $\alpha 4 \beta 2$ receptor (Flores, et al., 1991).

Dopamine neurons are sensitized by high or chronic levels of nicotine to increase DA secretion, and nicotine also inhibits DA reuptake thus enhancing the availability of DA (Benwell and Balfour, 1992; Izenwasser, et al., 1991; Shoaib, et al., 1994;). This would suggest that in chronic doses, as nicotine receptors get desensitized, the capability to activate dopamine neurons is compromised thus eliciting a need for more nicotine, which eventually leads to negative effects. Researchers report that experimental animals need a "time out" from nicotine self administration because the presence of nicotine with receptors desensitized, becomes aversive. Time off reduces drug levels and minimizes receptor desensitization (Balfour and Fagerström, 1996). Possibly, smokers seek smoke to replenish nicotine levels, overcome desensititized receptors, and recruit non- 
desensitized receptors to trigger neurotransmission and therefore increase dopamine release, thus contributing to the "calming" effects of nicotine (Gilbert, et al., 1997; Pomerleau and Pomerleau, 1987).

\section{$\underline{\text { 5-hydroxytryptamine (serotonin) secretion }}$}

Nicotine has been shown to decrease serotonin in selected regions of the mammalian brain while decreasing the neurotransmitter in others (Balfour, et al., 1975; Bannon, et al., 1998; Benwell and Balfour, 1979). The mammalian forebrain gets its serotonergic innervation from the median and dorsal raphe nuclei located in the brain stem (pons and medulla) (Haines, 1991). These nuclei express a significant amount of the $\alpha 4$ subunit of the nicotinic receptor (Wada, et al., 1989). Other brain areas with considerable amounts of 5-hydroxytryptamine (5-HT) include the hypothalamus, limbic system and pituitary gland (Benwell and Balfour, 1979).

Serotonin is believed to modulate a number of behavioral aspects, including pain perception, sleep, depression, anxiety, mood changes and sexual activity and acts through different receptors including 5- $\mathrm{HT}_{1}, 5-\mathrm{HT}_{2}, 5-\mathrm{HT}_{3}, 5-\mathrm{HT}_{4}$ (Kidd, et al., 1993). Antidepressants are used to modulate serotonin levels or antagonize receptors (Charney, et al., 1990; Graeff, et al., 1996; Kandel, 1991; Kidd, et al., 1993). The 5-HT 1a $_{\text {receptor plays }}$ a role in fear conditioning in the amygdala while $5-\mathrm{HT}_{2}$ mediates mood states (Charney, et al., 1990; Fernandes, et al., 1997; Graeff, et al., 1996). The 5-HT 3 receptor is found in high densities in the brain and is significantly localized in nerve terminals of amygdala where it evokes fast excitatory transmission (Kidd, et al., 1993; Sugita, et al., 
1992). Kawahara et al., (1993), reported that psychological stress increases serotonin in the amygdala, and 5- $\mathrm{HT}_{3}$ antagonists have been shown to be anxiolytic in animal models of behavior (Charney, et al., 1990; Graeff, et al., 1996).

Nicotine has been shown to decrease serotonin in selected regions of the mammalian brain, this may be possibly because of increased metabolism of the neurotransmitter caused by nicotine (Bannon, et al., 1998). Nicotine decreases serotonin in the hippocampus, but increases this neurotransmitter in the amygdala (Balfour, et al., 1975; Benwell and Balfour, 1979). Balfour, et al., (1975), demonstrated that acute injections of nicotine in normal rats cause a transitory decrease in hippocampal serotonin, decreases were observed within 45 minutes, with a rise occurring by 60 minutes. In stressed rats, acute nicotine caused a persistent reduction in serotonin for up to 75 minutes (Balfour, et al., 1975). Chronic infusion of $0.4 \mathrm{mg} / \mathrm{kg}$ for 40 days evoked a more stable, persistent, regionally selective decrease in hippocampal serotonin, resulting from selective reduction in the biosynthesis of serotonin (Benwell and Balfour, 1982). A regional reduction in serotonin and the metabolite 5-hydroxyindole acetic acid, and an upregulation of serotonin receptors, like nAChRs, has been observed in postmortem tissue of habitual smokers (Benwell, et al., 1988; Benwell, et al., 1990). This supports the notion that this system may play a role in the psychopharmacological response to nicotine and its contribution to the habit of tobacco smoking (Balfour and Fagerström, 1996).

$\underline{\text { Role in nicotine dependence. }}$ Nicotine withdrawal is strongly associated with symptoms of depression, while nicotine dependence has been associated with a history of depression (Breslau, et al., 1993; West and Hajek, 1997). Rasmussen, (1997) studied 
effects of nicotine withdrawal on serotonergic neurons in rat nucleus raphe, using $5 \mathrm{HT}_{\mathrm{IA}}$ receptor agonist 8-OH-DPAT. They reported that nicotine withdrawal increased sensitivity to the auditory startle response, indicating sensitivity to external stimuli. In a

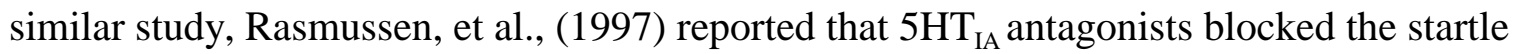
response that is enhanced by nicotine withdrawal. These researchers concluded that the serotonergic system is possibly associated with symptoms of nicotine withdrawal. A study by Hurt, et al, (1997), tested the antidepressant bupropion (which possibly functions on both serotonergic and noradrenergic receptors) for smoking cessation in a study that involved 615 subjects. The researchers reported that compared to placebo, more smokers who received the sustained-release form of bupropion were able to stay smoke free for the duration of the (one year) tested time. This suggested that the antidepressive effects of bupropion enabled subjects to have a decreased need for nicotine. However, neural mechanisms underlying the antidepressive properties of nicotine have yet to be elucidated.

\section{Nicotine and the NMDA receptor}

The NMDA receptor is involved in responses to chronic nicotine (Shoaib and Stolerman, 1992; Shoaib, et al., 1994; Shoaib, et al., 1997). The NMDA receptor plays an important role in long term potentiation in the amygdala and nicotine has stimulatory effects on glutamate release (McGehee and Role, 1996; Toth, et al., 1992). In pyramidal cells of the prefrontal cortex, excitatory synaptic potentials mediated by glutamate are potentiated by nicotine (Vidal, 1996; Vidal and Changeux, 1993). Since glutamate plays a role in synaptic plasticity, the enhancement of glutamatergic terminals by nicotine in the 
prefrontal cortex further explains the role of nicotine in learning and memory (Shoaib, et al., 1994; Shoaib, et al., 1997). These studies point to functional cooperation between nicotinic and glutamatergic systems in the cortex which would represent a unified involvement of the two systems in cognitive processes (Toth, et al., 1992; Vidal, 1996).

\section{Positive reinforcing properties of nicotine}

The effects of nicotine on animal behavior are impacted by several factors including dose, route of administration, species and strain, prior exposure to the drug and nature of test used (Balfour and Fagerström, 1996; Donny, et al., 1998). Similar to psychostimulants like amphetamine and cocaine, the effects of acute nicotine on animals are manifested by locomotor stimulation (Hakan and Ksir, 1991; Mifsud, et al., 1989). Acute high doses or chronic low doses decrease locomotor stimulation due to receptor desensitization Ksir, et al., (1987) and also because high doses decrease ACh release (Armitage, et al., 1968). Positive reinforcing properties (rewarding properties) of addictive drugs are manifested in the animal's self administration of the drug as measured using the self administration paradigm (Balfour, 1982; Balfour and Fagerström, 1996; Donny, et al., 1998). With amphetamine and cocaine, both the acquisition and maintenance of drug usage behavior have been shown to depend on an intact DA system (Glick, et al., 1996), that is, DA projections to the NAcc, where a large increase in DA overflow is observed after drug treatment (Benwell and Balfour, 1992; Izenwasser, et al., 1991; Shoaib, et al., 1994). 
Maintenance of nicotine self administration also involves DA neurons that project from the VTA, but the paradigm is not easy to demonstrate in animals, because nicotine has weaker reinforcing properties compared to cocaine and amphetamine (Corrigall and Coen, 1989; Corrigall, et al., 1992; Corrigall, et al., 1994). In a study by Dawe, et al., (1995), on humans who were initially treated with haloperidol, a DA receptor antagonist, individuals were found to increase their smoking to overcome this blockade and once achieved they maintained the new dose of smoke, with satisfaction. In the self administration paradigm, the response for nicotine is reported to be bell shaped, with higher doses possibly becoming aversive rather than rewarding (Balfour, 1982; Balfour and Fagerström, 1996; Hildebrand, et al., 1997; Rose and Corrigall, 1997; Valentine, et al., 1997). CRF has also been implicated to play a role in drug seeking behaviors in that intracerebroventricular injections of CRF to stressed animals induced a relapse to cocaine seeking, an effect that was attenuated by the presence of the antagonist, $\alpha$-helical CRF and d-phe CRF (Heinrichs, et al., 1998).

\section{$\underline{\text { Nicotine and neurological diseases }}$}

As discussed earlier, animal and human studies on nicotinic receptors suggest that neuronal nicotinic systems play a major role in cognitive functions and dysfunctions (Balfour and Fagerström, 1996; Clarke and Pert, 1985; Levin, 1992). Nicotine and analogues seem to influence brain neural systems that are implicated in psychiatric and neural disorders (Balfour and Fagerström, 1996; Roozendaal, et al., 1997; West and Hajek, 1997). Regionally selective losses of the nicotinic receptors that bind $\left[{ }^{3} \mathrm{H}\right](-)$-nicotine and 
$\left[{ }^{3} \mathrm{H}\right]-\mathrm{ACh}$ are associated with cognitive impairments observed in diseases like Alzheimer's (AD) which affects memory and Parkinson's (PD) which affects mobility (Flynn and Mash, 1986; Jones, et al., 1992; Nordberg, et al., 1989). Nicotine therefore, could be used therapeutically to treat these diseases (Levin, 1992). For example, Alzheimer's and Parkinson's diseases are characterized by a loss of cortical nAChRs and patients show an improvement in memory and attention after nicotine treatment (Kellar, et al., 1987; Levin, 1992; Vidal, 1996). CRF is also decreased in AD and PD, suggesting a possible interaction between nicotine and CRF in the etiology of these pathologies (De Souza, 1995; De Souza, et al., 1985).

\section{Is nicotine anxiolytic?}

Smokers report that after exposure to stressful stimuli smoking has a calming effect (Benowitz and Jacob, III, 1997; Gilbert, et al., 1997; Pomerleau and Pomerleau, 1987). This is a paradox because nicotine elicits effects that resemble stressful stimuli, for example, increased norepinephrine secretion and circulating ACTH and corticosterone (Benwell and Balfour, 1982; Cam and Bassett, 1983; Jones, 1987). It should be noted that having a cigarette in the hand, something to pay attention to, may contribute to the alleviation of anxiety symptoms (Jones, 1987; West and Hajek, 1997). The role of nicotine as an anxiolytic has been observed using animal models of anxiety, including elevated plus maze, sensory motor gating and nicotine ingestion when exposed to stress (Acri, et al., 1994; Brioni, et al., 1993; Brioni, et al., 1994). Rats treated with nicotine $(0.01$ to $1.0 \mathrm{mg} / \mathrm{kg}$ ) were reported to spend more active time in the illuminated area than 
in the dark implying that animals were less fearful (Costall, et al., 1989). Neural mechanisms in the reinforcing properties of nicotine are possibly different from those of anxiolytic properties of nicotine in that they depend on desensitization of the nicotinic receptors located on synapses of pathways that mediate the stress response, for example CRF and NE (Balfour and Fagerström, 1996; Benwell and Balfour, 1997). Whether or not the apparent anxiolytic effects of nicotine may be similar to those evoked by antidepressants rather than anxiolytic drugs have yet to be investigated convincingly (Balfour and Fagerström, 1996).

A few researchers have examined effects of nicotine withdrawal using animal models of anxiety and it is still debatable whether or not nicotine or withdrawal from nicotine increases anxiety (Helton, et al., 1993; Jones, 1987; Rasmussen, et al., 1997; West and Hajek, 1997). Helton, et al., (1993), reported that nicotine withdrawal increased sensory motor reactivity suggesting a manifestation of anxiogenic effects. Studies by Costal, et al., (1989); Crooks and Dwoskin, (1997) used the light/dark box paradigm on mice and found that nicotine withdrawal caused an increase in anxiety. This anxiety was diminished by the antidepressant diazepam and by the $5-\mathrm{HT}_{3}$ receptor antagonist, ondasteron, indicating an interrelationship between GABAergic and serotonergic with cholinergic synapses (Costall, et al., 1989; Crooks and Dwoskin, 1997; Rasmussen, et al., 1997).

Smoking or self administration of nicotine by animals may be a way to seek a coping mechanism against aversive environmental stimuli (Balfour, 1982). A potent nicotinic receptor agonist ABT 418 was studied by (Sajdyk and Shekhar, 1997). The 
researchers found that $0.062-30 \mu \mathrm{mol} / \mathrm{kg}$ of ABT 418 caused anxiolytic effects in rats, as shown by increased activity in the elevated plus maze, effects that were also produced by nicotine. Kumari, et al., (1996), reported a decrease in prepulse inhibition of the acoustic startle suggesting an increase in the ability to screen irrelevant sensory stimuli, that is, increased attention. Anhedonic properties of aversive environmental stimuli can be depressive or anxiogenic and for individuals who have been exposed to smoking, this triggers the desire to smoke (Balfour, 1982; Jones, 1987). To further support the antidepressive properties of nicotine, a smoking cessation study by Hurt, et al, (1997), reported that compared to placebo, more smokers who received the sustained-release form of bupropion were able to stay smoke free for the duration of the (one year) tested time. These findings could suggest that in humans, the ability of nicotine to alleviate stress is a quality that enables this drug to reinforce its self-administration (Balfour and Fagerström, 1996; Jones, 1987). If nicotine is anxiolytic or antidepressive, we should expect that both doses $0.4 \mathrm{mg} / \mathrm{kg}$ and $1.0 \mathrm{mg} / \mathrm{kg}$ which give rat levels equivalent to $10-40 \mathrm{ng} / \mathrm{ml}$ ) maintained by regular smokers (Balfour and Fagerström, 1996; Isaac and Rand, 1972) would decrease CRF content in amygdala and hypothalamus.

\section{$\underline{\text { Is nicotine anxiogenic? }}$}

Anxiogenic responses can be measured using animal models of anxiety, including mazes and/or the acoustic startle responses. As discussed earlier, CRF has been reported to induce defensive withdrawal symptoms in mazes and potentiate acoustic startle responses. Acri, et al., (1993) and (1994), used very high doses (6 and $12 \mathrm{mg} / \mathrm{kg}$ ) of 
nicotine and the acoustic startle paradigm. The $6 \mathrm{mg} / \mathrm{kg} / \mathrm{day}$ dose gives rat levels equivalent to $(40-80 \mathrm{ng} / \mathrm{ml})$ those of a human smoking 3 packs of 20 cigarettes per day (Isaac and Rand, 1972). The researchers found that nicotine treated animals had increased acoustic startle responses compared to untreated. The studies indicated that nicotine treated rats had increased attention processes, as expected, but this also suggested anxiogenic effects of nicotine.

The researchers (Acri, 1994; Acri, et al., 1994; Kumari, et al., 1996) further reported that nicotine elevated sensory gating as measured by prepulse inhibition of the acoustic startle. Like CRF, nicotine manifests anxiogenic and stress symptoms. The inference from these studies is that nicotine can be anxiolytic or anxiogenic, depending on the dose and whether treatment is acute or chronic. For the present study, if nicotine is anxiogenic, we should expect that acute doses of $0.4 \mathrm{mg} / \mathrm{kg}$ or $1.0 \mathrm{mg} / \mathrm{kg}$ which give rat levels equivalent to the $10-40 \mathrm{ng} / \mathrm{ml}$ maintained by regular smokers (Balfour and Fagerström, 1996; Isaac and Rand, 1972), would elavate CRF content in the amygdala and hypothalamus.

\section{Nicotine and corticosterone}

Acute and chronic nicotine have been shown induce increased plasma ACTH and corticosterone levels (Benwell and Balfour, 1979; Benwell and Balfour, 1982; Cam and Bassett, 1983; Freund, et al., 1988). The increase is dose dependent and is observed within 15 minutes and persists for up to 60 minutes after acute treatment and up to two weeks after chronic treatment (Benwell and Balfour, 1979; Benwell and Balfour, 1982; 
Cam and Bassett, 1983; Freund, et al., 1988; Pauly, et al., 1990). Corticosterone and its metabolites have been reported to decrease excitability in the nervous system and this effect is through the modulation of the GABA receptor (Harrison and Simmonds, 1984; Kendall, et al., 1982; Majewska, et al., 1985) and nicotine has been reported to modulate glutamate activity on the NMDA receptor (Vidal and Changeux, 1993). Caggiula, et al., (1993), reported increased tail flick latencies in nicotine treated rats with intact adrenals compared to adrenalectomized and stressed rats, thus confirming the nociceptive effects of nicotine and possibly enhancement by corticosterone. The observations led Caggiula, et al., (1993); Caggiula, et al., (1998) and Pauly, et al., (1988) to conclude that the increase in corticosterone after nicotine treatment is a way for neuronal systems to cope with the effects of nicotine.

Nicotine also manifests an increase in corticosterone through the its peripheral effects on the adrenal cortex, an effect that was reported by (Bugaski, et al., 1998). In conjunction with studying effects of indomethacin (a cyclooxygynase inhibitor) regarding nicotine-induced effects on ACTH and corticosterone levels, the researchers confirmed inhibitory effects of hexamethonium, a peripheral nicotinic receptor inhibitor, on corticosterone synthesis.

The increase in corticosterone by nicotine administration reflects an increase in the activation of the HPA axis, as seen in acute and chronic stress. Pretreatment with corticosterone reduces responsiveness to nicotine and effects of nicotine are manifested differently in stressed and unstressed rats because stressed rats already have increased levels of corticosterone (Bullock, et al., 1997; Caggiula, et al., 1993). Balfour, et al., 
(1975); Hall and Morrison, (1973) tested effects of nicotine on stressed and unstressed rats and found that acute nicotine increased corticosterone in unstressed rats but had no effects on the feedback inhibition exerted by high corticosterone levels in stressed rats. These effects were confirmed by the antagonistic effects of metyrapone on adrenal corticosterone synthesis (Balfour, et al., 1975). The findings further confirm that corticosterone has a role in modulating the animal's response to nicotine.

Chronic nicotine causes an up-regulation of nicotinic receptors in the brain (Benwell, et al., 1988; Rowell and Li, 1997; Schwartz and Keller, 1983; Ulrich, et al., 1997) and corticosterone also causes an up-regulation of nicotinic receptors (Pauly, et al., 1990). Corticosterone and nicotine possibly have a synegystic effect in the up-regulation of nicotinic receptors. The upregulated $\mathrm{nAChRs}$ are believed to be nonfunctional, possibly because they are maintained at a refractory state, and thus contribute to the tolerance to nicotine (McGehee and Role, 1996). Behavioral and receptor binding tests on mice, by Pauly, et al., (1992) confirmed that chronic levels of corticosterone induce tolerance to nicotine. These studies suggest that this tolerance may also be mediated through corticosterone's up-regulation of nicotinic receptors (Johnson, et al., 1995; Pauly, et al., 1990; Sapolsky, et al., 1990). Conditioned tolerance occurs to some behavioral and endocrine effects of nicotine (Marks, et al., 1983; Sharp and Matta, 1993). Nicotine administration induced a dose dependent tolerance to nicotine's effects on heart rate, respiration rate, locomotor activity, acoustic startle responses, body temperature and seizure threshold (Marks, et al., 1983; Marks, et al., 1985; Hakan and Ksir, 1991). Pauly, et al., (1988) ran behavioral tests including the Y-maze and startle response, and 
monitored heart rate and body temperature of normal and adrenalectomized rats. The researchers found that adrenalectomized rats, (with deficient corticosterone) exhibited increased sensitivity to nicotine compared to non-adrenalectomized. The researchers concluded as mentioned above, that the increase in corticosterone is a way of coping with nicotine's effects.

High concentrations of corticosterone in rats were reported to decrease CRF receptor (CRH-R) mRNA in the PVN and BLA confirming the negative feedback inhibition of CRF by corticosterone (Makino, et al., 1995). In this study, Makino, et al., (1995), further demonstrated that chronic stress up-regulated CRF-R mRNA, indicating that the stress input can override the feedback inhibitory effects of corticosterone to upregulate CRH-R mRNA in the PVN.

\section{Nicotine versus CRF}

The discussed literature suggests that nicotine and CRF could influence each other in neuronal systems either directly or indirectly through other neurotransmitters. In their study of possible involvement of interleukin-2 and nitric oxide in CRF release, Raber, et al., (1995), also reported that both acetylcholine and norepinephrine induced the release of CRF from the hypothalamus and amygdala. The acetylcholine effect was antagonized by both atropine and mecamylamine indicating the involvement of both muscarinic and nicotinic receptors. The norepinephrine effect was also antagonized by phentolamine and propranolol suggesting that both $\alpha$ and $\beta$ adrenergic receptors are involved in stimulation of CRF release in amygdala and hypothalamus. 
It is believed that affective disorders are influenced by changes in biogenic amine transmission (Schwartz and Kandel, 1991). Both nicotine and CRF influence neurotransmitters such as norepinephrine and serotonin (5-hydroxytryptamine), suggesting that nicotine exerts its CNS effects by influencing these systems (Calogero, et al., 1989; Fu, et al., 1998). Nicotine craving or nicotine withdrawal are reported to be associated with affective disorders (Balfour and Fagerström, 1996; Fergusson, et al., 1996; Frederick, et al., 1998) while CRF is implicated in affective disorders (De Souza, 1995; Nemeroff, et al., 1991; Owens and Nemeroff, 1993; Owens, et al., 1991). Indeed, behavioral models of anxiety including social interaction, elevated plus maze and fear potentiated startle indicate that CRF is anxiogenic (Dunn and Berridge, 1990; Liang, et al., 1992a; Liang, et al., 1992b; Koob and Bloom, 1985). Some of these anxiogenic reactions can also be observed after nicotine administration (Acri, 1994; Acri, et al., 1994; Kumari, et al., 1996).

Diseases like Alzheimer's and Parkinson's are manifested by a decrease in CRF levels and an up-regulation of CRF receptors, while hypersecretion of CRF results in down regulation of receptors (De Souza, 1995; De Souza, et al., 1985; De Souza, et al., 1986; Nemeroff, et al., 1988). Nicotinic receptors are significantly decreased in the cerebral cortex of patients with Alzheimer's and Parkinson's diseases (Jones, et al., 1992; Kellar, et al., 1987; Vidal, 1996). These observations, would suggest a relationship between nicotinic receptor activation and CRF metabolism, and possibly in the etiology of these diseases (Christensen, et al., 1992). It is conceivable that nicotine used therapeutically for these diseases (Jones, et al., 1992), would also improve CRF levels, but this possibility still needs to be studied. 
Like nicotine, CRF administration induces metabolism of brain stem catecholamines. CRF stimulates NE release from LC (Rivier, et al., 1984; Valentino, et al., 1991) but nicotine also increases NE release in hypothalamus and brain stem catecholaminergic regions (Andersson, et al., 1981; Fu, et al., 1997; Fu, et al., 1998; Yoshida, et al., 1980). Nicotine influences NE and has cardiovascular effects, (Grunberg, et al., 1988; Pauly, et al., 1988), and the amygdala which is influenced by CRF and NE also has effects on the cardiovascular system (Davis, 1992; Gray and Bingaman, 1996). With CRF and NE neuronal systems colocalized (Gray and Bingaman, 1996; McDonald, 1996; Van Bockstaele, et al., 1996), the question is whether or not nicotine also modulates CRF, which in turn modulates NE or possibly nicotine influences these neurotransmitters simultaneously. Since NMDA and CRF receptors colocalize, CRF and glutamate influence each other, while nicotine influences glutaminergic systems, and possibly CRF (Gray and Bingaman, 1996).

Both nicotine and CRF exert anorexic effects, and CRF has thermogenic effects (Balfour and Fagerström, 1996; Le Feuvre, et al., 1991; Owens and Nemeroff, 1991; Winders and Grunberg, 1990). The anorexic effects of nicotine have been reported in humans, with smokers reporting weight gain after smoking cessation (Jones, 1987). It has been documented that CRF suppresses food consumption and modulates gastric motility in rats, and CRF levels have been reported to be increased in anorexic patients (De Souza, 1995; Monnikes, et al., 1992; Owens and Nemeroff, 1991). High levels of CRF trigger sympathetic outflow which results in hyperglycemia as a result of activated gluconeogenic pathways, this leads to increased energy utilization and decreased body weight (Brown, et 
al., 1982; Heinrichs, et al., 1996). The role of CRF in body weight is consistent with the fact that the hypothalamus has a vital role in body thermoregulation and food intake (Le Feuvre, et al., 1991; Leal and Moreira, 1996). Animal studies have shown that nicotine diminished feeding, increased energy utilization and therefore caused a decrease in body weight (Grunberg, et al., 1984; Grunberg, et al., 1988; Winders and Grunberg, 1990).

Nicotine has been shown to modulate a number of neurotransmitter systems that also interact with CRF in the rat brain, including among others: norepinephrine, dopamine and serotonin. Whether or not nicotine influences CRF in the amygdala has not been extensively documented except for recent study by (Matta, et al., 1997). It is yet to be documented whether or not nicotine also modulates CRF levels to achieve its CNS effects. The effects of nicotine on CRF would certainly depend on dose and the duration of the treatment and nicotine withdrawal would possibly have a different outcome. From the discussed literature, it can be assumed that if nicotine is anxiogenic, acute doses would transiently increase CRF in rat amygdala and hypothalamus or decrease the content if it is anxiolytic, while causing a decrease in the brain stem. Chronic nicotine on the other hand would cause increased content of CRF in the hypothalamus and extrahypothalamic regions. No change would occur if the CNS effects of nicotine do not involve CRF. 


\section{CHAPTER III}

\section{METHODS}

\section{$\underline{\text { Sample }}$}

The sample consisted of 104 male Sprague Dawley rats (Hill Top, Hill Top, PA) aged 2-4 months and weighing 250-450 grams. Rats were kept at animal quarters of WVU Health Sciences Center, with 12 hour dark/light hours, food and water freely available. Controls included untreated rats and saline (vehicle) treated to control for the stress of injection.

\section{$\underline{\text { Drug Solutions }}$}

Nicotine hemisulfate salt $\left(\mathrm{C}_{10} \mathrm{H}_{14} \mathrm{~N}_{2} \cdot 1 / 2 \mathrm{H}_{2}\right.$, Molecular weight $=213.3$ grams, Fisher Scientific) approximately $40 \%$ weight/volume (w/v) was kindly provided by Drs. W.W. Fleming, and D.A. Taylor, (Pharmacology \& Toxicology, WVU Health Sciences Center). Nicotine was prepared in $0.9 \%$ saline to $4.7 \mathrm{mM}$ and $2.0 \mathrm{mM}$ solutions and stored in the refrigerator. These nicotine solutions were equivalent to $1.0 \mathrm{mg} / \mathrm{ml}$ and 0.4 $\mathrm{mg} / \mathrm{ml}$ respectively and were injected at $1.0 \mathrm{ml} / \mathrm{kg}$ body weight to give doses of $1.0 \mathrm{mg} / \mathrm{kg}$ and $0.4 \mathrm{mg} / \mathrm{kg}$.

It has been reported that 2-3 packs/day of 20 cigarettes per pack give a smoker plasma levels of $40-80 \mathrm{ng} / \mathrm{ml}$ nicotine and in rat these are equivalent to $3-6 \mathrm{mg} / \mathrm{kg} / \mathrm{day}$ (Balfour and Fagerström, 1996; Isaac and Rand, 1972). This makes a 20 cigarettes pack equivalent to $1.5 \mathrm{mg} / \mathrm{kg}$ in rat. In this study, the $1.0 \mathrm{mg} / \mathrm{kg}$ dose was chosen because it has been commonly used by other researchers (Andersson, et al., 1981; Sastry, et al., 1995; 
Sharp, et al., 1993; Ulrich, et al., 1997). For example, Sastry, et al., (1995) measured nicotine in the brain after $1.0 \mathrm{mg} / \mathrm{kg}$ and reported that nicotine can be detected in the brain from 5-50 after intravenous injection. The $0.4 \mathrm{mg} / \mathrm{kg}$ dose has also been frequently used by other researchers (Benwell and Balfour, 1985; Johnson, et al., 1995; Sharp, et al., 1993), and is half of the $0.8 \mathrm{mg} / \mathrm{kg}$ dose which is equivalent to plasma concentrations of nicotine elicited by smoking one 10 pack of cigarettes, that is, $10-25 \mathrm{ng} / \mathrm{ml}$ (Benowitz, et al., 1988; Isaac and Rand, 1972).

\section{$\underline{\text { Animal treatment procedure }}$}

Rats were treated and sacrificed between the hours of 9.00 am to 12.00 noon to capitalize on the time before changes influenced by diurnal rhythms (Leal and Moreira, 1996; Owens, et al., 1990). Two doses of nicotine were used for acute treatments; 0.4 $\mathrm{mg} / \mathrm{kg}$ intraperitoneal (ip) nicotine at 15 and 30 minute treatment, and $1.0 \mathrm{mg} / \mathrm{kg}$ (ip) at 15 , 30 and 60 minute treatments. Each time treatment was an individual experiment with 1224 rats. As indicated on Tables 1 and 2 , six animals received $0.4 \mathrm{mg} / \mathrm{kg}$ nicotine for 15 or 30 minutes and six to eight animals received $1.0 \mathrm{mg} / \mathrm{kg}$ nicotine for 15,30 , or 60 minutes, respetively.

Animals were weighed and a nicotine or saline solution of $0.25-0.45 \mathrm{ml}$ was injected to rats according to their weights. A 5-10 minute interval was allowed to interspace the injections and facilitate the treatment procedure. Rats were kept at 3-4 per cage during the procedure. The behavior of nicotine treated rats was observed during the duration of the treatment. After the duration of a given time point, animals were 
Table 1

$\underline{\text { Sample and dosing for micro-punch dissections }}$

\begin{tabular}{|c|c|c|c|}
\hline Experiment & $\mathrm{n}$ & Time (minutes) & $\begin{array}{l}\text { *Nicotine dose } \\
(\mathrm{mg} / \mathrm{kg})\end{array}$ \\
\hline 1 & 12 & 15 & 0.4 \\
\hline 2 & 20 & 30 & 0.4 \\
\hline Total & 32 & & \\
\hline
\end{tabular}

*Four to six animals received nicotine per time point 
Table 2

$\underline{\text { Sample and dosing for macro-dissections }}$

\begin{tabular}{|c|c|c|c|}
\hline Experiment & $\mathrm{n}$ & Time (minutes) & $\begin{array}{l}\text { *Nicotine dose } \\
(\mathrm{mg} / \mathrm{kg})\end{array}$ \\
\hline 3 & 24 & 15 & 1.0 \\
\hline 4 & 24 & 30 & 1.0 \\
\hline 5 & 24 & 60 & 1.0 \\
\hline Total & 72 & & \\
\hline
\end{tabular}

*Eight animals received nicotine per time point 
decapitated and brains carefully removed from cranium, placed in vial with temporal lobe facing away from the surface, vial capped and immediately frozen in liquid nitrogen. The brains were kept in dry ice box and later stored at $-70^{\circ} \mathrm{C}$ before dissections. For each rat, trunk blood was collected into labeled microcentrifuge tubes (immediately after decapitation) for corticosterone assays. These were kept in ice and later centrifuged at $3000 \mathrm{rpm}$ for 30 minutes using a cold microcentrifuge. Plasma was separated (using a Pasteur pipette) into a new set of labeled microcentrifuge tubes and then stored at $-20^{\circ} \mathrm{C}$ until corticosterone radioimmunoassay.

\section{Cryostat frozen sections of the brain}

The cryostat-micro-punch procedure was the initial method in this study and was used only on animals treated with $0.4 \mathrm{mg} / \mathrm{kg}$ (ip) nicotine at 15 and 30 minutes. The cryostat, (Micron, GmbH, HM 505E, Germany, Walldorf.) was provided by Dr. W.T. Stauber, Physiology Department, WVU and Dr. J. Flores, Biology Department, WVU. A 12 centimeter blade (Leica Instruments) was used for sectioning, with cryostat temperature maintained at $-6^{\circ} \mathrm{C}$ to- $10{ }^{\circ} \mathrm{C}$. For each brain, coronal sections of 300 microns were made (Palma and Brownstein, 1985). The sections were placed onto 10-15 labeled glass slides and kept frozen in slide box placed in closed dry ice container and later stored at $-20^{\circ} \mathrm{C}$, until the micro-punch procedure. 


\section{Micro-punch dissections of brain nuclei}

The micro-punch dissection method of (Palma and Brownstein, 1985), was used to obtain nuclei from cryostat coronal sections. The amygdaloid nuclei, paraventricular nucleus of the hypothalamus and locus coeruleus/parabrachial nucleus (LCPB) were obtained separately to give three samples for each animal. Micro-punches were accomplished by using a $1 \mathrm{~mm}$ or $2 \mathrm{~mm}$ curette with slide placed on a glass petri dish placed on dry ice. The rat brain atlas (Paxinos and Watson, 1986) was used to decipher the landmarks; the amygdala distributed on plates $25-32$, PVN plates $20-25$ and LCPB plates 52-59. Tissue were immediately placed in labeled tubes containing $2.0 \mathrm{ml}$ ice-cold $0.5 \mathrm{~N} \mathrm{HCl}$ solution containing $1.0 \mathrm{mg} / \mathrm{ml}$ ascorbic acid and $1.0 \%$ Triton $\mathrm{X}-100$, for extraction. Homogenization of samples was accomplished with ultrasonic disruption (sonication) at setting 3 (Branson Sonic Power, Branson instruments Inc. Melville, L.I. NY). Samples were heated at $70^{\circ} \mathrm{C}$ for 10 minutes to denature enzymes and then stored at $-70^{\circ} \mathrm{C}$ until lyophilizations and protein assays. In this procedure, it is assumed that $\mathrm{CRF}$ is spared from denaturation because it is a low molecular weight peptide. The cryostatmicro-punch method had both advantages and disadvantages.

\section{$\underline{\text { Advantages }}$}

1. Good sections are obtained and different nuclei in a region could be accessed with different size curettes.

2. All the three regions per animal could be punched out in one sitting, the sequential order of sections allowed for an ordered access to the specific nuclei. 
3. Curettes allowed for a more accurate access to nuclei and less extraneous tissue was obtained.

\section{$\underline{\text { Disadvantages }}$}

1. The method is labor intensive, have to give identification numbers and use about 10 or more glass slides to obtain three to four coronal sections per slide. Only four to five brains could be punched out per day because of setting up and micropunching out the three regions which were distributed in four or more slides.

2. If the brain separated from the chuck amidst sectioning, some sections were likely lost in the process of readjusting to the appropriate width.

3. If the integrity of sections was compromised, nuclei were not easily accessed, therefore loss of CRF could have occurred and thus contribute to the variability in the results.

4. Caution needed to be taken as to avoid the formation of mist from the dry ice as this turned cloudy and camouflaged the tissue when the mist settled on the glass slide.

5. With this method, it took about five weeks or more to obtain the final results depending on the number of animals used.

\section{$\underline{\text { Macro-dissections of brain regions }}$}

This procedure of macro-dissection was used on brains of animals treated with 1.0 $\mathrm{mg} / \mathrm{kg}$ (ip) nicotine at 15, 30 and 60 minutes. This followed the dissection method for 
slice experiments, already established in the laboratory. For the amygdala, the temporal lobe was targeted, the whole of the hypothalamus and median eminence are obtained together and the whole of the brain stem was accessed. Dissections were accomplished by placing brain on glass petri dish mounted on ice and using a scalpel. Tissue were immediately placed in labeled tubes containing $3.0 \mathrm{ml}$ ice cold $0.5 \mathrm{~N} \mathrm{HCl}$ solution containing $1.0 \mathrm{mg} / \mathrm{ml}$ ascorbic acid and $1.0 \%$ Triton $\mathrm{X}-100$, for extraction.

Homogenization of samples was accomplished with ultrasonic disruption (sonication) at setting 3 (Branson Sonic Power, Branson instruments Inc. Melville, L.I. NY). Samples were heated at $70^{\circ} \mathrm{C}$ for 10 minutes to denature enzymes and then stored at $-70^{\circ} \mathrm{C}$ until lyophilizations and protein assays (Clarke and Gillies, 1988; Smith, et al., 1986). The method has advantages and disadvantages.

\section{$\underline{\text { Advantages }}$}

1. The method was fast, 12 brains (three regions each) could be dissected, and homogenized in one day.

2. The sequential removal of unwanted tissue resulted in easy access to the regions of interest.

3. There was little likelihood of living any nuclei out.

\section{$\underline{\text { Disadvantages }}$}

1. The method allowed for extraneous tissue to be obtained which made samples need to be more dilute $(3.0 \mathrm{ml}$ instead of $2.0 \mathrm{ml}$ used with nuclei). 
2. For the amygdala, the whole of the temporal lobe was accessed, and CRF levels would reflect levels from neighboring areas including piriform cortex .

3. The median eminence was obtained and this would augment hypothalamic CRF to about 10 times the levels in PVN (Chappell, et al., 1986).

4. Assaying the whole brain stem did not only involve the PBN and LC but also the other nuclei including, nucleus tractus solitarius, raphe nuclei, dorsal vagal complex and Barrington's nucleus, nuclei which also contain CRF.

5. With brain stem, the increased amount of tissue in some samples reduced the available supernatant after micro-centrifugation. Extreme care was needed to minimize agitation of supernatant.

6. Overall, results from the two methods; micro- and macro-dissections could not be compared, because two variables were different, the dose and dissection method.

\section{$\underline{\text { Lyophilization of acidic extracts }}$}

Each animal had three brain regions to be assayed for both radioimmunoassays (RIA) and Lowry protein assays. The two different dissection methods produced two sets of samples brain region and nuclei (Table 3). For each animal and per brain region, a 500 $\mu \mathrm{HCl}$ extract was microcentrifuged using the Eppendorf table-top microcentrifuge at $14,000 \mathrm{rpm}$ for 30 minutes. Parallel to samples, $500 \mu \mathrm{l}$ of $0.5 \mathrm{~N} \mathrm{HCl}$ was also microcentrifuged to be used in RIA buffer matrix. A $300 \mu$ l aliquot of supernatant was transferred to another labeled microcentrifuge tube. The $300 \mu \mathrm{l}$ samples and HCL were lyophilized (freeze-dried in vacuum) using Savant Speed Vac concentrator, for three to 
Table 3

Assayed brain regions and nuclei

Micro-punch dissections

(nuclei)
Macro-dissections

(brain region)
Amygdaloid nuclei

Paraventricular nucleus

Locus coeruleus/parabrachial nucleus
Amygdala

Hypothalamus

Brain stem 
four hours with heat or overnight without heat. The lyophilate was stored at $-70^{\circ} \mathrm{C}$ until radioimmunoassay for CRF. For the assay, acidic lyophilized extracts were resuspended in $1.5 \mathrm{ml}$ RIA buffer (30 mM phosphate buffer with $25 \mathrm{mM}$ EDTA, containing $0.1 \mathrm{ml}$ Triton X-100 and $0.02 \mathrm{mg} / \mathrm{ml}$ aprotinin). A $300 \mu \mathrm{l}$ aliquot of this solution was used for the radioimmunoassay of $\mathrm{CRF}$.

\section{$\underline{\text { Radioimmunoassays }}$}

Radioimmunoassay (RIA) is the measurement of concentration of antigen (e.g. hormone) by determining the extent to which it combines with antibody. A limited amount of antibody is reacted with the corresponding hormone (CRF, corticosterone) labeled with a radioisotope. Upon addition of an increasing amount of hormone, a corresponding decrease in amount of labeled hormone is bound to the antibody. The secondary antibody recognizes and binds the antibody bound CRF or corticosterone. After separation of bound and unbound labeled hormone, the amount of radioactivity in the bound fraction is calculated and used to construct a standard curve against which concentrations of unknown samples are measured. Non specific binding (NSB) is determined in the absence of antibody.

\section{$\underline{\text { Corticotropin releasing factor }(\mathrm{CRF}) \text { radioimmunoassays }}$}

The method of Vale, et al., (1983), was used for the RIA for CRF. RIA on lyophilized $300 \mu \mathrm{l}$ of $\mathrm{CRF}$ extracts (per brain region) were done with a $\mathrm{C}$-terminal directed rabbit anti-human/rat CRF antibody, RC 70, (provided by Dr. Wylie Vale, Salk 
Institute, San Diego, CA) and ${ }^{125}$ I-iodohistidyl-CRF (Amersham, Arlington Heights, IL). After treatment with secondary antibody, (anti-rabbit gamma globulin), the antibody-CRF complex was precipitated using $2 \%$ polyethylene glycol (Sigma, St Louis, MO). Amount of radioactivity in the complex (pellet) was counted for two minutes on the gamma counter (Wallac-1470 Wizard automatic gamma counter, Wallac Inc, Gaithersburg MD).

\section{$\underline{\text { Procedure }}$}

Day 1: RIA buffer (30 mM phosphate buffer with 25 mM EDTA, containing 0.1 $\mathrm{ml}$ Triton X-100 and $0.02 \mathrm{mg} / \mathrm{ml}$ aprotinin). A lyophilized CRF standard of 200,000 $\mathrm{pg} /$ tube stored at $-70^{\circ} \mathrm{C}$ freezer was reconstituted fresh on day of use, with $1 \mathrm{ml}$ of RIA buffer to make tube $\# A_{1}$. Primary antibody was rabbit anti-rat CRF, $50 \mu$ l aliquots were stored in Fisherbrand microcentrifuge tubes at $-70^{\circ} \mathrm{C}$. The $50 \mu$ l aliquot of antibody (1:250) was combined with $450 \mu$ l RIA buffer. Rabbit serum was stored in $-20^{\circ} \mathrm{C}$ freezer in $300 \mu \mathrm{l}$ aliquots and primary antibody $(\mathrm{Ab})$ cocktail consisted of RIA buffer, rabbit serum and the antibody, at a final concentration of 1:500,000. Buffer matrix was made of lyophilized HCL resuspended in $1.5 \mathrm{ml}$ RIA buffer and pooled together.

$\underline{\text { Standards }}$ were prepared in labeled Sarstedt polypropylene $(75 \times 12 \mathrm{~mm})$ tubes by serial dilution of tube $\# \mathrm{~A}_{1}$ with RIA buffer and concentrations of standard ranged from 0-25 pg/ $\mu \mathrm{l}$. A volume of $20 \mu \mathrm{l}$ of the standard was injected into appropriate tubes. The zero CRF standard was done in quintuplicate and the rest were done in triplicates. An aliquot of $300 \mu \mathrm{l}$ of buffer matrix was mixed with an appropriate standard (20 $\mu \mathrm{l})$ in a standard polypropylene tubes. Two nonspecific binding tubes were prepared, in which the 
standards and primary antibody were replaced by an equivalent amount of RIA buffer.

The lyophilized acidic samples and HCL extracts were thawed, reconstituted with $1.5 \mathrm{ml}$ RIA buffer, vortexed and then microcentrifuged for approximately two minutes. A $300 \mu \mathrm{l}$ aliquot of diluted lyophilate was injected into three labeled tubes (for triplicates) and $20 \mu \mathrm{l}$ sample matrix was added to maintain a volume equal to standards. A volume of $100 \mu \mathrm{l}$ of primary antibody cocktail final concentration, 1:500,000 was added to standards and samples (except nonspecific binding tubes). The tubes were shaken gently to mix, covered with parafilm and then incubated at $4{ }^{\circ} \mathrm{C}$ for at least 24 hours.

Day 2. The lyophilized label ( ${ }^{125}$ Iodohistidyl-CRF, Amersham) was diluted (on day of arrival) with $200 \mu \mathrm{l}$ RIA buffer containing $0.1 \%$ acetic acid and stored at $-70^{\circ} \mathrm{C}$ in $10 \mu \mathrm{l}$ aliquots $(0.5 \mu \mathrm{Ci}) .{ }^{125} \mathrm{I}-\mathrm{CRF}(10 \mu \mathrm{l})$ was reconstituted with RIA buffer in plastic beaker for $100 \mu \mathrm{l} /$ tube (on day of use). The activity of ${ }^{125} \mathrm{I}$-CRF solution was measured on the gamma counter before addition to assay. When fresh, a $10 \mu \mathrm{l}$ aliquot diluted to $12 \mathrm{ml}$ RIA buffer yielded approximately 10,000-12,000 cpm/100 $\mu \mathrm{l}$ (counts per minute). Adjustments were made to buffer volumes according to age of label. $100 \mu \mathrm{l}$ of ${ }^{125} \mathrm{I}-\mathrm{CRF}$ solution (>10,000 cpm/tube) was added to all the tubes, after which the tubes were shaken gently, covered with parafilm and further incubated for at least $20-24$ hours at $4{ }^{\circ} \mathrm{C}$ (refrigerator).

Day 3. Precipitating solution was composed of polyethylene glycol (PEG, ( 1.45 $\mathrm{g} / 10 \mathrm{ml}$ buffer) secondary antibody and made fresh on day of use. Secondary antibody (sheep anti-rabbit $\mathrm{IgG}$ ) stored in $2.0 \mathrm{ml}$ aliquots in $-20^{\circ} \mathrm{C}$ freezer was diluted 1:4 with RIA buffer. A volume of $100 \mu \mathrm{l}$ of secondary antibody was added to each tube, after which 
$100 \mu \mathrm{l}$ of PEG solution (final concentration 2\%) was added and the contents vortexed.

The tubes were covered and incubated for 20 minutes at room temperature for precipitation, and then centrifuged at $4000 \mathrm{~g}$ for $20 \mathrm{~min}(5,000 \mathrm{rpm}$, on Sorvall centrifuge).

The supernatant which contained unbound radioactive CRF was aspirated and radioactivity of pellets counted for two minutes on the gamma counter (Wallac-1470 Wizard automatic gamma counter, Wallac Inc, Gaithersburg MD)

\section{Corticosterone radioimmunoassays}

The ImmuChem ${ }^{\mathrm{TM}}$ double antibody ${ }^{125} \mathrm{I}$ corticosterone RIA kit for rat and mice was used to assay plasma samples for all tested rats. The kit was stored in a $4{ }^{\circ} \mathrm{C}$ refrigerator until day of use. The contents of the kit were as follows:

a. Steroid diluent, a phosphate gelatin buffer (ph 7.0 \pm 0.1 ) containing rabbit gamma globulin.

b Anticorticosterone (corticosterone-3-carboxymethyloxamine) developed using bovine serum albumin (BSA) as the antigen.

c. Six corticosterone calibrators (standards) with concentrations ranging from 25-1000 $\mathrm{ng} / \mathrm{ml}$.

d. Precipitating solution was a mixture of polyethylene glycol (PEG) and goat anti rabbit gamma globulins contained in TRIS buffer.

e. The corticosterone ${ }^{125} \mathrm{I}$ derivative, a $0.2 \mathrm{ml}$ aliquot of this radioactive derivative would provide approximately $50,000 \mathrm{cpm}$ at $75 \%$ counter efficiency, on day of shipment.

f. Prediluted lyophilized form of rat corticosterone controls $(0.1 \mathrm{ml}$ each $)$. The high 
control had corticosterone levels of 517-777 $\mathrm{ng} / \mathrm{ml}$ and the low control had 78-112 $\mathrm{ng} / \mathrm{ml}$.

\section{$\underline{\text { Procedure }}$}

All contents of the kit were brought to room temperature before use. Rat plasma sample was diluted 1:200, by adding $10 \mu \mathrm{l}$ plasma to $2.0 \mathrm{ml}$ steroid diluent, the contents were mixed using a vortex mixer and $100 \mu \mathrm{l}$ was assayed. For assay, glass test tubes of size $12 \times 75 \mathrm{~mm}$ were used and samples were assayed in triplicates. The procedure was followed as directed in the kit. The tubes were mixed thoroughly and centrifuged in Sorval centrifuge, at 2300 to $2500 \mathrm{rpm}(1000 \mathrm{~g})$ for 15 minutes. The supernatant containing unbound radioactivity, was aspirated and the precipitate was counted in the Gamma counter (Wallac-1470 Wizard automatic gamma counter, Wallac Inc, Gaithersburg MD) for two minutes.

\section{$\underline{\text { Protein determination on acidic extracts }}$}

The Lowry protein assay method was employed to measure protein levels in all six sets of acidic samples (Table 3); for use in the determination of CRF content relative to the protein obtained from macro-dissections and micro-punches. The Lowry protein assay is based on interaction of proteins with the phenol reagent and copper under alkaline conditions. The blue color reaction arises from a copper catalyzed oxidation of aromatic amino acids and other groups by the heteropolyphosphate reagent (Lowry, et al., 1951; Pomeranz and Meloan, 1987). The intensity of the blue color is not strictly proportional to 
the amount of protein in the sample, and the assay has a narrow linear range of between 10 to $70 \mu \mathrm{g}$ protein. The method was appropriate for this study though, because samples were of similar type, from same brain regions and were highly dilute. Assuming that most tissue is about $95 \%$ water and $5 \%$ protein, levels would be approximately $5 \mu \mathrm{g}$ protein per milligram tissue weight. The brain would contain lower levels of protein because of its high lipid content.

\section{$\underline{\text { Procedure }}$}

An aliquot of the $\mathrm{HCl}$ homogenate of brain region samples was placed in $12 \times 75$ glass tube and then combined with $1 \mathrm{~N} \mathrm{NaOH}$ to make a total volume of $500 \mu$ l. The tubes were sealed and refrigerated until the protein assay. On day of assay, Bovine serum albumin (BSA) standard $(1.0 \mathrm{mg} / \mathrm{ml})$ was prepared using distilled water. Standard solutions of $0,5,10,20,30,50,60,80$ and $100 \mu \mathrm{l}(0-100 \mu \mathrm{g})$ were aliquoted into $13 \times 100$ mm glass tubes. The volume was made up to $100 \mu$ using $1 \mathrm{~N}(\mathrm{NaOH})$. Standards and samples were run in triplicates. For assay, a $50 \mu 1$ or $100 \mu l$ aliquot of alkaline sample was pipetted into $13 \times 100 \mathrm{~mm}$ glass tube and the volume made up to $100 \mu \mathrm{l}$ with $1 \mathrm{~N}$ $\mathrm{NaOH}$.

The Lowry reagents were $2 \%$ sodium carbonate $\left(\mathrm{Na}_{2} \mathrm{CO}_{3}\right), 1 \%$ copper sulfate $\left(\mathrm{CuSO}_{4}\right), 2 \%$ sodium tartrate and $2 \mathrm{~N}$ Folin phenol reagent. The blue color was read on spectrophotometer at 750 nanometers, with distilled water used as reference blank. 


\section{CHAPTER IV \\ DATA AND ANALYSIS}

Treatment of data

Radioimmunoassay results (gamma counts) for both CRF and corticosterone were coded into a Microsoft Excel spreadsheet. Since all standards and samples were run in triplicates, counts from the blank were subtracted from all standard or sample counts and an average of triplicates was obtained. A standard curve was constructed and regression analysis used to calculate concentrations. Percent binding was related to counts per sample, divided by total counts added and at low amounts of CRF, there was high binding of radioligand, that is, more counts, and vice versa. The ratio of binding per sample to the zero level $\left(\mathrm{B} / \mathrm{B}_{0}\right)$ was obtained and a plot against the log of standard CRF concentrations gives sigmoidal curve. The curve was converted to a straight line by plotting logit (natural $\log ) \mathrm{B} / \mathrm{B}_{0} / 1-\mathrm{B} / \mathrm{B}_{0}$ against the $\log$ of standard $\mathrm{CRF}$ concentrations, after which the concentration of the standard and samples were obtained. To obtain CRF content in brain regions, all dilutions employed, from dissections to radioimmunoassays, were accounted for. Taking into consideration that $2.0 \mathrm{ml}$ or $3.0 \mathrm{ml} \mathrm{HCL}$ was the original dilution, with a $300 \mu \mathrm{l}$ aliquot lyophilized, resuspended in $1.5 \mathrm{ml}$ RIA buffer and $300 \mu \mathrm{l}$ assayed, the final dilution factor was 35 or 50 respectively.

Protein assays were run on all the brain regions for both doses and treatment time points. Absorbance values were coded into a Microsoft Excel spreadsheet. Results from the blank were subtracted from all standard or sample counts and an average of triplicates was obtained. A standard curve was constructed and regression analysis used to calculate 
concentrations. To obtain the original amount of protein in each sample, the protein in the assayed $50 \mu \mathrm{l}$ or $100 \mu \mathrm{l}$ was converted to the $1: 500$ aliquot and finally to content in $3.0 \mathrm{ml}$ or $2.0 \mathrm{ml}$ of the acidic sample. For each brain region and treatment, protein levels were grouped together and average protein obtained per brain region/nucleus was calculated, for all time points, to indicate the average amount of protein obtained with dissections. However, individual protein values per sample were used to calculate concentration in picograms of CRF per milligram of protein ( $\mathrm{pg} \mathrm{CRF} / \mathrm{mg}$ protein) for the corresponding sample. For example, rat number one after treatment for fifteen minutes with $0.4 \mathrm{mg} / \mathrm{kg}$ nicotine had three samples; amygdaloid nuclei, paraventricular nucleus and brain stem nuclei. The protein value from the each brain-region-sample was used to calculated CRF content, that is, amygdaloid samples (CRF and protein) for rat \#1 in the $0.4 \mathrm{mg} / \mathrm{kg}$ group were used correspondingly.

An overall mean protein concentration ( $\mathrm{pg} \mathrm{CRF} / \mathrm{mg}$ ) of the untreated groups per brain region was used for comparisons with means of nicotine and saline treated rats. A factor was calculated to normalize individual experiments to an overall mean of the untreated group. This was achieved by grouping together $\mathrm{pg} \mathrm{CRF} / \mathrm{mg}$ protein for untreated rats, per brain region, at all treatment time points, after which gross mean was calculated. For example, $\mathrm{CRF}$ levels for amygdaloid nuclei of untreated rats at 15 and 30 minutes time points were grouped and their gross mean calculated. After calculating mean CRF levels of untreated rats per treatment time point, the gross mean was divided by the mean for untreated rats for each time point to get the factor for normalizing individual experiments. This factor was used to multiply individual values of $\mathrm{pg} C R F / \mathrm{mg}$ protein. 
Final concentration values were grouped according to treatments and then used for statistical comparisons. The outlier test was used for individual experiments to discard any value $\leq \mathrm{x}-2 \mathrm{SD}$ or $\geq \mathrm{x}+2 \mathrm{SD}$.

\section{$\underline{\text { Statistics }}$}

Data was analyzed using the Microsoft Excel spreadsheet and GB-Stat statistical package. Descriptive statistics (mean, SD and SE), two way (time, treatment) analysis of variance (ANOVA) and post-hoc comparison by Tukey's t-tests were used to test for statistical significance. Hypotheses were tested using the critical probability values of alpha at $\underline{p} \leq$ 0.05 as significant. 


\section{CHAPTER V}

\section{RESULTS}

\section{$\underline{\text { Sources of error }}$}

Errors could have arisen from a number of stages in the procedure of this study including: storage, sectioning, dissections, pipetting and individuality of animals. On the cryostat, technical errors led to minor losses due to deformities in some sections and micro-punch dissections depended mainly on the integrity of the sections. Macrodissections were possibly not completely uniform and this could have led to an unevenness in amount of tissue obtained thus causing a variation in amount of CRF relative to protein. Pipetting errors in all various stages of the experiment including lyophilization and radioimmunoassays could introduce variability in results. Over-aspiration of radioactive supernatant could have led to minute losses of pellet with loss of radioactive counts, and under-aspiration could leave droplets of radioactive material, leading to an over-estimation of counts. Another source of error could arise from the protein assay where pipetting could introduce errors that could over- or under-estimate protein levels. In corticosterone assays, errors could have arisen mainly from pipetting and aspiration of the radioactive material. Control rats, being not under the influence of the stress of injection could have had enhanced variability due to the individuality of the animals.

\section{$\underline{\text { Animal observations }}$}

Nicotine treated rats exhibited tremors, fast breathing and mild convulsions a minute after the injection. They also showed paralysis of the hind limbs and decreased 
locomotion which agrees with previous observations that high doses of nicotine decrease locomotion in drug naive rats (Armitage, et al., 1969; Hakan and Ksir, 1991). On the separation of plasma, it was noted that some blood samples had lysed. Lysis does not affect the corticosterone levels, and use of either plasma or serum exhibits no variation in corticosterone levels. Generally, for micro-punch dissections (brain nuclei) CRF levels for untreated groups were comparable at all time points. Similarly, saline treated rats showed no significant differences at the two treatment time points. The same pattern was observed in macro-dissections for 15 and 30 minutes time points, but for the brain stem, the 60 minute time point had considerable high levels of CRF compared to 15 and 30 minutes and this may have been due to inconsistences in decapitations and dissections.

\section{Expected results}

Studies on nicotine pharmacokinetics indicated that nicotine accumulates in the rat brain within five minutes after intravenous injection (Sastry, et al., 1995; Schmiterlöw, et al., 1967). Nicotine peaks at about 20 minutes, with levels remaining high for up to 50 minutes but declined by 60 minutes. In this study, it was assumed that the response of CRF after 15 minutes treatment would correspond to the peaking of nicotine in the brain while the 60 minutes response would correspond to the relatively low levels. For the present study, if nicotine is anxiogenic, we should expect that acute doses of $0.4 \mathrm{mg} / \mathrm{kg}$ or $1.0 \mathrm{mg} / \mathrm{kg}$ would elavate CRF content in the amygdala and hypothalamus, while decreasing CRF, if nicotine is anxiolytic or antidepressive. Corticosterone levels were utilized as positive control for nicotine effects. Results are presented such that 
corticosterone is addressed first. Even though microdissections were the initial method used, whole regions: hypothalamus, amygdala and brain stem are addressed before their nuclei.

\section{$\underline{\text { Plasma corticosterone }}$}

Figure 1 shows plasma corticosterone levels after 15 and 30 minutes treatment with $0.4 \mathrm{mg} / \mathrm{kg}$ nicotine. Results are expressed in nanograms/milliliter $(\mathrm{ng} / \mathrm{ml})$, mean \pm S.E.M per treatment. After 15 minutes treatment, mean corticosterone levels were $368 \pm 32,291$ \pm 79 and $178 \pm 71$ for nicotine, saline and untreated respectively. The thirty minute time point exhibited values of $473 \pm 39,174 \pm 39$ and $199 \pm 53$ for nicotine, saline and untreated rats respectively. Fifteen minutes treatment with nicotine produced significant effects compared to no treatment and 30 minutes nicotine produced significant effects compared to both saline treated and untreated rats.

Shown on Figure 2 are serum corticosterone levels 15, 30 and 60 min after treatment of rats with $1.0 \mathrm{mg} / \mathrm{kg}$ nicotine. Results are expressed in $\mathrm{ng} / \mathrm{ml}$, mean \pm S.E.M per treatment. After 15 minutes treatment, mean corticosterone levels were $364 \pm 45,220 \pm$ 36 and $111 \pm 24$ for nicotine, saline and untreated respectively. The 30 minute time point exhibited values of $216 \pm 28,134 \pm 26$ and $111 \pm 24$ for nicotine, saline and untreated rats respectively. After 60 minutes treatment, mean corticosterone values of $306 \pm 65$, $83 \pm 31$ and $111 \pm 24$ for nicotine, saline and untreated rats respectively were observed. Significant effects of nicotine were observed at 15, 30 and 60 minutes versus untreated rats and at 15 and 60 minutes compared to saline treated rats. 


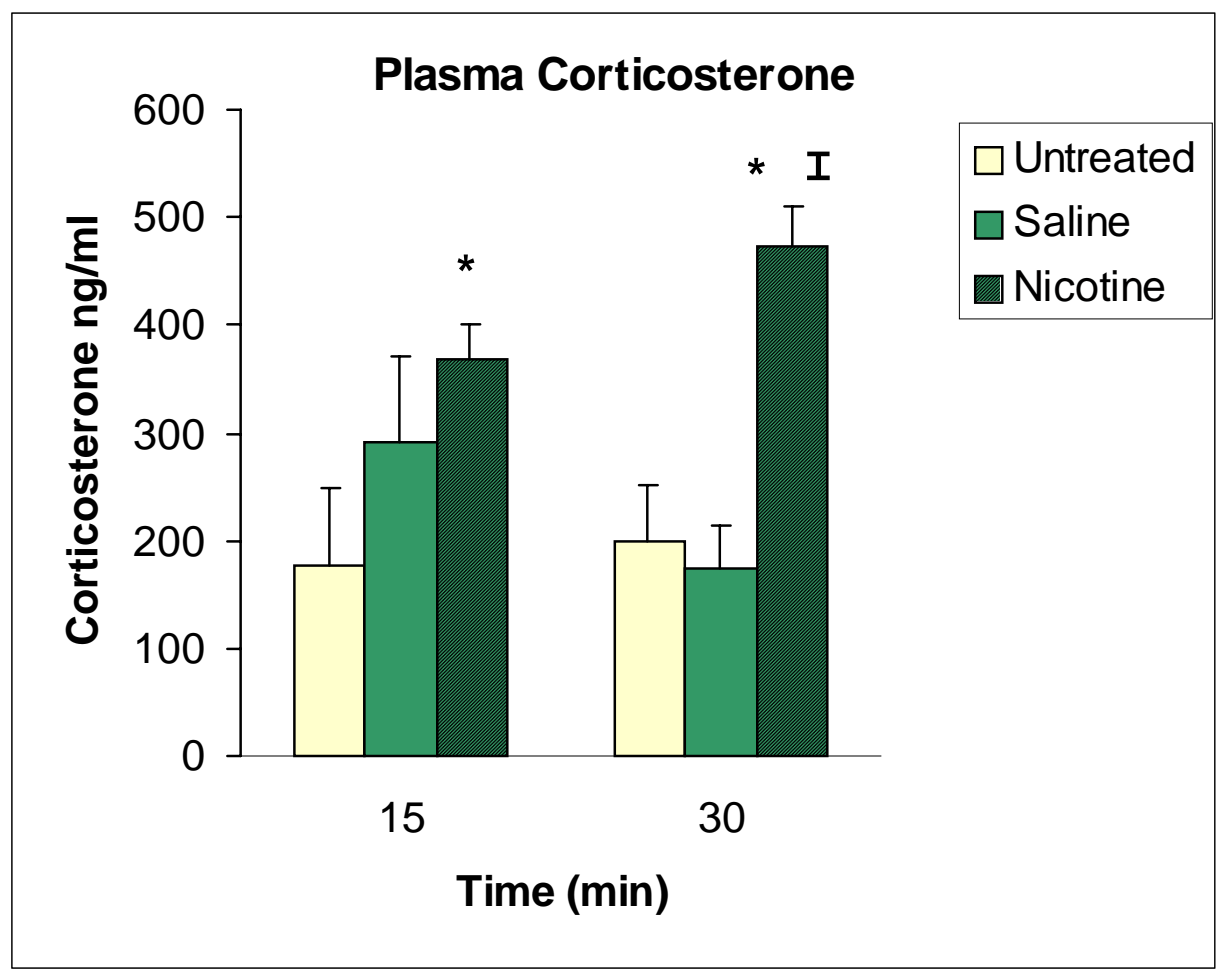

Figure 1. Plasma corticosterone levels after 15 and 30 minutes treatment with nicotine $0.4 \mathrm{mg} / \mathrm{kg}, 0.9 \%$ saline (vehicle $1.0 \mathrm{ml} / \mathrm{kg}$ ) or no treatment: 15 minutes nicotine $(\mathrm{n}=4)$, saline $(n=4)$ and untreated $(n=4), 30$ minutes nicotine $(n=8)$, saline $(n=8)$ and untreated $(\mathrm{n}=8)$. Values are expressed in $\mathrm{ng} / \mathrm{ml}$, mean \pm S.E.M per treatment. $*$ denotes significant effect of nicotine versus sham and $\ddagger$ denotes significant effects of nicotine versus saline, $\mathrm{P}$ $\leq 0.05$, ANOVA and Tukey's t test. Overall treatment effect $F=10.8(2,34) \mathrm{p}=0.0003$. 


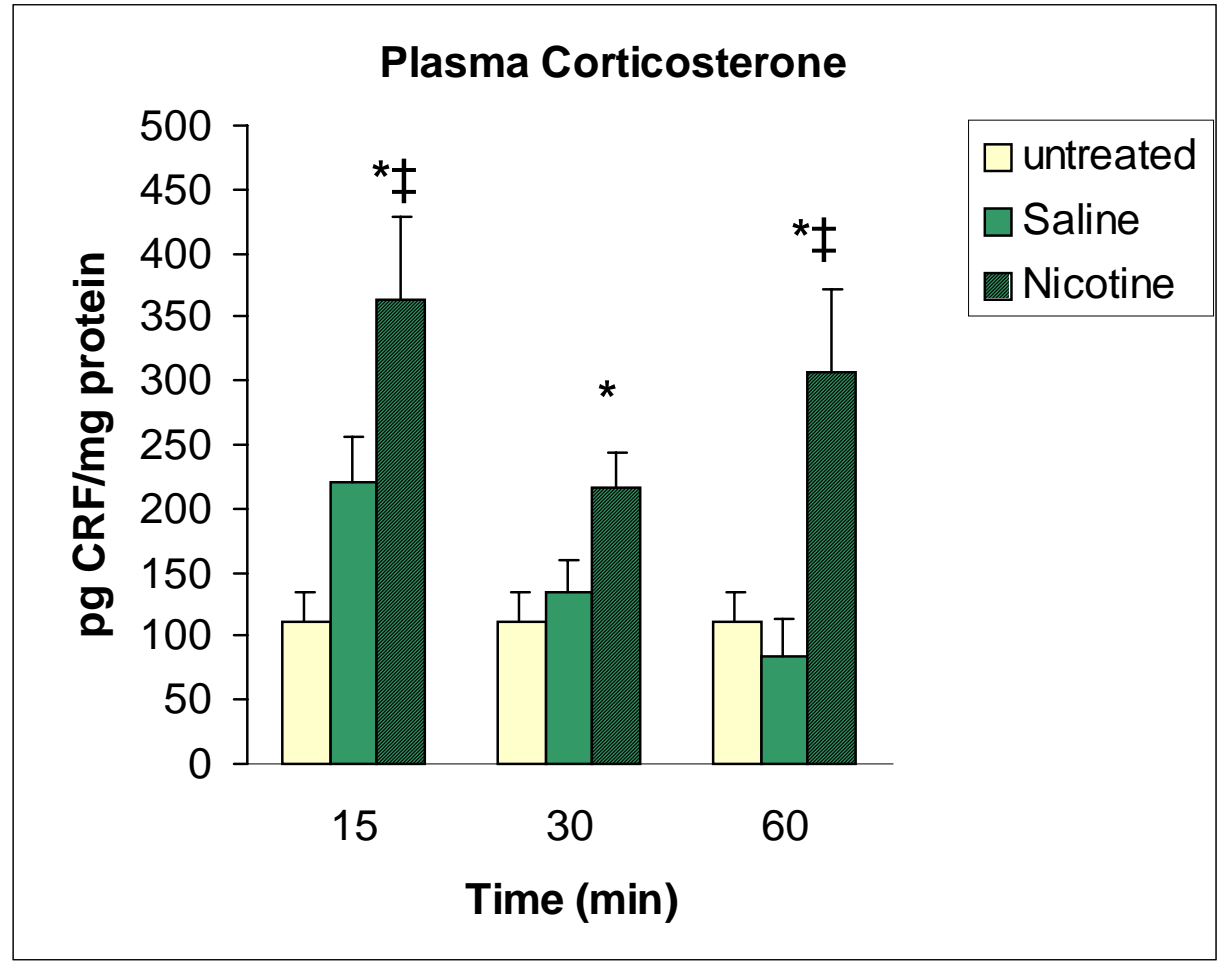

Figure 2. Plasma corticosterone levels after 15, 30 and 60 minutes treatment with nicotine $1.0 \mathrm{mg} / \mathrm{kg}, 0.9 \%$ saline (vehicle, $1.0 \mathrm{ml} / \mathrm{kg}$ ) or no treatment: 15 minutes nicotine $(n=6)$, saline $(n=8)$ and untreated $(n=6), 30$ minutes nicotine $(n=6)$, saline $(n=6)$ and untreated $(n=7)$, and 60 minutes nicotine $(n=4)$, saline $(n=4)$ and untreated $(n=7)$. Values are expressed in $\mathrm{ng} / \mathrm{ml}$, mean \pm S.E.M per treatment. *denotes significant effect of nicotine versus sham and $\ddagger$ significant effects of nicotine versus saline, $\mathrm{P} \leq 0.05$, ANOVA and Tukey's t test. Overall treatment effect at $1.0 \mathrm{mg} / \mathrm{kg}$ nicotine $\mathrm{F}=8.6(2,53) \mathrm{p}=$ 0.0007. Overall time effect at $1.0 \mathrm{mg} / \mathrm{kg}$ nicotine $\mathrm{F}=3.27(2,53) \mathrm{p}=0.05$. 
$\underline{\text { Summary of protein levels for all experimental rats }}$

Lowry protein assay results for each dissection and all time points were summarized to indicate the average of amount of protein obtained in dissections. Individual protein values were used to convert corresponding values of CRF to picograms CRF per milligram protein. Values are expressed in milligrams $(\mathrm{mg})$, mean \pm S.E.M. A summary of protein levels from micro-punch dissections on animals treated with $0.4 \mathrm{mg} / \mathrm{kg}$ nicotine for 15 and 30 minutes indicated that in amygdaloid nuclei, mean levels of $3.16 \pm 0.16 \mathrm{mg}$ protein were obtained. The paraventricular nucleus and locus coeruleus/parabrachial nucleus had mean protein levels of $1.53 \pm 0.08 \mathrm{mg}$ and $1.89 \pm 0.14 \mathrm{mg}$ respectively. For macrodissections on animals treated with $1.0 \mathrm{mg} / \mathrm{kg}$ nicotine for 15,30 and 60 minutes, brain stem samples contained more protein $($ mean $=61.12 \pm 2.08 \mathrm{mg}$ ) compared to hypothalamus and amygdala with means levels of $21.10 \pm 0.59 \mathrm{mg}$ and $36.27 \pm 0.92 \mathrm{mg}$ respectively.

\section{$\underline{\mathrm{CRF} \text { content in the rat brain after nicotine treatment }}$}

\section{$\underline{\mathrm{CRF} \text { content in untreated rats }}$}

Figure 3 is a summary of CRF content in brain regions of untreated rats for both micro- and macro-dissections at all tested time points. Values are expressed in pg $\mathrm{CRF} / \mathrm{mg}$ protein (mean \pm S.E.M). CRF levels were higher in micro-punch dissections compared to macro-dissections and this was to be expected, because micro-punches were more precise at targeting areas where CRF is more concentrated. Comparison of mean pg $\mathrm{CRF} / \mathrm{mg}$ protein in micro-punches of all the three brain nuclei revealed that in micro- 


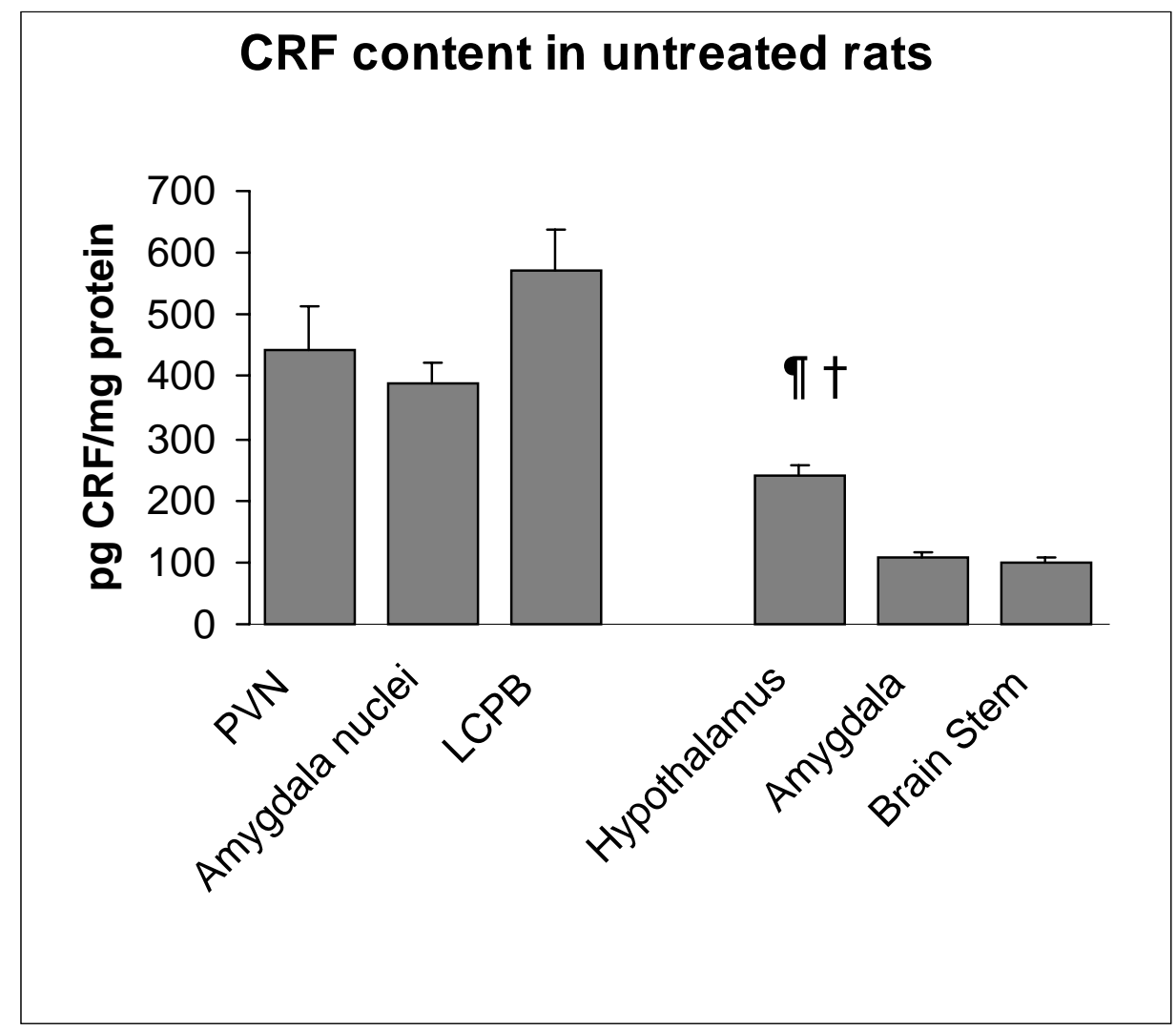

Figure 3. CRF content (pg CRF/mg protein) in untreated rats. Comparison of mean CRF content in: (1) micro-punches $(0.4 \mathrm{mg} / \mathrm{kg}$ treatments $)$ of all the three brain nuclei, paraventricular nucleus (PVN), amygdaloid nuclei and locus coeruleus/parabrachial nucleus (LCPB) and (2) macro-dissections $(1.0 \mathrm{mg} / \mathrm{kg}$ treatments) of three brain regions, hypothalamus, amygdala and brain stem of untreated rats. Values are expressed in pg $\mathrm{CRF} / \mathrm{mg}$ protein, mean \pm S.E.M per treatment. II Denotes significant differences between hypothalamus versus amygdala and $\dagger$ denotes significant differences between hypothalamus versus brain stem. 
punches, the locus coeruleus/parabrachial nucleus region had generally higher levels of CRF compared to PVN and amygdaloid nuclei, although this was not statistically significant. These results are agreeable with those reported by Chappell, et al., (1986), in that study, controls had CRF levels of approximately 500 pg/mg, 600 pg/mg and 800 $\mathrm{pg} / \mathrm{mg}$ for PVN, amygdala and brain stem respectively. In macro-dissections, the hypothalamus had significantly increased levels compared to amygdala and brain stem. This is consistent with the fact that the median eminence contains the highest levels of the neuropeptide (Chappell, et al., 1986; Palkovits, et al., 1985).

\section{$\underline{\text { CRF content in hypothalamus and paraventricular nucleus (PVN) }}$}

It was hypothesized that there would be significant increases in hypothalamic CRF levels in nicotine treated rats compared to untreated and saline treated rats, at a given dose and time point. Figure 4 shows CRF content in macro-dissections of rat hypothalamus after 15,30 , and 60 treatment with $1.0 \mathrm{mg} / \mathrm{kg}$ nicotine. Values are expressed in $\mathrm{pg}$ $\mathrm{CRF} / \mathrm{mg}$ protein, mean \pm S.E.M per treatment. Mean CRF content for untreated rats from the three time points was $240 \pm 16$ and this was compared to means of nicotine and saline treatments. At the 15 minute time point, mean CRF levels were $338 \pm 50$ and $290 \pm 20$ for nicotine and saline rats respectively. After 30 minutes, mean CRF levels were $231 \pm$ 30 and $236 \pm 21$ for nicotine and saline rats respectively. Sixty minutes of treatment exhibited mean CRF levels of $252 \pm 24$ and $289 \pm 32$ for nicotine and saline respectively. CRF levels were significantly higher in rats treated with nicotine for 15 minutes compared to untreated. 


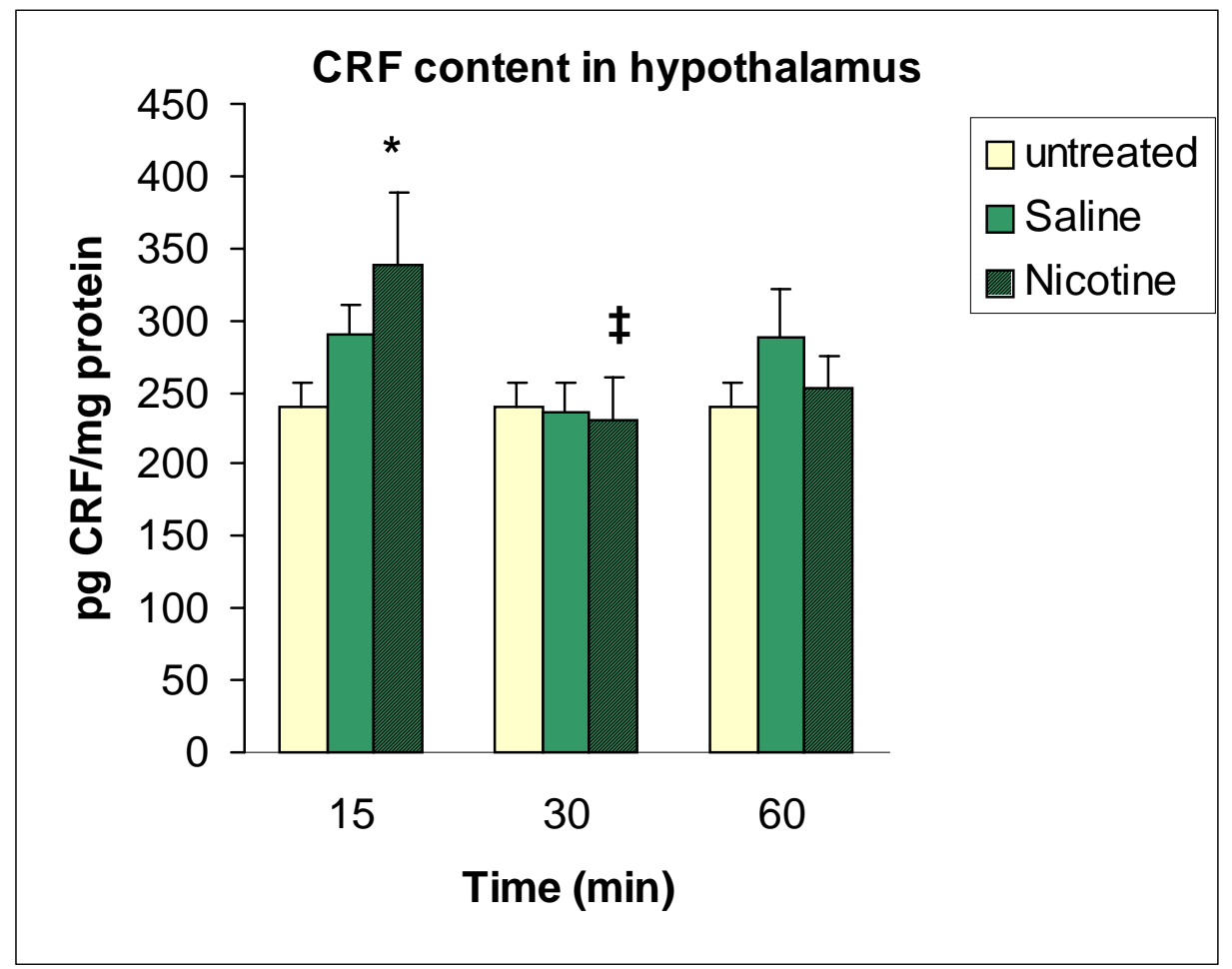

Figure 4. CRF content in macro-dissections of hypothalamus after 15, 30 and 60 minutes treatment with nicotine $1.0 \mathrm{mg} / \mathrm{kg}, 0.9 \%$ saline (vehicle, $1.0 \mathrm{ml} / \mathrm{kg}$ ) or no treatment: 15 minutes nicotine $(n=8)$, saline $(n=8), 30$ minutes nicotine $(n=8)$, saline $(n=8), 60$ minutes nicotine $(n=7)$, saline $(n=7)$ and total untreated $(n=17)$. Values are expressed in pg CRF/mg protein, mean \pm S.E.M per treatment. *Denotes significant effects of nicotine versus untreated rats at 15 minutes treatment, and $\ddagger$ significant time effects for nicotine 15 versus 30 minutes, $\mathrm{P} \leq 0.05$ ANOVA and Tukey's t-test. The overall treatment effects at $1.0 \mathrm{mg} / \mathrm{kg}$ nicotine were $\mathrm{F}=(2,96) \mathrm{p}=0.039$. 
No significant effects were observed between saline and nicotine treated rats. Significant time effects were seen between 15 minutes and 30 minutes nicotine treated groups.

A summary of CRF content in micro-punches of PVN after 15 and 30 min treatment with $0.4 \mathrm{mg} / \mathrm{kg}$ nicotine is shown on Figure 5. Values are expressed in pg CRF/mg protein, mean \pm S.E.M per treatment. Mean CRF content for untreated rats from both time points was $445 \pm 70$ and this was compared to means of nicotine and saline treatments. After 15 minutes treatment, mean CRF levels were $447 \pm 51$ and $495 \pm 26$ for nicotine and saline respectively. The thirty minute time point exhibited values of $531 \pm 72$ for nicotine and $568 \pm 69$ for saline treated rats. No significant effects were observed between nicotine versus saline versus untreated group and there were no significant time effects.

\section{$\underline{\text { CRF content in amygdala and amygdaloid nuclei }}$}

The hypothesis was that there would be significant increases in amygdaloid CRF levels in nicotine treated rats compared to untreated and saline treated rats, at a given dose and time point. Figure 6 summarizes the CRF content in macro-dissections of rat amygdala after 15, 30, and 60 treatment with $1.0 \mathrm{mg} / \mathrm{kg}$ nicotine. Values are expressed in pg CRF/mg protein, mean \pm S.E.M per treatment. As the figure shows, mean CRF content for untreated rats from the three time points was $106 \pm 10$. At the 15 minute time point, mean CRF levels were $128 \pm 15$ and $115 \pm 9$ for nicotine and saline rats respectively. After 30 minutes, mean CRF levels were $133 \pm 16$ and $97 \pm 4$ for nicotine and saline rats respectively. 


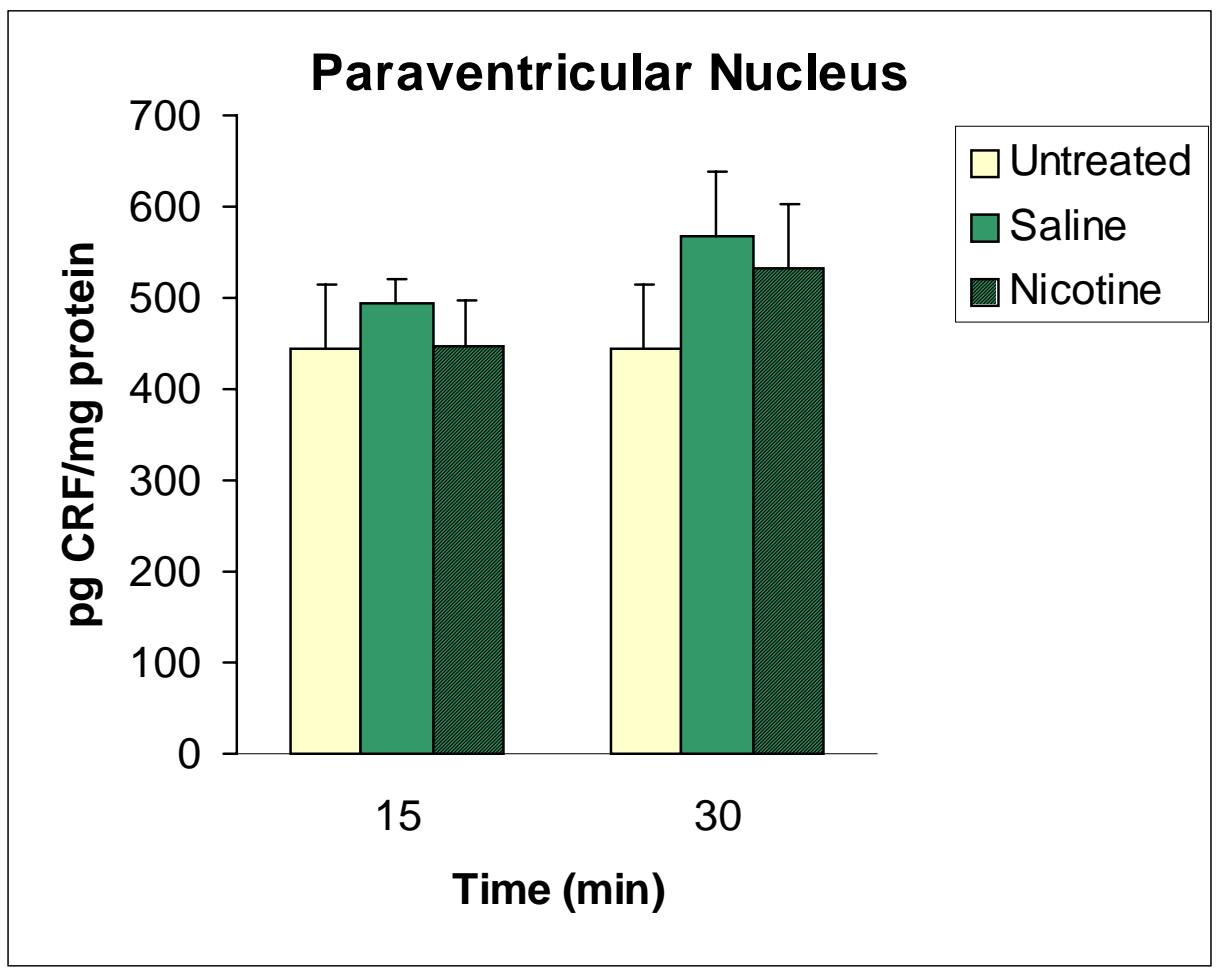

Figure 5. CRF content in micro-punches of paraventricular nucleus of the hypothalamus after 15 and 30 minutes treatment with nicotine $0.4 \mathrm{mg} / \mathrm{kg}, 0.9 \%$ saline (vehicle $1.0 \mathrm{ml} / \mathrm{kg}$ ) or untreated: 15 minutes nicotine $(n=4)$, saline $(n=4), 30$ minutes nicotine $(n=8)$, saline $(\mathrm{n}=7)$ and total untreated group $(\mathrm{n}=8)$. Values are expressed in $\mathrm{pg} C \mathrm{CRF} / \mathrm{mg}$ protein, mean \pm S.E.M per treatment. 


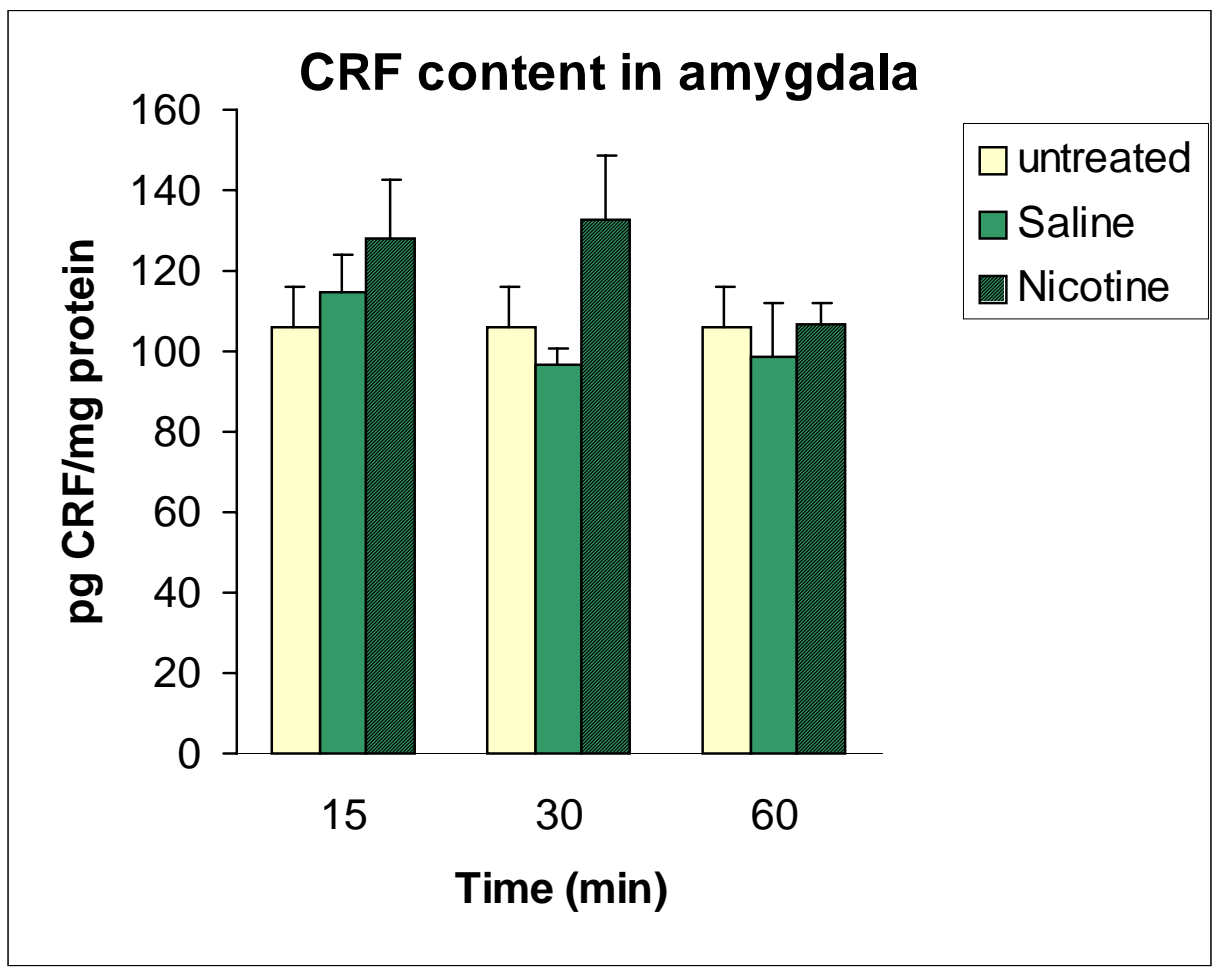

Figure 6. CRF content in macro-dissections of amygdala after 15, 30 and 60 minutes treatment with nicotine $1.0 \mathrm{mg} / \mathrm{kg}, 0.9 \%$ saline (vehicle, $1.0 \mathrm{ml} / \mathrm{kg}$ ) or no treatment: 15 minutes nicotine $(n=8)$, saline $(n=8), 30$ minutes nicotine $(n=8)$, saline $(n=7), 60$ minutes nicotine $(n=7)$, saline $(n=7)$ and total untreated $(n=23)$. Values are expressed in $\mathrm{pg} \mathrm{CRF/mg} \mathrm{protein,} \mathrm{mean} \pm$ S.E.M per treatment. 
Sixty minutes of treatment exhibited mean CRF levels of $106 \pm 10$ and $99 \pm 13$ for nicotine and saline respectively. No significant treatment and time effects were observed between nicotine versus saline versus untreated group at all time points.

Shown on Figure 7 is CRF content in micro-punches of amygdaloid nuclei after 15 and 30 min treatment with $0.4 \mathrm{mg} / \mathrm{kg}$ nicotine. Values are expressed in $\mathrm{pg} \mathrm{CRF} / \mathrm{mg}$ protein, mean \pm S.E.M per treatment. Untreated groups from both time points had a mean of $390 \pm 32$. After 15 minutes treatment mean CRF levels were $471 \pm 80$ and $417 \pm 68$ for nicotine and saline respectively. The thirty minute time point exhibited values of 331 \pm 25 for nicotine and $362 \pm 29$ for saline treated rats. No significant treatment effects were observed between nicotine versus saline versus untreated group, at all time points. However, the Tukey's t-test indicated that significant time effects occurred in the nicotine treated group in that, when compared to the 15 minutes group, the 30 minutes nicotine treated rats had significantly decreased levels of CRF in the amygdala.

\section{$\underline{\mathrm{CRF} \text { content in brain stem and the locus coeruleus/parabrachial nucleus }}$}

It was hypothesized that there would be significant decreases in brain stem CRF levels in nicotine treated rats compared to untreated and saline treated rats, at a given dose and time point. Figure 8 shows a summary of CRF content in macro-dissections of rat brain stem after 15, 30, and 60 treatment with $1.0 \mathrm{mg} / \mathrm{kg}$ nicotine. Values are expressed in pg CRF/mg protein, mean \pm S.E.M per treatment. Mean CRF levels of untreated rats from both time points were $101 \pm 7$. After 15 minutes treatment, mean CRF levels were $100 \pm$ 10 and $117 \pm 5$ for nicotine and saline treated rats respectively. 


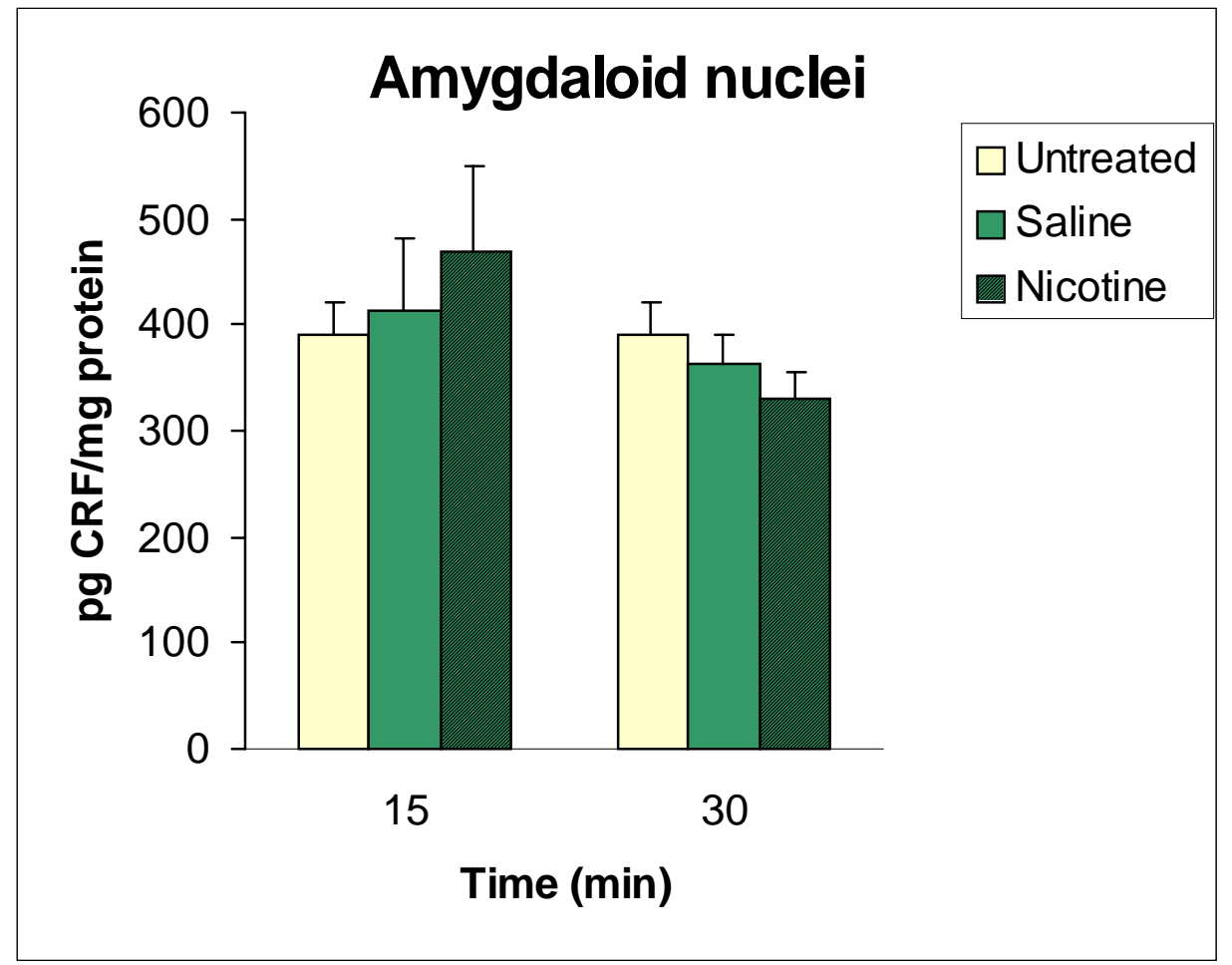

Figure 7. CRF content in micro-punches of amygdaloid nuclei after 15 and 30 minutes treatment with nicotine $0.4 \mathrm{mg} / \mathrm{kg}, 0.9 \%$ saline (vehicle $1.0 \mathrm{ml} / \mathrm{kg}$ ) or no treatment: 15 minutes nicotine $(n=4)$, saline $(n=48), 30$ minutes nicotine $(n=8)$, saline $(n=7)$ and total untreated group $(n=8)$. Values are expressed in $\mathrm{pg} C R F / \mathrm{mg}$ protein, mean \pm S.E.M per treatment. *Denotes significant effects of treatment time for 15 minutes nicotine versus 30 minutes, $\mathrm{p} \leq 0.05$ ANOVA and Tukey's t-test. Overall treatment effects at 0.4 $\mathrm{mg} / \mathrm{kg} \mathrm{F}=3.6(1,36) \mathrm{p}=0.069$. 


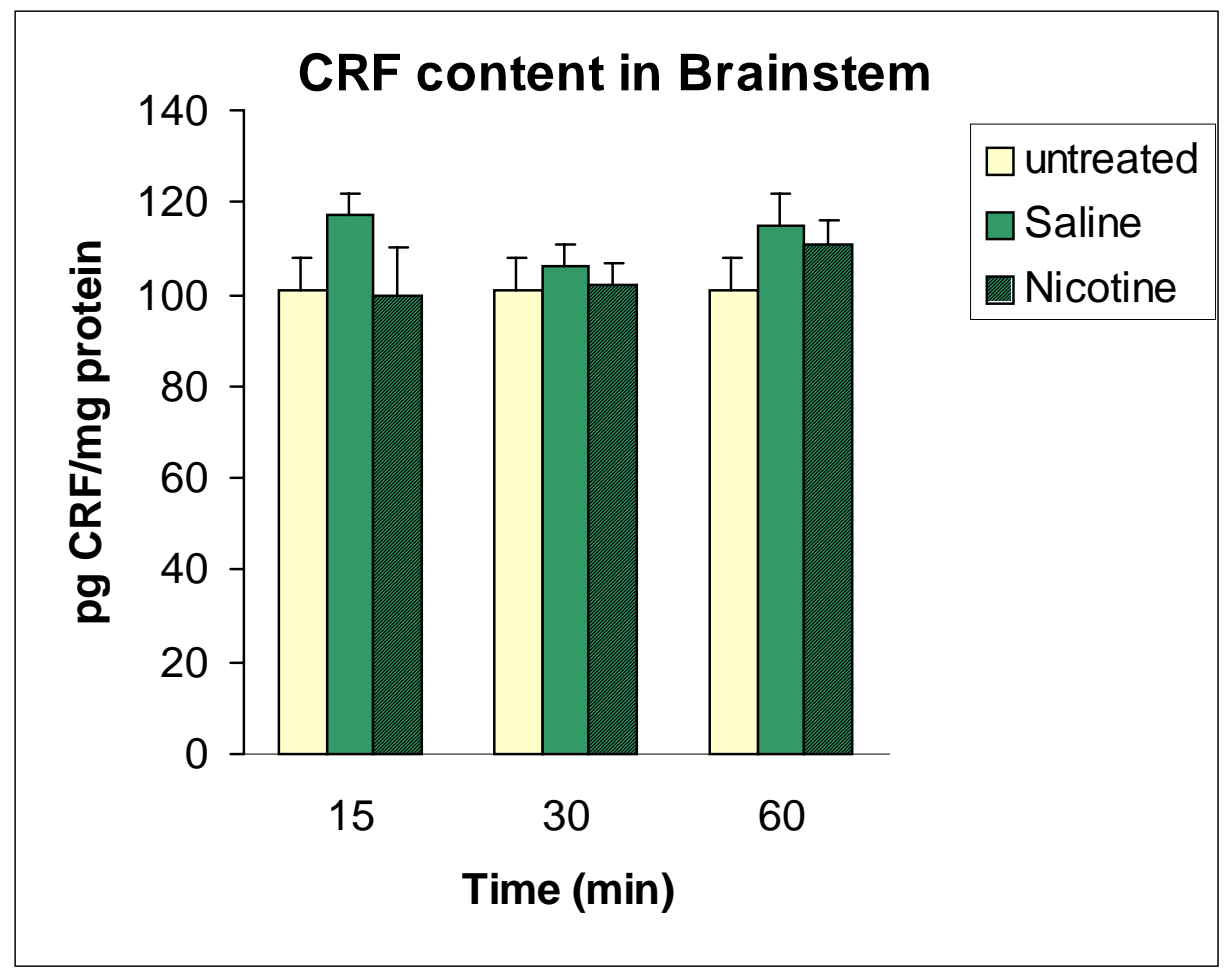

Figure 8. CRF content in macro-dissections of brain stem after 15, 30 and 60 minutes treatment with nicotine $1.0 \mathrm{mg} / \mathrm{kg}, 0.9 \%$ saline (vehicle, $1.0 \mathrm{ml} / \mathrm{kg}$ ) or no treatment: 15 minutes nicotine $(n=8)$, saline $(n=8), 30$ minutes nicotine $(n=7)$, saline $(n=8), 60$ minutes nicotine $(n=6)$, saline $(n=8)$ and total untreated $(n=24)$. Values are expressed in $\mathrm{pg} \mathrm{CRF/mg} \mathrm{protein,} \mathrm{mean} \pm$ S.E.M per treatment. 
After 30 minutes, mean CRF levels were $102 \pm 5$ and $106 \pm 5$ for nicotine and saline treated rats respectively. Sixty minutes of treatment exhibited mean CRF levels of $111 \pm$ 5 and $115 \pm 7$ for nicotine and saline respectively. No significant treatment and time effects were observed between nicotine versus saline versus untreated group, at all time points.

Figure 9 summarizes CRF content in micro-punches of locus coeruleus and parabrachial nucleus (LCPB) after 15 and 30 minutes treatment with $0.4 \mathrm{mg} / \mathrm{kg}$ nicotine. Values are expressed in pg CRF/mg protein, mean \pm S.E.M per treatment. The figure shows that mean CRF content in untreated rats from both time points was $570 \pm 66$. After 15 minutes treatment, mean CRF levels were $433 \pm 79$ and $579 \pm 79$ for nicotine and saline respectively. The thirty minute time point exhibited values of $512 \pm 43$ for nicotine and $475 \pm 14$ for saline treated rats. No significant treatment and time effects were observed in brain stem nuclei. 


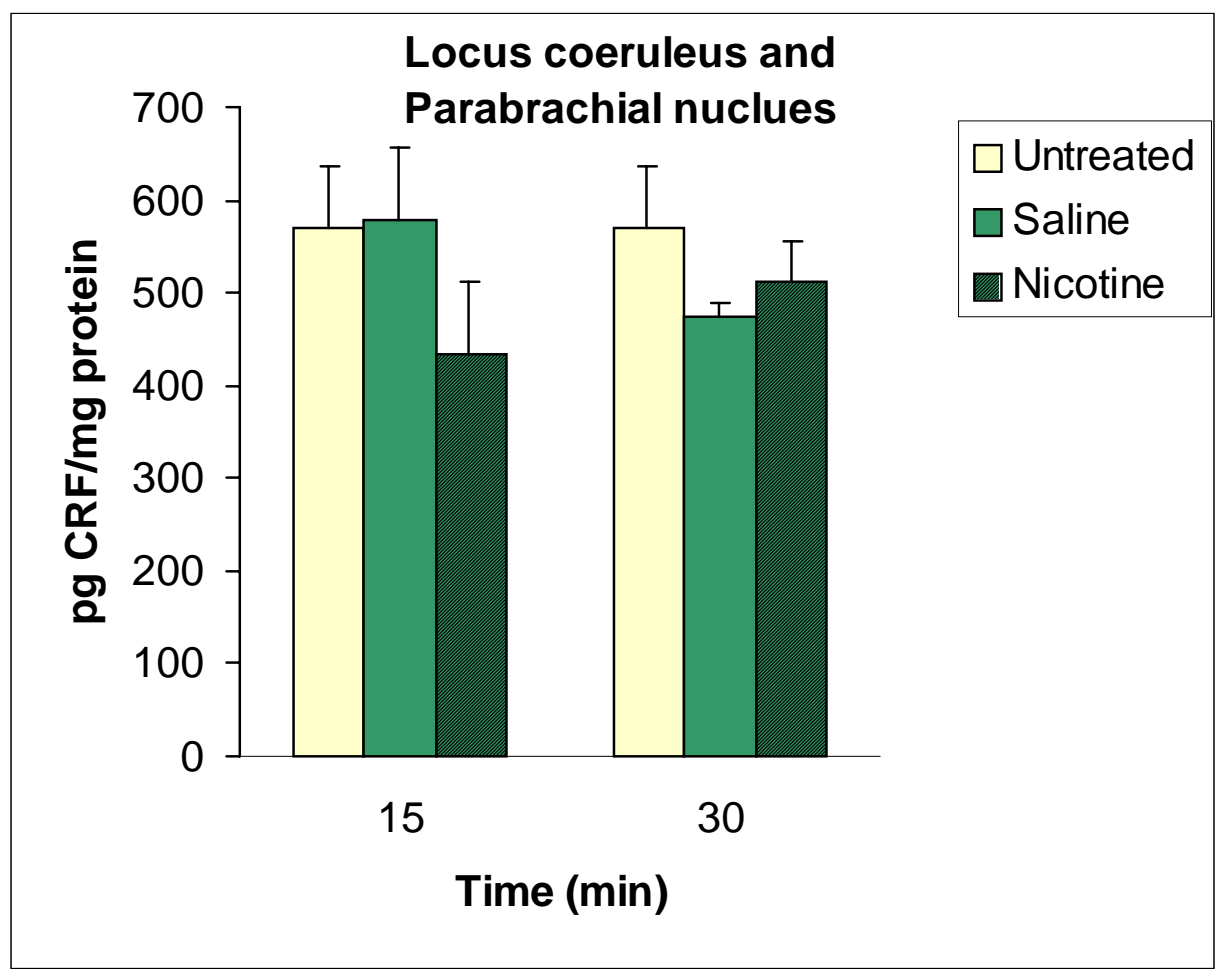

Figure 9. CRF content in micro-punches of locus coeruleus and parabrachial nucleus (LCPB) after 15 and 30 minutes treatment with nicotine $0.4 \mathrm{mg} / \mathrm{kg}, 0.9 \%$ saline (vehicle $1.0 \mathrm{ml} / \mathrm{kg})$ or no treatment: 15 minutes nicotine $(\mathrm{n}=4)$, saline $(\mathrm{n}=4), 30$ minutes nicotine $(n=8)$, saline $(n=8)$ and total untreated group $(n=8)$. Values are expressed in pg $\mathrm{CRF} / \mathrm{mg}$ protein, mean \pm S.E.M per treatment. 
CHAPTER VI

DISCUSSION AND FUTURE DIRECTIONS

\section{$\underline{\text { Discussion }}$}

Effects of nicotine on hypothalamic and extrahypothalamic CRF have not been extensively reported. A recent study by (Matta, et al., 1997), reported increased c-fos expression in CRF positive neurons after low dose nicotine treatment. The protooncogene c-fos is an early indicator of neuronal activity, and this suggested that nicotine induced neuronal activity in CRF expressing neurons. The present study is the first to assess effects of nicotine on the content of CRF in the whole hypothalamus, amygdala and brain stem, and selected nuclei in these brain regions, at different time points. The study utilized two different doses of nicotine, $0.4 \mathrm{mg} / \mathrm{kg}$ and $1.0 \mathrm{mg} / \mathrm{kg}$. The $1.0 \mathrm{mg} / \mathrm{kg}$ dose was examined for 15, 30 and 60 minutes whereas the 0.4 dose was examined for 15 and 30 minutes only.

In this study, it was assumed that the response of CRF after 15 minutes treatment would respond to the peaking of nicotine in the brain which occurs about 20 minutes after intravenous administration while the 60 minute response would correspond to relatively low levels of nicotine (Sastry, et al., 1995; Schmiterlöw, et al., 1967). The assumption was that acute nicotine would evoke changes in CRF content due to one or more of the following: (I) increased release and utilization leading to decreased content, (II) increased synthesis, processing or reuptake leading to increased levels, (III) decreased utilization and degradation, leading to increased levels and (IV) inhibition of release leading to increase levels. The present study did not directly address these mechanisms but only 
measured CRF content. Electrophysiological, immunocytochemical, microdialysis and molecular biological techniques would be necessary to further elucidate the mechanisms of nicotine-induced changes in CRF content. Corticosterone levels were utilized as positive control for the presence of nicotine.

\section{$\underline{\text { Plasma Corticosterone after } 0.4 \mathrm{mg} / \mathrm{kg} \text { treatment }}$}

Rats treated with nicotine $0.4 \mathrm{mg} / \mathrm{kg}$ for 15 minutes had significantly increased levels of corticosterone compared to untreated rats. Thirty minutes treatment with nicotine produced a strongly significant increase in levels of plasma corticosterone compared to both saline treated and untreated. These results confirm the results reported by other researchers, that nicotine injection augments plasma corticosterone. Corticosterone has been reported to peak at 10 to 30 minutes after injection and persist for up to 60 minutes (Benwell and Balfour, 1982; Cam and Bassett, 1983; Freund, et al., 1988).

\section{$\underline{\text { Plasma Corticosterone after } 1.0 \mathrm{mg} / \mathrm{kg} \text { treatment }}$}

Rats treated with nicotine $1.0 \mathrm{mg} / \mathrm{kg}$ at either 15,30 or 60 minutes exhibited a strongly significant increase in levels of plasma corticosterone compared to saline treated and untreated. There were no significant differences between 15, 30 and 60 minutes treatment with nicotine. These results also confirm the results by other researchers, that nicotine injection increases plasma corticosterone peaking at 10 to 30 minutes, and these increases persist for up to 60 minutes after nicotine injection (Benwell and Balfour, 1982; Freund, et al., 1988; Cam and Bassett, 1983). The present results also confirm that 
nicotine activates the release of hypothalamic CRF causing increases in plasma corticosterone. How long this release of CRF continues is not clear; possibly the persistently high corticosterone levels reflect the continued release of CRF until the usable pool is depleted. The strongly significant increases in corticosterone are agreeable with the fact that nicotine administration augments plasma corticosterone which in turn quells down CNS effects of nicotine (Caggiula, et al., 1993, Caggiula, et al., 1998). This effect may also be due to the contribution of peripheral effects of nicotine directly on the adrenal cortex (Bugaski, et al., 1998; Malin, et al., 1997). Although levels were lower in all treatment groups at the 60 minutes time point compared to 15 and 30 , nicotine treated rats still showed corticosterone levels significantly higher than untreated. The results further suggest that the stress of handling animals is minimal as shown by the lack of corticosterone response to saline injection.

\section{$\underline{\mathrm{CRF} \text { content in brain regions }}$}

Two doses of nicotine $0.4 \mathrm{mg} / \mathrm{kg}$ and $1.0 \mathrm{mg} / \mathrm{kg}$ were used to study effects on CRF content in hypothalamus, amygdala and brain stem. As expected, the hypothalamus had higher levels of CRF compared to amygdala and brain stem. Overall, there were no clear cut treatment effects of nicotine in all tested brain regions after 15, 30, and 60 minutes. The use of two different doses and methods may have confounded the results. Employing the cryostat-microdissection method at different doses would be more useful. 


\section{Hypothalamus}

In macro-dissections of the hypothalamus there were significant treatment and time effects. Rats treated with $1.0 \mathrm{mg} / \mathrm{kg}$ nicotine showed a strongly significant increase in levels of CRF in the hypothalamus after 15 minutes treatment. Thirty minutes of treatment did not produce differences between treatments but the time effects of nicotine were prominent. Compared to the 15 minutes treatment time point, CRF was significantly decreased in the hypothalamus of nicotine treated rats after 30 minutes. This decrease persisted even though non-significantly, to 60 minutes. This decrease signified that CRF had been released from the median eminence and transported to the pituitary to trigger the release of ACTH thus causing the increased release of corticosterone from the adrenal cortex. The initial increase which was paralleled by increased corticosterone was probably due to the nicotine-induced mobilization of pre-pro CRF from PVN resulting in increased levels in whole hypothalamus, with this dose $(1.0 \mathrm{mg} / \mathrm{kg})$. Increased utilization of CRF could possibly lead to a decrease in PVN levels due to depletion of pre-pro CRF, with time. The micro-punch method to examinine individual nuclei would help determine which nucleus of the hypothalamus has increased levels. No effects of saline treated versus untreated rats were observed signifying that the treatment and time effects were specific to nicotine.

It would be expected that a significant rise in plasma corticosterone would be paralleled by a significant fall in the hypothalamic CRF and our results showed this. The present results indicated that after an initial rise at 15 minutes, CRF in the hypothalamus returned to baseline levels by 30 and 60 minutes after nicotine treatment. This suggested 
an initial increase in processing of pre-pro CRF, which was followed by facilitation of release and increased utilization. The return to baseline levels was expectedly due to the corticosterone feedback inhibition. Notably, this initial increase in CRF after 15 minutes was also paralleled by increased corticosterone levels, indicating that this time point may be too early to detect feedback inhibition.

Acute and chronic stress have been shown to reduce CRF-like immunoreactivity in the ME while causing an increase in the anterior hypothalamus (Chappell, et al., 1986; Feldman and Weidenfeld, 1996a). Notably, Swanson and Simmons, (1989), and Makino, et al., (1994), showed that administration of increasing doses of corticosterone to adrenalectomized animals caused a decrease in CRF mRNA in the hypothalamus confirming the feedback inhibition. In animals and humans, increased anxiety or fear have been reported to increase circulating levels of CRF and glucocorticoids (Nemeroff, et al., 1991; Owens, et al., 1991) indicating a disregulation of the HPA axis. Studying effects of nicotine directly on corticosterone synthesis in adrenal cortex would be useful in determining the direct contribution of nicotine to circulating corticosterone and to clarify why increased levels of corticosterone were observable when CRF levels had returned to baseline after 30 and 60 minutes.

\section{$\underline{\text { Paraventicular nucleus }}$}

Acute and chronic stress have been shown to cause no changes in CRF-like immunoreactiviy in the paraventricular nucleus (PVN) (Chappell, et al., 1986; Feldman and Weidenfeld, 1996a). In the present study, microdissections of the PVN showed that 
there were no significant effects after 15 minutes treatment, for nicotine $(0.4 \mathrm{mg} / \mathrm{kg})$ versus untreated versus saline injection. A slight increase in CRF was observed in 30 minutes but was not statistically significant. This would indicate that nicotine and the saline injection induced the processing of pre-pro-CRF in PVN, which would unite with existing pool of CRF get transported into the ME and be rapidly utilized to continue to elicit ACTH release in pituitary and maintain elevated plasma corticosterone. It has been reported by Sharp, et al., (1993), that c-Fos mRNA in hypothalamus was observable after 30 minutes of intraperitoneal nicotine which would confirm continued activation of the HPA axis. This regulation of c-Fos by nicotine is modiated through brain stem neurotransmitters (Valentine, et al., 1996). The question remains whether or not nicotine would induce CRF mRNA. As time passes and approaches 60 minutes or more, would pre-pro CRF be depleted enough to manifest a decrease in CRF levels for mRNA to be induced? Would the induction of mRNA be counteracted by corticosterone feedback inhibition? A higher dose of nicotine will be needed to assess effects on different hypothalamic nuclei, using microdissections.

\section{$\underline{\text { Amygdala }}$}

In amygdala macro-dissections, there were no significant treatment and time effects at $1.0 \mathrm{mg} / \mathrm{kg}$ nicotine. Even though there was an apparent increase in CRF levels in 15 and 30 min treatments, these were not significant. This would suggest that since the whole of amygdala including the piriform cortex were dissected, CRF that had been released from the CeA was still in the surrounding neurons, not yet metabolized, therefore detectable. 
However, the apparent increase in CRF levels in 15 and 30 min treatments may suggest a typical effect on CRF releasing nuclei, because a significant increase was also observed in the hypothalamus. Administration of increasing doses of corticosterone to adrenalectomized animals has been reported to correspond to as much as five fold increase in CRF mRNA expression in the CeA of the amygdala, while CRF mRNA in the hypothalamus decreased (Makino, et al., 1994; Swanson and Simmons, 1989). Whether or not nicotine-induced corticosterone can cause such effects is not known.

\section{$\underline{\text { Amygdaloid nuclei }}$}

In microdissections of amygdaloid nuclei, the time effect that was observed could not be taken as a clear cut indication of nicotine time effects, because there were no significant differences between saline treated or untreated rats at these time points. Treatment for 15 and $30 \mathrm{~min}$ with $0.4 \mathrm{mg} / \mathrm{kg}$ did not affect levels of CRF in the amygdala for nicotine versus saline versus untreated animals. Even though there was a slight increase in CRF for nicotine treated rats, at 15 minutes compared to saline treated and untreated, this was not significant. Therefore, $0.4 \mathrm{mg} / \mathrm{kg}$ nicotine slightly elevated $\mathrm{CRF}$ in the amygdala but the levels declined to the levels of untreated rats after 30 minutes. These findings poissibly follow the pattern of initial increase in content of CRF as seen with hypothalamus and amygdala data. A higher dose of nicotine will be needed to determine if there are any effects on CRF content in amygdaloid nuclei. 


\section{Brain stem}

Macro-dissected brain stem showed no treatment or time effects on CRF content after $1.0 \mathrm{mg} / \mathrm{kg}$ nicotine treatments at all time points, 15, 30 and 60 minutes. This brain region was prone to having discrepancies in results due to two reasons; (I) inconsistencies in dissections which were more likely to occur with the brain stem and (II) this area was prone to damage during decapitations and removal from the cranium. Like all macrodissections, in brain stem, effects of nicotine could have been masked by the fact that even after release from the nuclei, CRF was still in the neighboring CRF areas of the brain stem and would be detectable. In addition to the locus coeruleus/parabrachial nucleus (LCPB), other nuclei including nucleus solitarius, raphe nuclei and dorsal vagal complex express CRF immunoreactivity (Chappell, et al., 1986). As discussed earlier, CRF originating from the amygdala is believed to trigger activation of LC for catecholamine release and nicotine has been shown to cause noradrenergic activation and release of norepinephrine into the hypothalamus and amygdala for activation of $\mathrm{CRF}$ release (Fu, et al., 1997; Fu, et al., 1998; Matta, et al., 1993b; Mitchell, 1993). Since CRF expressing neurons originate from the amygdala, significant changes in amygdaloid CRF would need to occur before changes in the brain stem would be obvious.

\section{$\underline{\text { Brain stem nuclei (Locus coeruleus and parabrachial nucleus) }}$}

The microdissected brain stem nuclei: locus coeruleus and parabrachial nucleus showed a nonsignificant decrease in CRF content after 15 minutes treatment. This initial decrease in CRF content followed by recovery to untreated levels is an opposite effect 
compared to nicotine's effects on hypothalamus and amygdala. This is to be expected because the brain stem nuclei do not synthesize CRF and once utilized replenishment of $\mathrm{CRF}$ has to come from the amygdala. A possible role of nicotine to trigger CRF release which in turn triggers LC activation would be inferred by a decrease in content of CRF resulting from increased utilization in the brain stem. A higher dose of nicotine would need to be utilized to study effects on CRF in brain stem.

\section{$\underline{\text { General conclusion }}$}

The present study examined effects of nicotine on CRF content in rat amygdala, hypothalamus and brain stem, using two doses of nicotine 0.4 and $1.0 \mathrm{mg} / \mathrm{kg}$ and two dissection methods at different treatment time points. The macro-dissection method revealed significant effects of nicotine $(1.0 \mathrm{mg} / \mathrm{kg})$ in the hypothalamus with 15 minutes treatment. No significant effects were seen in the amygdala and brain stem. Time dependent effects were observed between 15 and 30 minutes nicotine $(1.0 \mathrm{mg} / \mathrm{kg})$ treated rat hypothalami. The microdissection method using $0.4 \mathrm{mg} / \mathrm{kg}$ did not exhibit any treatment effects with all tested nuclei. Overall, no clear cut effects were observed with both dissections and doses of nicotine. Studies on CRF content in specific nuclei using varying doses of nicotine and various time points would help elucidate if indeed there are interactions. 


\section{$\underline{\text { Future directions }}$}

For further research, the method of choice would be the cryostat-microdissection method. With this method, the nuclei could be accessed individually and characteristic CRF levels detected for brain region nuclei. For example: (I) in the amygdala, the central nucleus (CeA) and basolateral nuclei (BLA) could be micro-punched individually, CRF levels should vary because the CeA contains more output CRF neurons (cell bodies) while basolateral has more receptors (terminals), (II) in the hypothalamus, PVN is the main source of CRF versus median eminence which contains the storage terminals, and other hypothalamic nuclei could be accessed, and (III) in brain stem, the locus coeruleus and parabrachial nucleus could be micro-punched separately and other nuclei including nucleus tractus solitarius and Barrington's nucleus can be accessed. Chappell, et al., (1986), was able micro-punch out several nuclei in the hypothalamus, amygdala and brain stem for CRF assessment. Determining CRF levels in the PVN and ME individually after 15,30 and 60 minutes of treatment with nicotine $(0.4 \mathrm{mg} / \mathrm{kg}$ and $1.0 \mathrm{mg} / \mathrm{kg})$, would help clarify if indeed there are effects on CRF content, and the more rapid method of macro dissections could be utilized for these nuclei. Varying doses of nicotine could be utilized to determine dose response relationships on CRF content in nuclei of the hypothalamus, amygdala and brain stem.

Molecular biological techniques to examine CRF mRNA would help determine when the induction of CRF synthesis occurs after nicotine administration. Microdialysis techniques can be utilized to monitor CRF release after treatment with lower doses of nicotine; lower doses of the drug are used for direct delivery into the nuclei. Microdialysis 
techniques would mostly be useful in the study of earlier time points from 0-20 minutes after nicotine treatment since nicotine accumulates in the brain within 5 minutes after intravenous administration. Effects of acute nicotine on CRF content in the brain could also be best determined between 5-20 minutes after administration, to coincide with peak levels. These earlier time points could be best understood if researched at specified time intervals for up to 30 or more minutes.

Immunocytochemical techniques and/or receptor binding techniques can be utilized to determine CRF receptors after acute or chronic nicotine treatment. The effects of chronic nicotine using minipumps and/or injections and the effects of nicotine withdrawal can be determined using these techniques. Nicotine administered acutely or chronically, and withdrawal from nicotine all exhibit different effects on animals (Helton, et al., 1993). In acute doses, nicotine naive rats could be compared to rats that have been pretreated with nicotine. With chronic nicotine treatments, the role that desensitization and tolerance play on CRF content still needs to be studied. Cognitive facilitation has been observed in rats up to four weeks after nicotine treatment (Levin, et al., 1992), therefore, effects of nicotine withdrawal would help in the elucidation of whether or not CRF is involved in the addictive effects of nicotine.

Future studies must involve the administration of neuronal nAChR antagonists namely: mecamylamine, dihydro- $\beta$-erythroidine or chlorisondamine (Dessirier, et al., 1998; Fu, et al., 1998; Malin, et al., 1994). This would help confirm whether or not effects are exerted on neuronal $\mathrm{nAChR}$, that is, the specificity of nicotine. Whether or not nicotine stimulates CRF directly or indirectly through brain stem neurotransmitters is yet 
to be documented. The interaction of CRF systems with cholinergic and noradrenergic systems and also with other systems could be investigated by injecting agonists or antagonist for these systems before nicotine injection.

Nicotine evokes different effects on stressed and unstressed animals and humans (Balfour, et al., 1975; Donnerer and Lembeck, 1990). The effects of nicotine-induced corticosterone will need to be assessed because stress reverses the inhibitory effects of high levels of corticosterone on CRF, causing a disregulation of the HPA axis (Makino, et al., 1995). Hexamethonium, a peripheral nAChR antagonist could be used to determine the role played in CRF modulation, by nicotine-induced adrenal corticosterone (Bugaski, et al., 1998; Malin, et al., 1997). Administration of metyrapone, a corticosterone synthesis inhibitor, before nicotine treatment would help determine the extent to which CRF is modulated by nicotine without the input from corticosterone.

The above mentioned techniques could be applied to stressed rats after acute or chronic nicotine treatment. This would demonstrate the effects of nicotine on stressed rats, and these are expected to vary from normal. The same techniques could be used on rats treated prenatally with nicotine to determine if the interaction of nicotine with $\mathrm{CRF}$ is manifest in the offspring. The plight of prenatal exposure to nicotine; effects on the offspring, was the impetus for this present study. 


\section{References}

Acri JB (1994) Nicotine modulates effects of stress on acoustic startle reflexes in rats: Dependence on dose, stressor and initial reactivity. Psychopharmacology (Berl) 116:255-265.

Acri JB, Morse DE, Popke EJ, and Grunberg NE (1994) Nicotine increases sensory gating measured as inhibition of the acoustic startle reflex in rats. Psychopharmacology 114:369-374.

Adir J, Miller RP, and Rotenberg KS (1976) Disposition of nicotine in the rat after intravenous administration. Res.Comm.Chem.Pathol.Pharmacol. 13:173-183.

Ahima RS and Harlan RE (1990) Charting of Type II glucocorticoid receptor-like immunoreactivity in the rat central nervous system. Neuroscience 39:579-604.

Allen J and Allen C (1974) Role of the amygdaloid complexes in the stress-induced release of ACTH in the rat. Neuroendocrinology 15:220-230.

Amaral DG, Price JL, Pitkänen A, and Carmichael ST (1992) Anatomical Organization of the Primate Amygdaloid Complex. In: The Amygdala Neurobiological aspects of emotion, memory, and mental dysfunction (Aggleton JP ed), pp 1-66. New York, NY: Wiley-Liss.

Anderson SM, Kant GJ, and De Souza EB (1993) Effects of chronic stress on anterior pituitary and brain corticotropin-releasing factor receptors. Pharmacol.Biochem.Behav. 44:755-761.

Andersson K, Eneroth P, and Agnati LF (1981) Nicotine-induced increases of noradrenaline turnover in discrete noradrenaline nerve terminal systems of the hypothalamus and the median eminence of the rat and their relationship to changes in the secretion of adenohypophyseal hormones. Acta Physiol.Scand. 113:227231.

Andersson K, Siegel R, Fuxe K, and Eneroth P (1983) Intravenous injections of nicotine induce very rapid and discrete reductions of hypothalamic catecholamine levels associated with increases of ACTH, vasopressin and prolactin secretion. Acta Physiol.Scand. 118:35-40.

Appel NM, Owens MJ, Culp S, Zaczek R, Contrera JF, Bissette G, Nemeroff CB, and De Souza EB (1991) Role for brain corticotropin-releasing factor in the weightreducing effects of chronic fenfluramine treatment in rats. Endocrinology 128:3237-3246. 
Armitage AK, Hall GH, and Morrison CF (1968) Pharmacological basis for the tobacco smoking habit. Nature 217:331-334.

Armitage AK, Hall GH, and Sellers CM (1969) Effects of nicotine on electrocortical activity and acetylcholine release from the cat cerebral cortex. Br.J.Pharmac. $35: 152-160$.

Balfour DJK (1973) Effects of nicotine on the uptake and retention of ${ }^{14} \mathrm{C}$-noradrenaline and ${ }^{14} \mathrm{C}-5$-Hydroxytryptamine by rat brain homogenates. Eur.J.Pharmacol. 23:1926.

Balfour DJK (1982) The pharmacology of nicotine dependence: A working hypothesis. Pharmacol.Ther. 15:239-250.

Balfour DJK and Fagerström KO (1996) Pharmacology of nicotine and its therapeutic use in smoking cessation and neurodegenerative disorders. Pharmacol.Ther. 72:51-81.

Balfour DJK, Khullar AK, and Longden A (1975) Effects of nicotine on plasma corticosterone and brain amines in stressed and unstressed rats. Pharmacol.Biochem.Behav. 3:179-184.

Bannon AW, Decker MW, Holladay MW, Curzon P, Donnelly-Roberts D, Puttfarcken PS, Bitner RS, Diaz A, Dickenson AH, Porsolt RD, Williams M, and Arneric SP (1998) Broad-spectrum, non-opioid analgesic activity by selective modulation of neuronal nicotinic acetylcholine receptors. Science 279:77-81.

Bassareo V, Tanda G, Petromilli P, Giua C, and Di Chiara G (1996) Non-psychostimulant drugs of abuse and anxiogenic drugs activate with differential selectivity dopamine transmission in the nucleus accumbens and in the medial prefrontal cortex of the rat. Psychopharmacology (Berl) 124:293-299.

Battaglia G, Webster E, and De Souza EB (1987) Characterization of corticotropinreleasing factor receptor-mediated adenylate cyclase activity in the rat central nervous system. Synapse 1:572-581.

Beaulieu S, Di Paolo T, and Barden N (1986) Control of ACTH secretion by the central nucleus of the amygdala: implication of the serotinergic system and its relevance to the glucocorticoid delayed negative feedback mechanism. Neuroendocrinology 44:247-254.

Beckett AH, Gorrod JW, and Jenner P (1972) A possible relation between $\mathrm{pKa}_{1}$ and lipid solubility and the amounts excreted in urine of some tobacco alkaloids given to man. J.Pharm.Pharmac. 24:115-120. 
Behan DP, Potter E, Lewis KA, Jenkins NA, Copeland N, Lowry PJ, and Vale WW (1993a) Cloning and structure of the human corticotrophin releasing factor-binding protein gene (CRHBP). Genomics 16:63-68.

Behan DP, Potter E, Sutton S, Fischer W, Lowry PJ, and Vale WW (1993b) Corticotropinreleasing factor-binding protein. A putative peripheral and central modulator of the CRF family of neuropeptides. Ann.NY Acad.Sci. 697:1-8.

Benowitz NL and Jacob P, III (1997) Individual differences in nicotine kinetics and metabolism in humans. In: Pharmacokinetics, Metabolism, and Pharmaceutics of Drugs of Abuse (USDHSS, Public Health Service, NIH, NIDA), pp48-64. Rockville, MD.

Benowitz NL, Porchet H, Sheiner L, and Jacob PI (1988) Nicotine absorption and cardiovascular effects with smokeless tobacco use: comparison with cigarettes and nicotine gum. Clin.Pharmacol.Ther. 44:23-28.

Benwell MEM and Balfour DJK (1979) Effects of nicotine administration and its withdrawal on plasma corticosterone and brain 5-hydroxyindoles. Psychopharmacology 63:7-11.

Benwell MEM and Balfour DJK (1982) Effects of chronic nicotine administration on the response and adaption to stress. Psychopharmacology 76:160-162.

Benwell MEM and Balfour DJK (1985) Nicotine binding to brain tissue from drug-naive and nicotine-treated rats. J.Pharm.Pharmacol. 37:405-409.

Benwell MEM and Balfour DJK (1992) The effect of acute and repeated nicotine treatment on nucleus accumbens dopamine and locomotor activity. Br.J.Pharmacol. 105:849-856.

Benwell MEM and Balfour DJK (1997) Regional variation in the effects of nicotine on catecholamine overflow in rat brain. Eur.J.Pharmacol. 325:13-20.

Benwell MEM, Balfour DJK, and Anderson JM (1988) Evidence that tobacco smoking increases the density of (-)-[ $\left.{ }^{3} \mathrm{H}\right]$ Nicotine binding sites in human brain. J.Neurochem. 50:1243-1247.

Benwell MEM, Balfour DJK, and Anderson JM (1990) Smoking-associated changes in the serotonergic systems of discrete regions of human brain. Psychopharmacology 102:68-72.

Bertrand D, Ballivet M, and Rungger D (1990) Activation and blocking of neuronal nicotinic acetylcholine receptor reconstituted in Xenopus oocytes. Proc.Natl.Acad.Sci.USA 87:1993-1997. 
Bhat RV, Marks MJ, and Collins AC (1994) Effects of chronic nicotine infusion on kinetics of high-affinity nicotine binding. J.Neurochem. 62:574-581.

Bremner JD, Krystal JH, Southwick SM, and Charney DS (1996) Noradrenergic mechanisms in stress and anxiety: I. Preclinical Studies. Synapse 23:28-38.

Breslau N, Kilbey MM, and Andreski MA (1993) Nicotine Dependence and major depression: New evidence from a prospective investigation. Arch.Gen.Psych. 50:31-35.

Brioni JD, O'Neill AB, Kim DJB, Buckley MJ, Decker MW, and Arneric SP (1994) Anxiolytic-like effects of the novel cholinergic channel activator ABT-418. J.Pharmacol.Exp.Therap. 271:353-361.

Brioni JD, O'Neill AB, Kim DJB, and Decker MW (1993) Nicotinic receptor agonists exhibit anxiolytic-like effects on the elevated plus-maze test. Eur.J.Pharmacol. 238:1-8.

Brown MR, Fisher LA, Spiess J, Rivier C, Rivier J, and Vale W (1982) Corticotropinreleasing factor: actions on the sympathetic nervous system and metabolism. Endocrinology 111:928-931.

Bugaski J, Gadek-Michalska A, Borycz J, and Glod R (1998) Effect of indomethacin on nicotine-induced ACTH and corticosterone response. J.of Physiol Pharmacol. 49:165-173.

Bullock AE, Clark AL, Grady SR, Robinson SF, Slobe BS, Marks MJ, and Collins AC (1997) Neurosteroids modulate nicotinic receptor function in mouse striatal and thalamic synaptosomes. J.Neurochem. 68:2412-2423.

Bylund DB and Yamamura HI (1990) Methods for receptor binding. In: Methods in Neurotransmitter Receptor Analysis (Yamamura HI ed), pp 1-35. New York: Raven Press.

Caggiula AR, Donny EC, Epstein LH, Sved AF, Knopf S, Rose C, McAllister CG, Antelman SM, and Perkins KA (1998) The role of corticosteroids in nicotine's physiological and behavioral effects. Psychoendocrinology 23:143-159.

Caggiula AR, Epstein LH, Antelman SM, Saylor S, Knopf S, Perkins KA, and Stiller R (1993) Acute stress or corticosterone administration reduces responsiveness to nicotine: implications for a mechanism of conditioned tolerance. Psychopharmacology 111:499-507. 
Cahill L, Haier RJ, Fallon J, Alkire MT, Tang C, Keator D, Wu J, and McGaugh JL (1996) Amygdala activity at encoding correlated with long-term, free recall of emotional information. Proc.Natl.Acad.Sci.USA 93:8016-8021.

Cahill L and McGaugh JL (1996) Modulation of memory storage. Curr.Opin.Neurobiol. 6:237-242.

Calogero AE, Bernardini R, Margioris AN, Bagdy G, Gallucci WT, Munson PJ, Tamarkin L, Tomai TP, Brady L, Gold PW, and Chrousos GP (1989) Effects of serotonergic agonists and antagonists on corticotropin-releasing hormone secretion by explanted rat hypothalami. Peptides 10:189-200.

Calogero AE, Gallucci WT, Chrousos GP, and Gold PW (1988) Interaction between GABAergic neurotransmission and rat hypothalamic corticotropin-releasing hormone secretion in vitro. Brain Res. 463:28-36.

Cam GR and Bassett JR (1983) The effect of acute nicotine administration on plasma levels of the thyroid hormones and corticosterone in the rat.

Pharmacol.Biochem.Behav. 19:559-561.

Campeau S, Miserendino MJD, and Davis M (1992) Intra-amygdala infusion of the $\mathrm{N}$ methyl-D-aspartate receptor antagonist AP5 blocks acquisition but not expression of fear-potentiated startle to an auditory conditioned stimulus. Behav.Neurosci. 106:569-574.

Carlsson A and Waldeck B (1958) A flurimetric method for the determination of dopamine (3-hydroxytyramine). Acta Physiol.Scand. 44:293-298.

Castro M, Lowenstein P, Glynn B, Hannah M, Linton E, and Lowry P (1991) Posttranslational processing and regulated release of corticotropin- releasing hormone $(\mathrm{CRH})$ in AtT20 cells expressing the human proCRH gene. Biochem.Soc.Trans. 19:246S-246S.

Chalmers DT, Lovenberg TW, and De Souza EB (1995) Localization of novel corticotropin-releasing factor receptor $\left(\mathrm{CRF}_{2}\right) \mathrm{mRNA}$ expression to specific subcortical nuclei in rat brain: Comparison with $\mathrm{CRF}_{1}$ receptor mRNA expression. J.Neurosci. 15:6340-6350.

Chalmers DT, Lovenberg TW, Grigoriadis DE, Behan DP, and De Souza EB (1996) Corticotrophin-releasing factor receptors: From molecular biology to drug design. Trends Pharmacol.Sci. 17:166-172.

Chappell PB, Smith MA, Kilts CD, Bissette G, Ritchie J, Anderson C, and Nemeroff CB (1986) Alterations in corticotropin-releasing factor like immunoreactivity in discrete rat brain regions after acute and chronic stress. J.Neurosci. 6:2908-2914. 
Charney DS, Woods SW, Krystal JH, and Heninger GR (1990) Serotonin function and human anxiety disorders. Ann.N.Y.Acad.Sci. 600:558-573.

Christensen H, Maltby N, Jorm AF, Creasy H, and Broe GA (1992) Cholinergic 'blocakade' as a model of the cognitive deficits in Alzheimer's disease. Brain 115:1681-1699.

Clarke MJO and Gillies GE (1988) Comparison of peptide release from fetal rat hypothalamic neurones cultured in defined media and serum-containing media. J.Endocrinol. 116:349-356.

Clarke PBS and Pert A (1985) Autoradiographic evidence for nicotine receptors on nigrostriatal and mesolimbic dopaminergic neurons. Brain Res. 348:355-358.

Clarke PBS, Pert CB, and Pert A (1984) Autoradiographic distribution of nicotine receptors in rat brain. Brain Res. 323:390-395.

Clarke PBS, Schwartz RD, Paul SM, Pert CB, and Pert A (1985) Nicotinic binding in rat brain: autoradiographic comparison of $\left[{ }^{3} \mathrm{H}\right]$ Acetylcholine, $\left[{ }^{3} \mathrm{H}\right] \mathrm{Nicotine}$, and $\left[{ }^{125} \mathrm{I}\right]-$ $\alpha$-Bungarotoxin. J.Neurosci. 5:1307-1315.

Collins AC, Romm E, and Wehner JM (1990) Dissociation of the apparent relationship between nicotine tolerance and up-regulation of nicotinic receptors. Brain Res.Bull. 25:373-379.

Colquhoun D, Ogden DC, and Mathie A (1987) Nicotinic acetylcholine receptors of nerve and muscle: functional aspects. Trends Pharmacol.Sci. 8:465-472.

Cooper E, Couturier S, and Ballivet M (1991) Pentameric structure and subunit stochiometry of a neuronal nicotinic acetylcholine receptor. Nature 350:235-238.

Corrigall WA and Coen KM (1989) Nicotine maintains robust self-administration in rats on a limited-access schedule. Psychopharmacology 99:473-478.

Corrigall WA, Coen KM, and Adamson KL (1994) Self-administered nicotine activates the mesolimbic dopamine system through the ventral tegmental area. Brain Res. 653:278-284.

Corrigall WA, Franklin KBJ, Coen KM, and Clarke PBS (1992) The mesolimbic dopaminergic system is implicated in the reinforcing effects of nicotine. Psychopharmacology 107:285-289.

Costall B, Kelly ME, Naylor RJ, and Onaivi ES (1989) The actions of nicotine and cocaine in a mouse model of anxiety. Pharmacol.Biochem.Behav. 33:197-203. 
Cratty MS and Birkle DL (1994) Depolarization-induced release of corticotropin-releasing factor (CRF) in primary neuronal cultures of the amygdala. Neuropeptides 26:113121.

Cratty MS, Ward HE, Johnson EA, Azzaro AJ, and Birkle DL (1995) Prenatal stress increases corticotropin-releasing factor $(\mathrm{CRF})$ content and release in rat amygdala minces. Brain Res. 675:297-302.

Crooks PA and Dwoskin LP (1997) Contribution of CNS nicotine metabolites to the neuropharmacological effects of nicotine and tobacco smoking.

Biochem.Pharmacol. 54:743-753.

Cummings S, Elde R, Ells J, and Lindall A (1983) Corticotropin-releasing factor immunoreactivity is widely distributed within the central nervous system of the rat: An immunhistochemical study. J.Neurosci. 3:1355-1368.

Davis M (1992) The role of the amygdala in fear and anxiety. Ann.Rev.Neurosci. 15:35375.

Dawe S, Gerada C, Russel MAH, and Gray JA (1995) Nicotine intake in smokers increases following a single dose of haloperidol. Psychopharmacology 117:110115 .

De SouzaEB (1987) Corticotrophin-releasing factor receptors in the rat central nervous system: Characterization and regional distribution. J.Neurosci. 7:88-100.

De Souza EB, Insel TR, Perrin MH, Rivier J, Vale W, and Kuhar MJ (1985)

Corticotropin-releasing factor receptors are widely distributed within the rat central nervous system: an autoradiographic study. J.Neurosci. 5:3189-3203.

De Souza EB (1995) Corticotropin-releasing factor receptors: physiology, pharmacology, biochemistry and role in central nervous system and immune disorders. Psychoneuroendocrinology 20:789-819.

De Souza EB, Insel TR, Perrin MH, Rivier J, Vale WW, and Kuhar MJ (1985) Differential regulation of corticotropin-releasing factor receptors in anterior and intermediate lobes of pituitary and in brain following adrenalectomy in rats. Neurosci.Lett. 56:121-128.

De Souza EB, Whitehouse PJ, Kuhar MJ, Price DL, and Vale WW (1986) Reciprocal changes in corticosterone-releasing factor (CRF)-like immunoreactivity and CRF receptors in cerebral cortex of Alzheimer's disease. Nature 319:593-595. 
Dessirier J-M, O'Mahony M, Sieffermann J-M, and Carstens E (1998) Mecamylamine inhibits nicotine but not capsaicin irritation on the tongue: psychophysical evidence that nicotine and capsaicin activate separate molecular receptors. Neurosci.Lett. 240:65-68.

Dieterich KD, Lehnert H, and De Souza EB (1997) Corticotropin-releasing factor receptors: An overview. Exp.Clin.Endocrinol.Diabetes 105:65-82.

Donnerer J and Lembeck F (1990) Different control of the adrenocorticotropincorticosterone response and of prolactin secretion during cold stress, anesthesia, surgery, and nicotine injection in the rat: involvement of capsaicin-sensitive sensory neurons. Endocrinology 126:921-926.

Donny EC, Caggiula AR, Mielke MM, Jacobs KS, Rose C, and Sved AF (1998) Acquisition of nicotine self-administration in rats: the effects of dose, feeding schedule, and drug contingency. Psychopharmacology (Berl) 136:83-90.

Dunn AJ and Berridge CW (1987) Corticotropin-releasing factor administration elicits a stress-like activation of cerebral catecholaminergic systems. Pharmacol.Biochem.Behav. 27:685-691.

Dunn AJ and Berridge CW (1990) Is corticotropin-releasing factor a mediator of stress responses? Ann.N.Y.Acad.Sci. 579:183-191.

Dunn AJ and Berridge CW (1990) Physiological and behavioral responses to corticotropin- releasing factor administration: Is CRF a mediator of anxiety or stress responses? Brain Res.Rev. 15:71-100.

Egan TM and North RA (1986) Actions of acetylcholine and nicotine on rat locus coeruleus neurons in vitro. Neuroscience 19:565-571.

Fallon JH and Ciofi P (1992) Distribution of monoamines within the amygdala. In: The Amygdala Neurobiological aspects of emotion, memory, and mental dysfunction (Aggleton JP ed), pp 97-114. New York, NY: Wiley-Liss.

Fanselow MS and Kim JJ (1994) Acquisition of contextual Pavlovian fear conditioning is blocked by application of an NMDA receptor antagonist D, L-2-amino-5phosphonovaleric acid to the basolateral amygdala. Behav.Neurosci. 108:210-212.

Farb C, Aoki C, Milner T, Kaneko T, and LeDoux J (1992) Glutamate immunoreactive terminals in the lateral amygdaloid nucleus: A possible substrate for emotional memory. Brain Res. 593:145-158.

Farb CR and LeDoux JE (1997) NMDA and AMPA receptors in the lateral nucleus of the amygdala are postsynaptic to auditory thalamic afferents. Synapse 27:106-121. 
Feldman S and Weidenfeld J (1996a) Involvement of amygdalar alpha adrenoceptors in hypothalamo-pituitary-adrenocortical responses. Neuroreport 7:3055-3057.

Feldman S and Weidenfeld J (1996b) Norepinephrine depletion in the amygdala inhibits CRF-41, ACTH, and corticosterone responses following photic simulation. Brain Res.Bull. 41:83-86.

Fergusson DM, Lynskey MT, and Horwood LJ (1996) Comorbidity between depressive disorders and nicotine dependence in a cohort of 16-year-olds. Arch.Gen.Psychiatry 53:1043-1047.

Fernandes C, McKittrick CR, File SE, and McEwen BS (1997) Decreased 5-HT ${ }_{1 \mathrm{~A}}$ and increased 5- $\mathrm{HT}_{2 \mathrm{~A}}$ receptor binding after chronic corticosterone associated with a behavioural indication of depression but not anxiety. Psychoneuroendocrinology 22:477-491.

Flores CM, Dávila-García MI, Ulrich YM, and Kellar KJ (1997) Differential regulation of neuronal nicotinic receptor binding sites following chronic nicotine administration. J.Neurochem. 69:2216-2219.

Flores CM, Rogers SW, Pabreza LA, Wolfe BB, and Keller KJ (1991) A subtype of nicotinic cholinergic receptor in rat brain is composed of $\alpha 4$ and $\beta 2$ subunits and is up-regulated by chronic nicotine treatment. Molec.Pharmacol. 41:31-37.

Flynn DD and Mash DC (1986) Characterization of L- $\left[{ }^{3} \mathrm{H}\right]$ nicotine binding in human cerebral cortex: comparison between Alzheimer's disease and the normal. J.Neurochem. 47:1948-1954

Frederick SL, Reus VI, Ginsberg D, Hall SM, Munoz RF, and Ellman G (1998) Cortisol and response to dexamethasone as predictors of withdrawal distress and abstinence success in smokers. Biol.Psychiatry 43:525-530.

Freund RK, Martin BJ, Jungschaffer DA, Ullman EA, and Collins AC (1988) Genetic differences in plasma corticosterone levels in response to nicotine injection. Pharmacol.Biochem.Behav. 30:1059-1064.

Fu YT, Matta SG, James TJ, and Sharp BM (1998) Nicotine-induced norepinephrine release in the rat amygdala and hippocampus is mediated through brainstem nicotinic cholinergic receptors. J.Pharmacol.Exp.Ther. 284:1188-1196.

Fu YT, Matta SG, Valentine JD, and Sharp BM (1997) Adrenocorticotropin response and nicotine-induced norepinephrine secretion in the rat paraventricular nucleus are mediated through brainstem receptors. Endocrinology 138:1935-1943. 
Furutani Y, Morimoto Y, Shibahara S, Noda M, Takahashi H, Hirose T, Asai M, Inayama S, Hayashida H, Miyata T, and Numa S (1983) Cloning and sequence analysis of cDNA for ovine corticotropin-releasing factor precursor. Nature 301:537-540.

Gabr RW, Birkle DL, and Azzaro AJ (1995) Stimulation of the amygdala by glutamate facilitates corticotropin-releasing factor release from the median eminence and activation of the hypothalamic-pituitary-adrenal axis in stressed rats. Neuroendocrinology 62:333-339.

Gallardo KA and Leslie FM (1998) Nicotine-stimulated release of $\left[{ }^{3} \mathrm{H}\right]$ norepinephrine from fetal rat locus coeruleus cells in culture. J.Neurochem. 70:663-670.

Galvez R, Mesches MH, and McGaugh JL (1996) Norepinephrine release in the amygdala in response to footshock stimulation. Neurobiol.Learn.Mem. 66:253-257.

Garris PA and Wightman RM (1994) Different kinetics govern dopaminergic transmission in the amygdala, prefrontal cortex, and striatum: An in vivo voltammetic study. J.Neurosci. 14:442-450.

Gean P-W and Chang F-C (1991) Bursting discharges in disinhibited amygdala slices: The role of excitatory amino acid receptors. Neuropharmacology 30:797-802.

Gean P-W and Chang F-C (1992) Pharmacological characterization of excitatory synaptic potentials in rat basolateral amygdaloid neurons. Synapse 11:1-9.

Gilbert DG, Estes SL, and Welser R (1997) Does noise stress modulate effects of smoking/nicotine? Mood, vigilance, and EEG responses. Psychopharmacology (Berl) 129:382-389.

Glick SD, Visker KE, and Maisonneuve IM (1996) An oral self-administration model of nicotine preference in rats: Effects of mecamylamine. Psychopharmacology (Berl) 128:426-431.

Goldstein LE, Rasmusson AM, Bunney BS, and Roth RH (1996) Role of the amygdala in the coordination of behavioral, neuroendocrine, and prefrontal cortical monoamine responses to psychological stress in the rat. J.Neurosci. 16:4787-4798.

Grady SR, Marks MJ, and Collins AC (1994) Desensitization of nicotine-stimulated $\left[{ }^{3} \mathrm{H}\right]$ Dopamine release from mouse striatal synaptosomes. J.Neurochem. 62:13901398.

Graeff FG, Guimaraes FS, De Andrade TGCS, and Deakin JFW (1996) Role of 5-HT in stress, anxiety, and depression. Pharmacol.Biochem.Behav. 54:129-141. 
Gray R, Rajan AS, Radcliffe KA, Yakehiro M, and Dani JA (1996) Hippocampal synaptic transmission enhanced by low concentrations of nicotine. Nature 383:713-716.

Gray TS (1992) Autonomic neuropeptide connections of the amygdala. In: Neuropeptides and Stress (Tache Y, Morley JE, Brown MR eds), pp 92-106. San Diego: Academic Press, Inc.

Gray TS (1993) Amygdaloid CRF pathways. Role in autonomic, neuroendocrine, and behavioral responses to stress. Ann.NY Acad.Sci. 697:53-60.

Gray TS and Bingaman EW (1996) The amygdala: corticotropin-releasing factor, steroids, and stress. Crit.Rev.Neurobio. 10:155-168.

Gray TS, Carney ME, and Magnuson DJ (1989) Direct projections from the central amygdaloid nucleus to the hypothalamic paraventricular nucleus: possible role in stress-induced adrenocorticotropin release. Neuroendocrinology 50:4433-4436

Gray TS and Magnuson DJ (1987) Neuropeptide neuronal efferents from the bed nucleus of the stria terminalis and central amygdaloid nucleus to the dorsal vagal complex in the rat. J.Comp.Neurol. 262:365-374.

Gray TS and Magnuson DJ (1992) Peptide immunoreactive neurons in the amygdala and the bed nucleus of the stria terminalis project to the midbrain central gray in the rat. Peptides 13:451-460.

Grunberg NE, Bowen DJ, and Morse DE (1984) Effects of nicotine on body weight and food consumption in rats. Psychopharmacology 83:93-98.

Grunberg NE, Popp KA, Bowen DJ, Nespor SM, Winders SE, and Eury SE (1988) Effects of chronic nicotine administration on insulin, glucose, epinephrine, and norepinephrine. Life Sci. 42:161-170.

Haines DE (1991) Neuroanatomy: An atlas of structures, sections and systems. Baltimore, Philadelphia: Willams and Wilkins.

Hakan RL and Ksir C (1991) Acute tolerance to the locomotor stimulant effects of nicotine in the rat. Psychopharmacology 104:386-390.

Hall GH and Morrison CF (1973) New evidence for a relationship between tobacco smoking, nicotine dependence and stress. Nature 243:199-201.

Harrigan EA, Magnuson DJ, Thunstedt GM, and Gray TS (1994) Corticotropin releasing factor neurons are innervated by calcitonin gene-related peptide terminals in the rat central amygdaloid nucleus. Brain Res.Bull. 33:529-534. 
Harrison NL and Simmonds MA (1984) Modulation of GABA receptor by steroid anaesthetics. Brain Res. 323:287-292.

Hauger RL, Irwin MR, Lorang M, Aguilera G, and Brown MR (1993) High intracerebral levels of CRH result in CRH receptor downregulation in the amygdala and neuroimmune desensitization. Brain Res. 616:283-292.

Hauger RL, Millan MA, Lorang M, Harwood JP, and Aguilera G (1988) Corticotropinreleasing factor receptors and pituitary adrenal responses during immobilization stress. Endocrinology 123:396-405.

Heckers S and Mesulam M-M (1994) Two types of cholinergic projections to the rat amygdala. Neuroscience 60:383-397.

Heilig M, Koob GF, Ekman R, and Britton KT (1994) Corticotropin-releasing factor and neuropeptide Y: Role in emotional integration. Trends Neurosci. 17:80-85.

Heinrichs SC, Klaassen A, Koob GF, Schulteis G, Ahmed S, and De Souza EB (1998) Corticotropin-releasing factor receptor blockade enhances conditioned aversive properties of cocaine in rats. Psychopharmacology (Berl) 136:247-255.

Heinrichs SC, Lapsansky J, Behan DP, Chan RKW, Sawchenko PE, Lorang M, Ling N, Vale WW, and De Souza EB (1996) Corticotropin-releasing factor-binding protein ligand inhibitor blunts excessive weight gain in genetically obese Zucker rats and rats during nicotine withdrawal. Proc.Natl.Acad.Sci.USA 93:15475-15480.

Hellendall RP, Godfrey DA, Ross CD, Armstrong DM, and Price JL (1986) The distribution of choline acetyltransferase in the rat amygdaloid complex and adjacent cortical areas, as determined by quantitative micro-assay and immunohistochemistry. J.Comp.Neur. 249:486-498.

Helmstetter FJ and Bellgowan PS (1993) Lesions of the amygdala block conditional hypoalgesia on the tail flick test. Brain Res. 612:253-257.

Helton DR, Modlin DL, Tizzano JP, and Rasmussen K (1993) Nicotine withdrawal: a behavioral assessment using schedule controlled responding, locomotor activity, and sensorimotor reactivity. Psychopharmacology 113:205-210.

Henke PG (1983) Unit-activity in the central amygdalar nucleus of rats in response to immobilization-stress. Brain Res.Bull. 10:833-837.

Herman JP, Schafer MKH, Thompson RC, and Watson SJ (1992) Rapid regulation of corticotropin-releasing hormone gene transcription in vivo. Mol.Endocrinol. 6:1061-1069. 
Hildebrand BE, Nomikos GG, Bondjers C, Nisell M, and Svensson TH (1997) Behavioral manifestations of the nicotine abstinence syndrome in the rat: Peripheral versus central mechanisms. Psychopharmacology (Berl) 129:348-356.

Honkaniemi J, Fuxe K, Rechardt L, Koistinaho J, Isola J, Gustafsson J-Å, Okret S, and Pelto-Huikko M (1992a) Colocalization of Fos- and glucocorticoid receptor-like immunoreactivities in the rat amygdaloid complex after immobilization stress. J.Neuroendocrinol. 4:547-555.

Honkaniemi J, Pelto-Huikko M, Rechardt L, Isola J, Lammi A, Fuxe K, Gustafsson J-Å, Wikström A-C, and Hökfelt T (1992b) Colocalization of peptide and glucocorticoid receptor immunoreactivities in rat central amygdaloid nucleus. Neuroendocrinology 55:451-459.

Hu S-B, Tannahill LA, Biswas S, and Lightman SL (1992) Release of corticotrophinreleasing factor-41, arginine, vasopressin and oxytocin from rat fetal hypothalamic cells in culture: Response to activation of intracellular second messengers and to corticosteroids. J.Endocrinol. 132:57-65.

Huang CC, Hsu KS, and Gean PW (1996) Isoproterenol potentiates synaptic transmission primarily by enhancing presynaptic calcium influx via $\mathrm{P}$ - and/or $\mathrm{Q}$ - type calcium channels in the rat amygdala. J.Neurosci. 16:1026-1033.

Hurt RD, Sachs DPL, Glover ED, Offord KP, Johnston JA, Dale LC, et al (1997) a comparison of sustained-release bupropion and placebo for smoking cessation. N. Engl. J. Med. 337:1195-1202

Ida Y, Tanaka M, Tsuda A, Kohno Y, Hoaki Y, Nakagawa R, Iimori K, and Nagasaki N (1984) Recovery of stress-induced increases in noradrenaline turnover is delayed in specific brain regions of old rats. Life Sci. 34:2357-2363.

Imperato A, Mulas A, and Di Chiara G (1986) Nicotine stimulates dopamine release in the limbic system of freely moving rats. Eur.J.Pharmacol. 132:337-338.

Isaac PF and Rand MJ (1972) Cigarette smoking and plasma levels of nicotine. Nature 236:308-310.

Izenwasser S, Jacocks HM, Rosenberger JG, and Cox BM (1991) Nicotine indirectly inhibits $\left[{ }^{3} \mathrm{H}\right]$ Dopamine uptake at concentrations that do not directly promote $\left[{ }^{3} \mathrm{H}\right]$ Dopamine release in rat striatum. J.Neurochem. 56:603-610.

Jadresic D (1992) The role of the amygdaloid complex in Gilles de la Tourette's syndrome. Br.J.Psychiatry 161:532-534. 
Joanny P, Steinberg J, Zamora AJ, Conte-Devolx B, Millet Y, and Oliver C (1989) Corticotropin-releasing factor release from in vitro superfused and incubated rat hypothalamus. Effect of potassium, norepinephrine, and dopamine. Peptides 10:903-911.

Johnson DH, Svensson AI, Engel JA, and Soderpalm B (1995) Induction but not expression of behavioural sensitization to nicotine in the rat is dependent on glucocorticoids. Eur.J.Pharmacol. 276:155-164.

Jones GMM, Sahakian BJ, Levy R, Warburton DM, and Gray JA (1992) Effects of acute subcutaneous nicotine on attention, information processing and short-term memory in Alzheimer's disease. Psychopharmacology 108:485-494.

Jones RT (1987) Tobacco Dependence. In: Psychopharmacology: The Third Generation of Progress (Meltzer HY ed), pp 1589-1595. New York: Raven Press.

Joseph MH, Peters SL, Prior A, Mitchell SN, razell MP, and ray JA (1990) Chronic nicotine administration increases tyrosine hydroxylase selectivity in the rat hippocampus. Neurochem.Int. 16:269-273.

Junien JL and Gue M (1993) Interaction between neuropeptide $Y$ and sigma ligands in the modulation of CRF and stress-induced alteration of gastrointestinal function. Ann.N.Y.Acad.Sci. 697:244-253.

Kalin NH, Takahashi LK, and Chen F-L (1994) Restraint stress increases corticotropinreleasing hormone mRNA content in the amygdala and paraventricular nucleus. Brain Res. 656:182-186.

Kandel ER (1991) Cellular mechanisms of learning and memory. In: Principles of Neural Science (Kandel ER, Schwartz JH, Jessell TM eds), pp 1009-1031. Norwalk: Appleton \& Lange.

Kandel ER (1991) Disorders of mood: Depression, mania and anxiety disorders. In: Principles of Neural Science (Kandel ER, Schwartz JH, Jessell TM eds), pp 869883. Norwalk: Appleton \& Lange.

Kasckow JW, Regmi A, Gill PS, Parkes DG, and Geracioti TD (1997) Regulation of corticotropin-releasing factor (CRF) messenger ribonucleic acid and CRF peptide in the amygdala: Studies in primary amygdalar cultures. Endocrinology 138:4774-4782.

Kawahara H, Yoshida M, Yokoo H, Nishi M, and Tanaka M (1993) Psychological stress increases serotonin release in the rat amygdala and prefrontal cortex assessed by in vivo microdialysis. Neurosci.Lett. 162:81-84. 
Kellar KJ, Whitehouse PJ, Martino-Barrows AM, Marcus K, and Price DL (1987) Muscarinic and nicotinic cholinergic binding sites in Alzheimer's disease cerebral cortex. Brain Res.436:62-68.

Kendall DA, McEwen BS, and Enna SJ (1982) The influence of ACTH and corticosterone on $\left[{ }^{3} \mathrm{H}\right] \mathrm{GABA}$ receptor binding in rat brain. Brain Res. 236:365-374.

Kidd, Lamporte AM, Langlois X, Fattaccini C-M, Doyen C, Lombard MC, Gozlan H, and Hamon M (1993) 5- $\mathrm{HT}_{3}$ receptors in the rat central nervous system are mainly located on nerve fibres and terminals. Brain Res. 612:289-298.

Kirch DG, Gerhardt GA, Shelton RC, Freedman R, and Wyatt RJ (1987) Effect of chronic nicotine administration on monoamine and monoamine metabolite concentrations in rat brain. Clin.Neuropharmacol. 10:376-383.

Koch B and Lutz-Bucher B (1991) Inhibition of protein kinase C activity in cultured pituitary cells attenuates both cyclic AMP-independent and -dependent secretion of ACTH. Mol.Cell.Endocrinol. 77:57-65.

Koegler-Muly SM, Owens MJ, Ervin GN, Kilts CD, and Nemeroff CB (1993) Potential corticotropin-releasing factor pathways in the rat brain as determined by bilateral electrolytic lesions of the central amygdaloid nucleus and the paraventricular nucleus of the hypothalamus. J.Neuroendocrinol. 5:95-98.

Koob GF and Bloom FE (1985) Corticotropin releasing factor and behavior. Fed.Proc. 44:259-263.

Koob GF, Heinrichs SC, Pich EM, Menzaghi F, Baldwin H, Miczek K, and Britton KT (1992) The role of corticotropin-releasing factor in behavioural responses to stress. In: Corticotropin-releasing factor (Chadwick DJ, Marsh J, Ackrill K eds), pp 277295. New York, NY: John Wiley and Sons.

Ksir C, Hakan RL, and Kellar KJ (1987) Chronic nicotine and locomotor activity: influences of exposure dose and test dose. Psychopharmacology 92:25-29.

Kumari V, Checkley SA, and Gray JA (1996) Effect of cigarette smoking on prepulse inhibition of the acoustic startle reflex in healthy male smokers. Psychopharmacology (Berl) 128:54-60.

Kupfermann I (1991) Hypothalamus and Limbic System: Peptidergic Neurons, Homeostasis, and Emotional Behavior. In: Principles of Neural Science (Kandel ER, Schwartz JH, Jessell TM eds), pp 735-749. New York: Elsevier. 
Larsen PJ, Jessop D, Patel H, Lightman SL, and Chowdrey HS (1993) Substance P inhibits the release of anterior pituitary adrenocorticotrophin via a central mechanism involving corticotrophin-releasing factor-containing neurons in the hypothalamic paraventricular nucleus. J.Neuroendocrinol. 5:99-105.

Le Feuvre RA, Aisenthal L, and Rothwell NJ (1991) Involvement of corticotrophin releasing factor $(\mathrm{CRF})$ in the thermogenic and anorexic actions of serotonin $(5-\mathrm{HT})$ and related compounds. Brain Res. 555:245-250.

Leal AMO and Moreira AC (1996) Feeding and the diurnal variation of the hypothalamicpituitary-adrenal axis and its responses to $\mathrm{CRH}$ and $\mathrm{ACTH}$ in rats. Neuroendocrinology 64:14-19.

Levin ED (1992) Nicotine systems and cognitive function. Psychopharmacology 108:417-431.

Levin ED, Briggs SJ, Christopher NC, and Rose JE (1992) Persistence of chronic nicotineinduced facilitation. Behav.Neural Biol. 58:152-158.

Li XF, Phillips R, and LeDoux JE (1995) NMDA and non-NMDA receptors contribute to synaptic transmission between the medial geniculate body and the lateral nucleus of the amygdala. Exp.Brain Res. 105:87-100.

Liang HC and Lee EHY (1988) Intra-amygdala injections of corticotropin-releasing factor facilitate inhibitory avoidance learning and reduce exploratory behavior in rats. Psychopharmacology 96:232-236.

Liang KC, Hon W, and Davis M (1994) Pre- and posttraining infusion of $N$-methyl-Daspartate receptor antagonists into the amygdala impair memory in an inhibitory avoidance task. Behav.Neurosci. 108:241-253.

Liang KC, Melia KR, Campeau S, Falls WA, Miserendino MJD, and Davis M (1992a) Lesions of the central nucleus of the amygdala, but not the paraventricular nucleus of the hypothalamus, block the excitatory effects of corticotropin-releasing factor on the acoustic startle reflex. J.Neurosci. 12:2313-2320.

Liang KC, Melia KR, Miserendino MJD, Falls WA, Campeau S, and Davis M (1992b) Corticotropin-releasing factor: Long-lasting facilitation of the acoustic startle reflex. J.Neurosci. 12:2303-2312.

Lightman SL and Harbuz MS (1993) Expression of corticotropin-releasing factor mRNA in response to stress. In: Corticotropin-Releasing Factor (Ciba Foundation Symposium 172) (Chadwick DJ, Marsh J, Ackrill K eds), pp 173-198. Chichester: Wiley. 
Lightman SL, Harbuz MS, Knight RA, and Chowdrey HS (1993) CRF mRNA in normal and stress conditions. Ann.NY Acad.Sci. 697:28-38.

Lovenberg TW, Chalmers DT, Liu CG, and De Souza EB (1995) $\mathrm{CRF}_{2} \alpha$ and $\mathrm{CRF}_{2} \beta$ receptor mRNAs are differentially distributed between the rat central nervous system and peripheral tissues. Endocrinology 136:4139-4142.

Lowry OH, Rosenbrough NJ, Farr AL, and Randall RJ (1951) Protein measurement with the Folin phenol reagent. J.Biol.Chem. 193:265-275.

Luetje CW and Patrick J (1991) Both $\alpha$ - and $\beta$-subunits contribute to the agonist sensitivity of neuronal nicotinic acetylcholine receptors. J.Neurosci. 11:837-845.

Lukas RJ (1995) Diversity and patterns of regulation of nicotinic receptor subtypes. Ann.N.Y.Acad.Sci. 757:153-168.

Majewska MD, Bisserbe J-C, and Eskay RL (1985) Glucocorticoids are modulators of $\mathrm{GABA}_{\mathrm{A}}$ receptors in brain. Brain Res. 339:178-182.

Makino S, Gold PW, and Schulkin J (1994) Corticosterone effects on corticotropinreleasing hormone mRNA in the central nucleus of the amygdala and the parvocellular region of the paraventricular nucleus of the hypothalamus. Brain Res. 640:105-112.

Makino S, Schulkin J, Smith MA, Pacák K, Palkovits M, and Gold PW (1995) Regulation of corticotropin-releasing hormone receptor messenger ribonucleic acid in the rat brain and pituitary by glucocorticoids and stress. Endocrinology 136:4517-4525.

Malin DH, Lake JR, Carter VA, Cunningham JS, Hebert KM, Conrad DL, and Wilson OB (1994) The nicotinic antagonist mecamylamine precipitates nicotine abstinence syndrome in the rat. Psychopharmacology 115:180-184.

Malin DH, Lake JR, Schopen CK, Kirk JW, Sailer EE, Lawless BA, Upchurch TP, Shenoi M, and Rajan N (1997) Nicotine abstinence syndrome precipitated by central but not peripheral hexamethonium. Pharmacol.Biochem.Behav. 58:695-699.

Mamalaki E, Kvetnansky R, Brady LS, Gold PW, and Herkenham M (1992) Repeated immobilization stress alters tyrosine hydroxylase, corticotropin-releasing hormone and corticosteroid receptor messenger ribonucleic acid levels in rat brain. J.Neuroendocrinol. 4:689-699.

Maren S (1996) Synaptic transmission and plasticity in the amygdala. Mol.Neurobiol. 13:1-22. 
Maren S, Aharonov G, and Fanselow MS (1996) Retrograde abolition of conditional fear after excitotoxic lesions in the basolateral amygdala of rats: Absence of a temporal gradient. Behav.Neurosci. 110:718-726.

Maren S, Aharonov G, Stote DL, and Fanselow MS (1996) $N$-methyl-D-aspartate receptors in the basolateral amygdala are required for both acquisition and expression of conditional fear in rats. Behav.Neurosci. 110:1365-1374.

Maren S and Fanselow MS (1995) Synaptic plasticity in the basolateral amygdala induced by hippocampal formation stimulation in vivo. J.Neurosci. 15:7548-7564.

Maren S and Fanselow MS (1996) The amygdala and fear conditioning: Has the nut been cracked? Neuron 16:237-240.

Markou A, Kosten TR, and Koob GF (1998) Neurobiological similarities in depression and drug dependence: A self-medication hypothesis. Neuropsychopharmacology 18:135-174.

Marks MJ, Burch JB, and Collins AC (1983) Effects of chronic nicotine infusion on tolerance development and nicotinic receptors. J.Pharmacol.Exp.Therap. 226:817825.

Marks MJ, Romm E, Bealer SM, and Collins AC (1985) A test battery for measuring nicotine effects in mice. Pharmacol.Biochem.Behav. 23:325-330.

Marshall DL, Redfern PH, and Wonnacott S (1997) Presynaptic nicotinic modulation of dopamine release in the three ascending pathways studied by in vivo microdialysis: Comparison of naive and chronic nicotine-treated rats. J.Neurochem. 68:15111519.

Matta SG, Foster CA, and Sharp BM (1993a) Nicotine stimulates the expression of cFos protein in the paravocellular paraventricular nucleus and brainstem catecholaminergic regions. Endocrinology 132:2149-2156.

Matta SG, Foster CA, and Sharp BM (1993b) Selective administration of nicotine into catecholaminergic regions of rat brainstem stimulates adrenocorticotropin secretion. Endocrinology 133:2935-2942.

Matta SG, Valentine JD, and Sharp BM (1997) Nicotinic activation of CRH neurons in extrahypothalamic regions of the rat brain. Endocrine 7:245-253.

McDonald AJ (1996) Glutamate and aspartate immunoreactive neurons of the rat basolateral amygdala: Colocalization of excitatory amino acids and projections to the limbic circuit. J.Comp.Neurol. 365:367-379. 
McDonough JT (1994) Stedman's Consice Medical Dictionary, Illustrated, p 695. Baltimore, Philadelphia: Willams and Wilkins.

McGaugh JL, Cahill L, and Roozendaal B (1996) Involvement of the amygdala in memory storage: Interaction with other brain systems. Proc.Natl.Acad.Sci.USA 93:1350813514.

McGehee DS and Role LW (1995) Physiological diversity of nicotinic acetylcholine receptors expressed by vertebrate neurons. Ann.Rev.Physiol. 57:521-546.

McGehee DS and Role LW (1996) Neurobiology - Memories of nicotine. Nature 383:670-671.

Meister B (1993) Gene expression and chemical diversity in hypothalamic neurosecretory neurons. Mol.Neurobiol. 7:87-110.

Mello LEAM, Tan AM, and Finch DM (1992) GABAergic synaptic transmission in projections from the basal forebrain and hippocampal formation to the amygdala: an in vivo iontophoretic study. Brain Res. 587:41-48.

Mereu G, Yoon K-WP, Boi C, Gessa GL, Naes L, and Westfall TC (1987) Preferential stimulation of ventral tegmental area dopaminergic neurons by nicotine. Eur.J.Pharmacol. 141:395-399.

Mifsud J-C, Hernandez L, and Hoebel BG (1989) Nicotine infused into the nucleus accumbens increases synaptic dopamine as measured by in vivo microdialysis. Brain Res. 478:365-367.

Mitchell SN (1993) Role of the locus coeruleus in the noradrenergic response to a systemic administration of nicotine. Neuropharmacology 32:937-949.

Moga MM and Gray TS (1985) Evidence for corticotropin-releasing factor, neurotensin, and somatostatin in the neural pathway from the central nucleus of the amygdala to the parabrachial nucleus. J.Comp.Neurol. 241:275-284.

Monji N and Castro A (1979) Plasma nicotine pharmacokinetics in dogs after intravenous administration: determination by radioimmunoassay.

Res.Comm.Chem.Pathol.Pharmacol. 23:267-77.

Monnikes H, Schmidt BG, Raybould HE, and TAche Y (1992) CRF in the paraventricular nucleus mediates gastric and colonic motor response to restraint stress. Amer.J.Physiol. 262:G137-G143

Morgan WW and Pfeil KA (1979) Mecamylamine blockade of nicotine enhanced noradrenaline turnover in rat brain. Life Sci. 24:417-420. 
Morris RGM, Anderson E, Lynch GS, and Baudry M (1986) Selective impairment of learning and blockade of long-term potentiation by an N-methyl-D-aspartate receptor antagonist, AP5. Nature 319:774-776.

Murakami K, Hashimoto K, and Ota Z (1985) Calmodulin inhibitors decrease the CRFand AVP-induced ACTH release in vitro: Interaction of Calcium-Calmodulin and the cyclic AMP system. Neuroendocrinology 41:7-12.

Mycek MJ, Gertner SB, and Perper MM (1992) Lippincott's illustrated reviews: Pharmacology. pp 25-44. Philadelphia: J.B. Lippincott Company.

Nemeroff CB, Bissette G, Akil H, and Fink M (1991) Neuropeptide concentrations in the cerebrospinal fluid of depressed patients treated with electroconvulsive therapy. Corticotrophin-releasing factor, $\beta$-endorphin and somatostatin. Br.J.Psychiatry 158:59-63.

Nemeroff CB, Owens MJ, Bissette G, Andorn AN, and Stanley M (1988) Reduced corticosterone releasing factor binding sites in the frontal cortex of suicide victims. Arch.Gen.Psychiatry 45:577-579.

Niehoff DL and Kuhar MJ (1983) Benzodiazepine receptors: Localization in rat amygdala. J.Neurosci. 3:2091-2097.

Nisell M, omikos GG, and vensson TH (1994) Infusion of nicotine in the ventral tegmental area or the nucleus accumbens of the rat differentially affects accumbal dopamine release. Pharmacol.Toxicol. 75:348-352.

Nordberg A, Romanelli L, Sundwall A, Bianchi C, and Beani L (1989) Effect of acute and subchronic nicotine treatment on cortical acetylcholine release and on nicotinic receptors in rats and guimea pigs. Brit.J.Pharmacol. 98:71-78.

Okuda H, Shioda S, Nakai Y, Nakayama H, Okamoto M, and Nakashima T (1993) The presence of corticotropin-releasing factor-like immunoreactive synaptic vesicles in axon terminals with nicotinic acetylcholine receptor-like immunoreactivity in the median eminence of the rat. Neurosci.Lett. 161:183-186.

Olianas MC and Onali P (1995) G protein-coupled corticotropin-releasing hormone receptors in rat retina. Regul.Pept. 56:61-70.

Owens MJ, Bartolome J, Schanberg SM, and Nemeroff CB (1990) CorticotropinReleasing Factor concentrations exhibit an apparent diurnal rhythm in hypothalamic and extrahypothalamic brain regions: differential sensitivity to corticosterone. Neuroendocrinology 52:626-631. 
Owens MJ, Bissette G, and Nemeroff CB (1989) Acute effects of alprazolam and adinazolam on the concentrations of corticotropin-releasing factor in the rat brain. Synapse 4:196-202.

Owens MJ and Nemeroff CB (1991) Physiology and pharmacology of corticotropin releasing factor. Pharmacol.Rev. 43:425-473.

Owens MJ and Nemeroff CB (1993) The role of corticotropin-releasing factor in the pathophysiology of affective and anxiety disorders: laboratory and clinical studies. In: Corticotropin Releasing Factor: Ciba Foundation Symposium 172 (Chadwick DJ, Marsh J, Ackrill K eds), pp 296-316. Chichester: John Wiley \& Sons.

Owens MJ, Overstreet DH, Knight DL, Rezvani AH, Ritchie JC, Bissette G, Janowsky DS, and Nemeroff CB (1991) Alterations in the hypothalamic-pituitary-adrenal axis in a proposed animal model of depression with genetic muscarinic supersensitivity. Neuropsychopharmacology 4:87-93.

Palkovits M, Brownstein MJ, and Vale W (1985) Distribution of corticotropin-releasing factor in rat brain. Fed.Proc. 44:215-219.

Palma E and Brownstein MJ (1985) Microdissection of brain areas by punch techniques. In:Brain Microdissection Techniques (Cuello,AC Volume 2:1-36 John Wiley \& Sons New York.

Papke RL, Boulter J, Patrick J, and Heinmann S (1989) Single-channel currents of rat neuronal nicotinic acetylcholine receptors expressed in Xenopus Oocytes. Neuron 3:589-596.

Pauly JR, Grun EU, and Collins AC (1990) Chronic corticosterone administration modulates nicotine sensitivity and brain nicotinic receptor binding in $\mathrm{C} 3 \mathrm{H}$ mice. Psychopharmacology 101:310-316.

Pauly JR, Grun EU, and Collins AC (1992) Tolerance to nicotine following chronic treatment by injections: a potential role for corticosterone. Psychopharmacology 108:33-39.

Pauly JR, Ullman EA, and Collins AC (1988) Adrenocortical hormone regulation of nicotine sensitivity in mice. Physiol.Behav. 44:109-116.

Paxinos G and Watson C (1986) The rat brain in sterotaxic coordinates. New York: Academic Press.

Petrov T, Krukoff TL, and Jhamandas JH (1994) Chemically defined collateral projections from the pons to the central nucleus of the amygdala and hypothalamic paraventricular nucleus in the rat. Cell Tissue Res. 277:289-295. 
Picciotto MR, Zoli M, Rimondini R, Lena C, Marubio LM, Pich EM, Fuxe K, and Changeux JP (1998) Acetylcholine receptors containing the beta2 subunit are involved in the reinforcing properties of nicotine. Nature 391:173-177.

Pietilä K, Salminen O, Leikola-Pelho T, and Ahtee L (1996) Tolerance to nicotine's effects on striatal dopamine metabolism in nicotine-withdrawn mice. Eur.J.Pharmacol. 318:17-22.

Plotsky PM (1988) Regulation of corticotrophin releasing factor secretion. Prog.Endocrinol. 891-896.

Pomeranz Y and Meloan CE (1987) Food Analysis, Theory and Practice, pp 759-760. N.Y.: Van Nostrand Reinhold company.

Pomerleau CS and Pomerleau OF (1987) The effects of a psychological stressor on cigarette smoking and subsequent behavioral and physiological responses. Psychophysiology 24:278-285

Potter E, Behan DP, Linton EA, Lowry PJ, Sawchenko PE, and Vale WW (1992) The central distribution of a corticotropin-releasing factor (CRF)-binding protein predicts multiple sites and modes of interaction with CRF.

Proc.Natl.Acad.Sci.USA 89:4192-4196.

Prendergast MA, Terry AV, Jr., Jackson WJ, Marsh KC, Decker MW, Arneric SP, and Buccafusco JJ (1997) Improvement in accuracy of delayed recall in aged and nonaged, mature monkeys after intramuscular or transdermal administration of the CNS nicotinic receptor agonist ABT- 418. Psychopharmacology (Berl) 130:276284.

Raber J, Koob GF, and Bloom FE (1995) Interleukin-2 (IL-2) induces corticotropinreleasing factor (CRF) release from the amygdala and involves a nitric oxidemediated signaling: Comparison with the hypothalamic response.

J.Pharmacol.Exp.Ther. 272:815-824.

Rainnie DG, Asprodini EK, and Shinnick-Gallagher P (1991b) Excitatory transmission in the basolateral amygdala. J.Neurophysiol. 66:986-998.

Rainnie DG, Asprodini EK, and Shinnick-Gallagher P (1991a) Inhibitory transmission in the basolateral amygdala. J.Neurophysiol. 66:999-1009.

Rainnie DG, Fernhout BJH, and Shinnick-Gallagher P (1992) Differential actions of corticotropin releasing factor on basolateral and central amygdaloid neurones, in vitro. J.Pharmacol.Exp.Ther. 263:846-858. 
Rainnie DG, Holmes KH, and Shinnick-Gallagher P (1994) Activation of postsynaptic metabotropic glutamate receptors by trans-ACPD hyperpolarizes neurons of the basolateral amygdala. J.Neurosci. 14:7208-7220.

Rapier C, Lunt GG, and Wonnacott S (1988) Stereoselective nicotine-induced release of dopamine from striatal synaptosomes: concentration dependence and repetitive stimulation. J.Neurochem. 50:1123-1130.

Rapier C, Lunt GG, and Wonnacott S (1990) Nicotinic modulation of [ ${ }^{3} \mathrm{H}$ ]Dopamine release from striatal synaptosomes: pharmacological characterisation. J.Neurochem. 54:937-945.

Rasmussen K and Czachura JF (1997) Nicotine withdrawal leads to increased sensitivity of serotonergic neurons to the 5- $\mathrm{HT}_{1 \mathrm{~A}}$ agonist 8-OH-DPAT. Psychopharmacology (Berl) 133:343-346.

Rasmussen K, Kallman MJ, and Helton DR (1997) Serotonin-1A antagonists attenuate the effects of nicotine withdrawal on the auditory startle response. Synapse 27:145152.

Rassnick S, Heinrichs SC, Britton KT, and Koob GF (1993) Microinjection of a corticotropin-releasing factor antagonist into the central nucleus of the amygdala reverses anxiogenic- like effects of ethanol withdrawal. Brain Res. 605:25-32.

Ratka A, Sutanto W, Bloemers M, and De Kloet ER (1989) On the role of brain mineralocorticoid (Type I) and glucocorticoid (Type II) receptors in neuroendocrine regulation. Neuroendocrinology 50:117-123.

Rattner BA, Michael SD, and Altland PD (1980) Plasma concentrations of hypophyseal hormones and corticosterone in male mice actually exposed to simulated high altitude. Proc.Soc.Exp.Biol.Med. 163:367-371.

Reul JMHM and De Kloet ER (1985) Two receptor systems for corticosterone in rat brain: microdistribution and differential occupation. Endocrinology 117:2505-2511.

Rivier C, Brownstein M, Spiess J, Rivier J, and Vale W (1982) In vivo corticotropinreleasing factor-induced secretion of adrenocorticotropin, B-endorphin, and corticosterone. Endocrinology 110:272-278.

Rivier CL and Plotsky PM (1986) Mediation by corticotropin-releasing factor (CRF) of adenohypophyseal hormone secretion. Ann.Rev.Physiol. 48:475-494.

Rivier J, Rivier C, and Vale W (1984) Synthetic competitive antagonists of corticotropinreleasing factor: effects on ACTH secretion in the rat. Science 224:889-891. 
Roozendaal B, Koolhaas JM, and Bohus B (1993) The central amygdala is involved in conditioning but not in retention of active and passive shock avoidance in male rats. Behav.Neural Biol. 59:143-149.

Roozendaal B, Portillo-Marquez G, and McGaugh JL (1996) Basolateral amygdala lesions block glucocorticoid-induced modulation of memory for spatial learning. Behav.Neurosci. 110:1074-1083.

Roozendaal B, Quirarte GL, and McGaugh JL (1997) Stress-activated hormonal systems and the regulation of memory storage. Ann.NY Acad.Sci. 821:247-258.

Roozendaal B, Van der Zee EA, Hensbroek RA, Maat H, Luiten PGM, Koolhaas JM, and Bohus B (1997) Muscarinic acetylcholine receptor immunoreactivity in the amygdala .2. Fear-induced plasticity. Neuroscience 76:75-83.

Rose JE and Corrigall WA (1997) Nicotine self-administration in animals and humans: Similarities and differences. Psychopharmacology (Berl) 130:28-40.

Rowell PP (1995) Nanomolar concentrations of nicotine increase the release of $\left[{ }^{3} \mathrm{H}\right]$ dopamine from rat striatal synaptosomes. Neuroscience 189:171-175.

Rowell PP and Hillebrand JA (1994) Characterization of nicotine-induced desensitization of evoked dopamine release from rat striatal synaptosomes. J.Neurochem. 63:561569.

Rowell PP and Li M (1997) Dose-response relationship for nicotine-induced up-regulation of rat brain nicotinic receptors. J.Neurochem. 68:1982-1989.

Rubboli F, Court JA, Sala C, Morris C, Chini B, Perry E, and Clementi F (1994) Distribution of nicotinic receptors in the human hippocampus and thalamus. Eur.J.Neurosci. 6:1596-1604.

Sajdyk TJ and Shekhar A (1997) Excitatory amino acid receptors in the basolateral amygdala regulate anxiety responses in the social interaction test. Brain Res. 764:262-264.

Salminen O, Lahtinen S, and Ahtee L (1996) Expression of Fos protein in various rat brain areas following acute nicotine and diazepam. Pharmacol.Biochem.Behav. 54:241248.

Sanakana M, Shibasaki T, and Lederis K (1986) Distribution and efferent projections of corticotropin-releasing factor-like immunoreactivity in the rat amygdaloid complex. Brain Res. 382:213-238. 
Sapolsky RM, Armanini MP, Packan DR, Sutton SW, and Plotsky PM (1990)

Glucocorticoid feedback inhibition of adrenocorticotropic hormone secretagogue release. Neuroendocrinology 51:328-336.

Sastry BV, Chance MB, Singh G, Horn JL, and Janson VE (1995) Distribution and retention of nicotine and its metabolite, cotinine, in the rat as a function of time. Pharmacology 50:128-136.

Sawchenko PE and Swanson LW (1990) Organization of CRF immunoreactive cells and fibers in the rat brain: immunohistochemical studies. In: Corticotropin-releasing factor: basic and clinical studies of a neuropeptide (De Souza EB, Nemeroff CB eds), pp 29-51. Boca Raton, Florida: CRC Press.

Schmiterlöw CG, Hansson E, Andersson G, Appelgren L-E, and Hoffmann PC (1967) Distribution of nicotine in the central nervous system. Ann.N.Y.Acad.Sci. 142:214.

Schwartz JH and Kandel ER (1991) Synaptic transmission mediated by second messengers. In: Principles of Neural Science (Kandel ER, Schwartz JH, Jessell TM eds), pp 173-193. Norwalk: Appleton \& Lange.

Schwartz RD and Kellar KJ (1985) In vivo regulation of $\left[{ }^{3} \mathrm{H}\right]$ Acetylcholine recognition sites in brain by nicotinic cholinergic drugs. J.Neurochem. 45:427-433.

Schwartz RD and Keller KJ (1983) Nicotinic cholinergic receptor binding sites in the brain: regulation in vivo. Science 220:214-216.

Seguela P, Wadiche J, Dineley-Miller K, Dani JA, and Patrick JW (1993) Molecular cloning, functional properties, and distribution of rat brain $\alpha_{7}$ : a nicotinic cation channel highly permeable to calcium. J.Neurosci. 13:596-604.

Sershen H, Balla A, Lajtha A, and Vizi ES (1997) Characterization of nicotinic receptors involoved in the release of noradrenaline from the hippocampus. Neuroscience 77:121-130.

Sharp BM, Beyer HS, McAllen KM, Hart D, and Matta SG (1993) Induction and desensitization of the c-Fos mRNA response to nicotine in rat brain. Mol.Cell.Neuroci. 4:199-208.

Sharp BM and Matta SG (1993) Detection by in vivo microdialysis of nicotine-induced norepinephrine secretion from the hypothalamic paraventricular nucleus of freely moving rats: dose-dependency and desensitization. Endocrinology 133:11-19. 
Shimada S, Inagake S, Marita N, and Takagi H (1992) Synaptic contacts between CGRPimmunoreactive terminals and enkephalin-immunoreative neurons in the central amygdaloid nucleus of the rat. Neurosci.Lett. 134:243-246.

Shimada S, Inagaki S, Kubota Y, Kito S, Funaki H, and Takagi H (1989a) Light and electron microscopic studies of calcitonin gene-related peptide-like immunoreactive terminals in the central nucleus of the amygdala and the bed nucleus of the stria terminals of the rat. Exp.Brain Res. 77:217-220.

Shimada S, Inagaki S, Kubota Y, Ogawa N, Shibasaki T, and Takagi H (1989b) Coexistence of peptides (corticotropin releasing factor/neurotensin and substance $\mathrm{P} /$ Somatostatin) in the bed nucleus of the stria terminals and central amygdaloid nucleus of the rat. Neuroscience 30:377-383.

Shimada S, Shiosaka S, Emson PC, Hillyard CJ, Girgis S, MacIntyre I, and Tohyama M (1985) Calcitonin gene-related peptidergic projection from the parabrachial area to the forebrain and diencephalon in the rat: an immunohistochemical analysis. Neuroscience 16:607-616.

Shimizu K, Amagaya S, and Ogihara Y (1983) Analysis of corticosterone in the serum of mice and rats using high-performance liquid chromatography. J.Chrom. 272:170175.

Shinohara Y, Yamano M, Matsuzaki T, and Tohyama M (1988) Evidence for the coexistence of substance $\mathrm{P}$, neurotensin and calcitonin gene-related peptide in single neurons of the external subdivision of the lateral parabrachial nucleus of the rat. Brain Res.Bull. 20:257-260.

Shioda S, Nakajo S, Hirabayashi T, Nakayama H, Nakaya K, Matsuda K, and Nakai Y (1997) Neuronal nicotinic acetylcholine receptor in the hypothalamus: morphological diversity and neuroendocrine regulations. Mol.Brain Res. 49:4554.

Shoaib M, Benwell MEM, Akbar MT, Stolerman IP, and Balfour DJK (1994) Behavioural and neurochemical adaptions to nicotine in rats: influence of NMDA antagonist. Br.J.Pharmacol. 111:1073-80.

Shoaib M, Schindler CW, Goldberg SR, and Pauly JR (1997) Behavioural and biochemical adaptations to nicotine in rats: influence of MK801, an NMDA receptor antagonist. Psychopharmacology (Berl) 134:121-130.

Shoaib M and Stolerman IP (1992) MK801 attenuates behavioural adaptation to chronic nicotine administration in rats. Br.J.Pharmacol. 105:514-515. 
Skofitsch G and Jacobowitz DM (1985) Distribution of corticotropin releasing factor-like immunoreactivity in the rat brain by immunohistochemistry and radioimmunoassay: Comparison and characterization of ovine and rat/human CRF antisera. Peptides 6:319-336.

Smith KM, Mitchell SN, and Joseph MH (1991) Effects of chronic and subchronic nicotine on tyrosine hydroxylase activity in noradrenergic and dopaminergic neurones in the rat brain. J.Neurochem. 57:1750-1756.

Smith MA, Bissette G, Slotkin TA, Knight DL, and Nemeroff CB (1986) Release of corticotropin-releasing factor from rat brain regions in vitro. Endocrinology 118:1997-2001.

Steinbach JH and Ifune C (1989) How many kinds of nicotinic acetylcholine receptor are there? Trends Neurosci. 12:3-6.

Stenzel-Poore MP, Heinrichs SC, Rivest S, Koob GF, and Vale WW (1994) Overproduction of corticotropin-releasing factor in transgenic mice: A genetic model of anxiogenic behavior. J.Neurosci. 14:2579-2584.

Sugita S and North RA (1993) Opioid actions on neurons of rat lateral amygdala in vitro. Brain Res. 612:151-155.

Sugita S, Shen K-Z, and North RA (1992) 5-Hydroxytryptamine is a fast excitatory transmitter at 5-HT3 receptors in rat amygdala. Neuron 8:199-203.

Svensson TH and Engberg G (1980) Effect of nicotine on single cell activity in the noradrenergic nucleus locus coeruleus. Acta Physiol.Scand.Suppl 479:31-34.

Swanson LW, Sawchenko PE, Rivier J, and Vale W (1983) Organization of ovine corticotropin-releasing factor immunoreactive cells and fibers in the rat brain: An immunohistochemical study. Neuroendocrinology 36:165-186.

Swanson LW and Simmons DM (1989) Differential steroid hormone and neural influences on peptide mRNA levels in CRH cells of the paraventricular nucleus: a hybridization histochemical study in the rat. J.Comp.Neur 285:413-435.

Swiergiel AH, Takahashi LK, and Kalin NH (1993) Attenuation of stress-induced behavior by antagonism of corticotropin-releasing factor receptors in the central amygdala in the rat. Brain Res. 623:229-234.

Swiergiel AH, Takahashi LK, Rubin WW, and Kalin NH (1992) Antagonism of corticotropin-releasing factor receptors in the locus coeruleus attenuates shockinduced freezing in rats. Brain Res. 587:263-268. 
Tache Y, Mönnikes H, Bonaz B, and Rivier J (1993) Role of CRF in stress-related alterations of gastric and colonic motor function. Ann.N.Y.Acad.Sci. 697:233241.

Tanaka T, Yokoo H, Mizoguchi K, Yoshida M, Tsuda A, and Tanaka M (1991) Noradrenaline release in the rat amygdala is increased by stress: Studies with intracerebral microdialysis. Brain Res. 544:174-176.

Thomas SR, Lewis ME, and Iversen SD (1985) Correlation of $\left[{ }^{3} \mathrm{H}\right]$ diazepam binding density with anxiolytic locus in the amygdaloid complex of the rat. Brain Res. 342:85-90.

Toth E, Sershen H, Hashim A, Vizi ES, and Lajtha A (1992) Effect of nicotine on extracellular levels of neurotransmitters assessed by microdialysis in various brain regions: role of glutamic acid. Neurochem.Res. 17:265-271.

Ulrich YM, Hargreaves KM, and Flores CM (1997) A comparison of multiple injections versus continuous infusion of nicotine for producing up-regulation of neuronal $\left[{ }^{3} \mathrm{H}\right]$ - epibatidine binding sites. Neuropharmacology 36:1119-1125.

Uryu K, Okumura T, Shibasaki T, and Sakanaka M (1992) Fine structure and possible origins of nerve fibers with corticotropin-releasing factor-like immunoreactivity in the rat central amygdaloid nucleus. Brain Res. 577:175-179.

Vale W, Spiess J, and Rivier J (1981) Characterization of a 41 amino acid residue ovine hypothalamic peptide that stimulates the secretion of corticotropin and betaendorphin. Science 213:1394-1397.

Vale W, Vaughan J, Yamamoto G, Bruhn T, Douglas C, Dalton D, Rivier C, and Rivier J (1983) Assay of corticotrophin-releasing factor. Meth.Enzymol. 103:565-577

Valentine JD, Hokanson JS, Matta SG, and Sharp BM (1997) Self-administration in rats allowed unlimited access to nicotine. Psychopharmacology (Berl) 133:300-304.

Valentine JD, Matta SG, and Sharp BM (1996) Nicotine-induced cFos expression in the hypothalamic paraventricular nucleus is dependent on brainstem effects: Correlations with cFos in catecholaminergic and noncatecholaminergic neurons in the nucleus tractus solitarius. Endocrinology 137:622-630.

Valentino RJ, Foote SL, and Aston-Jones G (1983) Corticotropin-releasing factor activates noradrenergic neurons of the locus coeruleus. Brain Res. 270:363-367.

Valentino RJ, Page ME, and Curtis AL (1991) Activation of noradrenergic locus coeruleus neurons by hemodynamic stress is due to local release of corticotropin-releasing factor. Brain Res. 555:25-34. 
Valentino RJ, Page ME, Luppi P-H, Zhu Y, Van Bockstaele E, and Aston-Jones G (1994) Evidence for widespread afferents to Barrington's nucleus, a brainstem region rich in corticotropin-releasing hormone neurons. Neuroscience 62:125-143.

Van Bockstaele EJ, Colago EEO, and Valentino RJ (1996) Corticotropin-releasing factorcontaining axon terminals synapse onto catecholamine dendrites and may presynaptically modulate other afferents in the rostral pole of the nucleus locus coeruleus in the rat brain. J.Comp.Neurol. 364:523-534.

Van de Kar LD, Piechowski RA, Rittenhouse PA, and Gray TS (1991) Amygdaloid lesions: Differential effect on conditioned stress and immobilization-induced increases in corticosterone and renin secretion. Neuroendocrinology 54:89-95.

Van der Zee EA, Roozendaal B, Bohus B, Koolhaas JM, and Luiten PGM (1997) Muscarinic acetylcholine receptor immunoreactivity in the amygdala .1. Cellular distribution correlated with fear- induced behavior. Neuroscience 76:63-73.

Van der Zee EA, Streefland C, Strosberg AD, Schroder H, and Luiten PGM (1992) Visualization of cholinoceptive neurons in the rat neocortex: colocalization of muscarinic and nicotinic acetylcholine receptors. Mol.Brain Res. 14:326-336

Vidal C (1996) Nicotinic Receptors in the Brain Molecular biology, function, and therapeutics. Mol.Chem.Neuropathol. 28:3-11.

Vidal C and Changeux J-P (1993) Nicotinic and muscarinic modulations of excitatory synaptic transmission in the rat prefrontal cortex in vitro. Neuroscience 56:23-32.

Wada E, Wada K, Boulter J, Deneris E, Heinemann S, Patrick J, and Swanson LW (1989) Distribution of alpha2, alpha3, alpha4, and beta2 neuronal nicotinic receptor subunit mRNAs in the central nervous system: a hybridization histochemical study in the rat. J.Comp.Neur 284:314-335.

Wang S-J, Huang C-C, and Gean P (1995) Tetrahydro-9-aminoacridine presynaptically inhibits glutaminergic transmission in the rat amygdala. Brain Res.Bull. 37:325327.

Warburton DM (1992) Nicotine as a cognitive enhancer. Prog.NeuroPsychopharmacol.Biol.Psychiat. 16:181-191.

Warburton DM and Rusted JM (1993) Cholinergic control of cognitive resources. Neuropsychobiology 28:43-46.

Washburn MS and Moises HC (1992) Electrophysiological and morphological properties of rat basolateral amygdaloid neurons in vitro. J.Neurosci. 12:4066-4079. 
Watson M, Roeske WR, and Yamamura HI (1987) Cholinergic Receptor Heterogeneity. In: Psychopharmacology: The Third Generation of Progress (Meltzer HY ed), pp 241-248. New York: Raven Press.

West R and Hajek P (1997) What happens to anxiety levels on giving up smoking. Am.J.Psychiatry 154:1589-1592.

Wiersma A, Baauw AD, Bohus B, and Koolhaas JM (1995) Behavioural activation produced by CRH but not $\alpha$-helical CRH (CRH-receptor antagonist) when microinfused into the central nucleus of the amygdala under stress-free conditions. Psychoneuroendocrinology 20:423-432.

Winders SE and Grunberg NE (1990) Effects of nicotine on body weight, food consumption and body composition in male rats. Life Sci. 46:1523-1530.

Womble MD and Moises HC (1993) Muscarinic modulation of conductances underlying the afterhyperpolarization in neurons of the rat basolateral amygdala. Brain Res. 621:87-96.

Yajeya J, Juan AD, Merchan MA, Riolobos AS, Heredia M, and Criado JM (1997) Cholinergic responses of morphologically and electrophysiologically characterized neurons of the basolateral complex in rat amygdala slices. Neuroscience 78:731743.

Yoshida K, Kato Y, and Imura H (1980) Nicotine-induced release of noradrenaline from hypothalamic synaptosomes. Brain Res. 182:361-368.

Yu B and Shinnick-Gallagher P (1994) Interleukin-1 $\beta$ inhibits synaptic transmission and induces membrane hyperpolarization in amygdala neurons. J.Pharmacol.Exp.Ther. 271:590-600. 


\author{
CURRICULUM VITAE \\ Sibonisiwe "Bonnie" Masilela \\ Department of Pharmacology and Toxicology \\ Robert C Byrd Health Sciences Center \\ P.O. Box 9223 \\ Morgantown, WV 26506 \\ Phone: (304) 293-4449
}

\title{
Education:
}

West Virginia University, Morgantown, West Virginia (1995-1999).

Master of Science: Pharmacology \& Toxicology

Thesis: Effects of nicotine on content of corticotropin releasing factor (CRF) in rat amygdala, hypothalamus and brain stem (Laboratory based research).

Indiana University of Pennsylvania, Indiana, PA. (1990-1992).

Master of Science: Food and Nutrition Sciences

Thesis: Lead Poisoning in Children: The awareness level of nutritionists on issues of lead poisoning and the role of nutrition in lead toxicity (42 item questionnaire).

University of Surrey, Guildford, Surrey, U.K. (1979-1983).

Bachelor of Science (Honors): $\quad$ Biochemistry (Medical)

Final Year Project: Investigation of candidate enzymes for a simultaneous enzyme immunoassay of two thyroid hormones: triiodothyronine and thyroxine (Laboratory based research).

\section{Professional Experience:}

Graduate Research Assistant: Pharmacology/Toxicology, Box 9223, Morgantown, WV 26506 (1996-1998).

- $\quad$ Neuropharmacology laboratory: whole animal studies.

- Accurately handled paperwork/glassware/chemicals/animals/>400 samples.

- $\quad$ Injected drugs intra-peritoneally; sacrificed rats; removed brains.

- Utilized cryostat frozen brain sections; employed micro-punch technique.

- $\quad$ Performed (micro)-centrifugation; lyophilization; radioimmunoassays.

- $\quad$ Collaborated in the implementation of stress paradigm to rats.

- $\quad$ Utilized computer for data entry/manipulation: Word Perfect 5.0-7.0; Microsoft Excel Spreadsheet, GB Stat, Reference Manager, Power Point.

- $\quad$ Reviewed journal articles/delivered presentations to faculty and students.

- Co-leader in medical students' conferences, on patient-based case studies.

- $\quad$ Participated in WVU School of Medicine Annual Van Liere Research Convocation (March 1996). 
GIS Class: Introduced to Geographic Information Systems (GIS), Fall 1998.

Research Assistant I: Tobacco Research, MBRCC, Box 9300, Morgantown, WV 26506. (4/1994-11/1994).

- $\quad$ Assisted in two clinical trials for tobacco substitutes.

- $\quad$ Proofread subject files for accuracy and completeness of collected data.

Graduate Teaching Assistant: Food \& Nutrition, Ackerman Hall, IUP, Indiana, PA 15705. (1990-1991).

- $\quad$ Supervised upperclassmen "Experimental Foods" laboratory.

- $\quad$ Calibrated and ensured readiness of laboratory equipment.

- $\quad$ Graded pre-laboratory assignments; coded scores into the computer.

- $\quad$ Studied nutrients: sources, digestion, absorption and biological action, in health and disease.

Laboratory Intern: Biochemistry Department, Edgware General Hospital, Middlesex, U.K. (1981-1982).

- $\quad$ Conducted assays for disease diagnosis.

- Involved specimen handling/identity; centrifugation/separation; weighing balances; buffer/reagent preparation; pipetting; calorimetry; spectrophotometry; fluorimetry; chromatography (TLC, GLC, HPLC); electrophoresis; ELISA, RIA, use of auto-analyzers.

Laboratory Intern: $\quad$ Cardiff and South Glamorgan Area Hospitals, Wales, U.K.

Diploma: Medical Laboratory Sciences/Technology (1977-1979).

- Clinical laboratories: microbiology/immunology, hematology/serology, histopathology/cytology, clinical chemistry (8 weeks/Lab).

- $\quad$ Prepared smears on glass slides; tissue embedding; microtome sectioning; staining procedures; microscopy; used Coulter Counter; culture media; bacterial cultures/cultivation/sterility/antibiotics.

\section{Honors:}

Association for Women in Science, West Virginia Chapter (1997).

BOT Minority Fellowship, West Virginia University (1996-1997).

Graduate Research Award: Indiana University of Pennsylvania (1992).

\section{Professional affiliation:}

Society for Neuroscience (1996-1999).

Society for Neuroscience, West Virginia Chapter (1996-1998).

Association for Women in Science (AWIS), West Virginia Chapter (1996-1999). 
Abstracts and Presentations:

Abstract: Corticotropin releasing factor $(\mathrm{CRF})$ is increased in amygdala and hypothalamus of prenatally stressed rats. D.L. Birkle, M.S. Swatts, D.A. White, S. Masilela and E.M. Krouse. J. Neurochem 69:S216. (1997).

Poster: Does nicotine exert its central nervous system (CNS) effects by modulating corticotropin releasing factor (CRF) in selected brain regions? Masilela, Sibonisiwe N., and D.L. Birkle. West Virginia University (WVU) School of Medicine "Research Day," (March 20, 1998).

Poster: Effects of nicotine on corticotropin releasing factor in the rat brain. Sibonisiwe "Bonnie" Masilela. 1998 AWIS-WV Spring Symposium.

Abstract: The Knowledge and Role of WIC Nutritionists Regarding Lead Poisoning in Children." S. Masilela, J.B. Steiner, M.A. Cessna and R.M. Johnson. J. Am. Diet. Assoc. September 1993_Supplement, 93(9): p. A-25.

Poster: "The Knowledge and Role of WIC Nutritionists Regarding Lead Poisoning in Children." American Dietetic Association's 76th Annual Meeting and Exhibition: Year 2000 Health Objectives, October 26, 1993.

\section{Manuscript Reviews:}

Reviewed five manuscripts on the subject of lead poisoning in children, for the serial, Environmental Health Perspectives. (1995-1998).

\section{Volunteer Service:}

Volunteer: Cheat Lake Elementary and Middle Schools, West Virginia (1994-99).

- Partaking in "Read aloud program."

- $\quad$ Chaperoned on School Field trips.

- $\quad$ Participated on "Science day" and "Sports Field Day."

Member: $\quad$ (MCAE) Monongalia County Association for Enrichment (1999).

Presentations: "Multi-culturalism and diversity" to Junior High and High School students (1998-1999).

Volunteer health educator: Cranwell International Center/YMCA, Virginia Tech, Blacksburg, VA. (1986-1987). 
Volunteer health educator: Cranwell International Center/YMCA, Virginia Tech, Blacksburg, VA. (1986-1987).

- $\quad$ Received (group) training from various health care givers in Montgomery County.

- $\quad$ Promoted awareness on access to health care, to newly arrived international students/families.

- $\quad$ Contributed to the publication international student pamphlet: "The health Resource Guide."

WIC Clinic and Red Cross volunteer: $\quad$ Montgomery County Health Department, Blacksburg, VA. (1983-1985).

- Hematocrit laboratory and anthropometric measures.

- $\quad$ Clerical work. 